\title{
Competitive Screening under Heterogeneous Information
}

\section{Daniel Garrett* $\quad$ Renato Gomes ${ }^{\dagger} \quad$ Lucas Maestri ${ }^{\ddagger}$}

First Version: November, 2013.

This Version: April, 2016.

\begin{abstract}
We build a theory of second-degree price discrimination under imperfect competition that allows us to study the substitutive role of prices and qualities in increasing sales. A key feature of our model is that consumers are heterogeneously informed about the offers available in the market, which leads to dispersion over price-quality menus in equilibrium. While firms are exante identical, their menus are ordered so that more generous menus leave more surplus uniformly over consumer types. We generate empirical predictions by exploring the effects of changes in market fundamentals on the distribution of surplus across types, and pricing across products. For instance, more competition may raise prices for low-quality goods; yet, consumers are better off, as the qualities they receive also increase. The predictions of our model illuminate empirical findings in many markets, such as those for cell phone plans, yellow-pages advertising, cable TV and air travel.
\end{abstract}

\section{JEL Classification: D82}

Keywords: competition, screening, heterogeneous information, price discrimination, adverse selection

\footnotetext{
${ }^{*}$ Toulouse School of Economics, University of Toulouse Capitole, daniel.garrett@tse-fr.eu.

${ }^{\dagger}$ Toulouse School of Economics, University of Toulouse Capitole (CNRS), renato.gomes@tse-fr.eu.

${ }^{\ddagger}$ Getulio Vargas Foundation (EPGE), maestri.lucas@gmail.com.
} 


\section{Introduction}

Price discrimination through menus of products, exhibiting different combinations of quality and price, is a widespread practice across many industries. Examples include flight tickets with different terms and conditions, cell phone plans with increasing usage allowances, and television subscriptions in basic and premium versions.

In these examples, the purchasing decisions of consumers depend on individual preferences as well as on price and quality differences across products. As noted by Jules Dupuit as early as 1849, and later by Mussa and Rosen (1978), distortions in the provision of quality are a key feature of the monopolistic optimum, as they help extract rents from consumers with high willingness to pay. ${ }^{1}$

In the presence of competition, the choice of price and qualities is bound to affect the volume of sales. Firms then have to design their menu of products accounting for consumers' choices of which firm to patronize, and which product to buy (within the firm menu). In this paper we build a theory of second-degree price discrimination under imperfect competition which allows us to study the substitutive role of prices and qualities in attracting consumers. Our theory generates a number of testable predictions, and unveils different patterns of firm behavior regarding pricing and quality provision under competition.

Our framework departs from existing theoretical work on second-degree price discrimination, which assumes that consumers enjoy perfect (and therefore homogeneous) information about the offers available in the market. This literature postulates that imperfect competition is due to product differentiation; see Champsaur and Rochet (1989), Rochet and Stole (1997, 2002) and Armstrong and Vickers (2001). ${ }^{2}$ Our focus on heterogeneously informed consumers also stands in contrast to most of the large empirical literature on product differentiation which follows the tradition of Berry, Levinsohn and Pakes (1995).

That consumers are often heterogeneously informed about available offers has long been recognized as an important driver of market power by firms, and has been widely documented empirically (see, for example, Chandra and Tappata (2011) and the references therein). Its importance for empirical work studying consumer demand and industry conduct is now increasingly recognized (see, for instance, Sovinsky Goeree (2008) and Draganska and Klapper (2011)). Theoretical work on competitive price discrimination with heterogeneously informed consumers, however, has to date been missing.

\footnotetext{
${ }^{1}$ The French engineer Jules Dupuit provided perhaps one of the first explanations of how quality distortions can raise revenue. In the context of railway transportation, he writes that "there is a presumption that those who are willing to make the largest sacrifice for their journey are also those who value their comfort most and who have their carriages luxuriously appointed inside and out. So this is the treatment the company gives them. It also tries to guard against their avarice, which might induce them to travel in a lower class, by differentiating as much as possible the comfort provided for passengers." See page 24 in Dupuit (1849).

${ }^{2}$ See also Stole (2007) for a comprehensive survey.
} 


\section{Model and Results}

We consider a canonical model of second-degree price discrimination. To isolate the effects of information heterogeneity on competition, we assume that consumer tastes only differ with respect to their valuation for quality (their "type"). That is, consumers have no "brand" preferences, and so evaluate the offers of different firms symmetrically. An offer is a menu of products, consisting in different combinations of price and quality. Each consumer observes a random sample of menus offered by the competing firms, and purchases from the menu with the most attractive product among those observed.

As in the early work on sample-size search, see Burdett and Judd (1983), we consider ex-ante identical firms and anticipate that they will make different offers in equilibrium. An equilibrium is then a distribution over menus such that every menu in its support is a profit-maximizing response to that distribution. As consumer preferences are private information, the menus offered by firms have to satisfy the self-selection (or incentive) constraints inherent to price discrimination.

It is useful to note that, were consumer preferences public information, all firms would provide quality efficiently to each consumer type. The reason is that, holding constant consumer payoffs, firms' profits would increase by setting qualities at their efficient levels. Under asymmetric information, however, a firm's choice of how much utility to leave to one type of consumer affects its ability to provide quality to other types, as incentive constraints must be satisfied. Such constraints create a link between the products designed for each consumer type as well as their prices.

A key step in our analysis is to express incentive constraints and firms' profits in terms of the indirect utilities offered to consumers. Doing so allows us to establish a crucial property of a firm's profit function: It satisfies increasing differences in the indirect utility left to low and high types. To understand why, note that leaving more indirect utility to high types relaxes incentive constraints, as high types now consider the low-type product less attractive. The quality of the low-quality product can therefore be raised without violating the high type's incentive constraint. This, in turn, increases the firms' marginal profit associated with increasing the indirect utility left to low types, as marginal sales generate greater surplus.

Building on this monotonicity property, we characterize an equilibrium of this economy, which, under mild qualifications, is the unique one. This equilibrium, which we call the ordered equilibrium, has the property that, for any two menus, one of them leaves more indirect utility uniformly across types. Accordingly, firms sort themselves on how generous they are (i.e., how much indirect utility they leave) to all consumer types. In equilibrium, all firms expect the same profits, as the less generous ones make fewer sales to each consumer type.

To better understand the behavior of firms, we translate the equilibrium characterization (in terms of indirect utilities) into properties of observable variables. Our analysis reveals that, while price reductions are the only instrument of competition for high types, three patterns of competition 
for low-type consumers emerge. For firms of low generosity, extra sales are generated by increasing both the quality and the price of the low-quality product. For firms of intermediate generosity, courting consumers combines quality enhancements and price reductions. For firms of high generosity, price reductions are the only instrument of competition for low types (as quality provision is efficient). These patterns reflect the fact that more generous firms compete more evenly for different consumer types, as the shadow costs of incentive constraints (and the associated distortions in quality provision) go down with the generosity of the menu.

\section{Empirical Implications}

To connect our theory to empirical work on price discrimination, we generate testable predictions exploring variations in market conditions. We consider increases in the degree of competition, as modeled by consumers observing a (probabilistically) larger sample of offers, and changes in the distribution of consumer tastes.

First, we show that, if competition is not too intense, more competition raises prices for the lowquality product. Intuitively, in a market close to monopoly, the quality of the low-type product is heavily distorted; hence the surplus, and also the profits, from low-type sales are small. To increase sales, firms are therefore willing to compete more aggressively for high types than for low types, raising high-type payoffs by more. This relaxes (downward) incentive constraints, and, as a result, low-type qualities sharply increase (in the appropriate probabilistic sense), and so do low-type prices.

Second, markups decrease faster for high types than for low types as competition intensifies. This follows from two observations. One is that high types benefit more from competition than low types, for the reason explained above. The other is that, unlike for high types, much (in some cases, all) of the higher payoffs that low types obtain from more competition take the form of higher quality provision, rather than lower prices.

Third, we assess the impact of variations in consumer tastes on quality provision and price differentials within firms' menus. We show that low-type qualities increase with the mass of low-type consumers, and show that price differentials are smaller (in the appropriate probabilistic sense) in markets with either more competition or more low-type consumers. Moreover, the impact of competition on price differentials is stronger in markets with fewer low-type consumers. Intuitively, the degree of competition and the fraction of low types work as substitutes for reducing price differentials.

Although our model is not conceived to describe in detail any specific market, the predictions above find empirical support in a range of examples, as we describe more extensively below. A case in point is the US airline industry in the 1990s and early 2000s, as documented by Gerardi and Shapiro (2009). This study provides evidence on the range of prices offered by individual airlines on different routes. Differences in ticket characteristics, such as refundability and Saturday night stayover restrictions, seem to explain much of the variation in an airline's prices on any given route (see Sengupta and Wiggins, 2014, for evidence). Moreover, it appears there was significant heterogeneity 
in the information available to consumers about the airfares available in the market (again, see the study by Sengupta and Wiggins). ${ }^{3}$

In line with our theoretical results, Gerardi and Shapiro (2009) find that entry by a new carrier on a given route is associated with a reduction in the variation in competitors' ticket prices on that route, due largely to a reduction in the highest ticket prices. The reduction is greatest on routes that seem a priori likely to have the highest proportion of business (or "high-valuation") passengers. We are unaware of empirical findings on how ticket restrictions (and the pricing of restricted tickets) vary with competition. However, Mazzeo (2003) does observe a positive correlation between an airline's on-time performance and the intensity of competition on a given route, which seems to suggest a positive influence of competition on quality. In Section 4, we relate the predictions of our model to empirical findings in other markets, such as those for cell phone plans, yellow-pages advertising, and cable TV.

Paper Outline

The rest of the paper is organized as follows. Below, we close the introduction by briefly reviewing the most pertinent literature. Section 2 describes the model. Section 3 characterizes equilibrium, focusing for analytical ease on the space of utilities that consumers derive from equilibrium menus. Section 4 then translates the findings in Section 3 into key economic implications, and relates them to existing empirical findings. Section 5 describes some possible extensions to our baseline model, and Section 6 concludes. All proofs are in the Appendix at the end of the document.

\subsection{Related Literature}

This paper brings the theory of nonlinear pricing under asymmetric information (Mussa and Rosen (1978), Maskin and Riley (1984) and Goldman, Leland and Sibley (1984)) to a competitive setting where consumers are heterogeneously informed about the offers made by firms. Other related literature is described below.

Competition in Nonlinear Pricing. This article primarily contributes to the literature that studies imperfect competition in nonlinear pricing schedules when consumers make exclusive purchasing decisions (exclusive agency). In one strand of this literature, firms' market power stems from comparative advantages for serving consumer segments. In Stole (1995) such comparative

\footnotetext{
${ }^{3}$ Although developments in e-commerce, such as price comparison websites and online booking, would seem to imply improvements in consumers' information about available fares in the later years of the study, Sengupta and Wiggins' study suggests information remained imperfect. In particular, they find in 2004 data that many air tickets were booked off-line, and that travelers booking off-line paid a systematically higher price (about 11 per cent higher on average), apparently because of inferior information about the available fares. Also related, Clemons, Hann and Hitt (2002) find significant price dispersion among online travel agents in 1997, and argue that search frictions are a natural explanation.
} 
advantages are exogenous, whereas in Champsaur and Rochet (1989) they are endogenous, as firms can commit to a range of qualities before choosing prices.

Another strand of this literature generates market power by assuming that goods are horizontally differentiated, i.e. consumers have preferences over brands; see Spulber (1989) for a one-dimensional model where consumers are distributed on a Salop circle, and Rochet and Stole (1997, 2002), Armstrong and Vickers (2001), and Yang and Ye (2008) for multi-dimensional models where brand preferences enter utility additively. These papers study symmetric equilibria, and show that (i) the equilibrium outcome under duopoly often lies between the monopoly and the perfectly competitive outcome, and that (ii) when brand preferences are narrowly dispersed, quality provision may be fully efficient with cost-plus-fixed-fee pricing prevailing. ${ }^{4}$

Our model presents several advantages relative to the aforementioned papers. First, it parsimoniously explains different firm behavior on how to compete for consumers. Indeed, the ability to describe various responses to competition (in terms of price and quality decisions) highlights the tractability of our model. In the horizontal-differentiation literature mentioned above, results analogous to those of this paper (e.g., comparative statics on the degree of competition) are analytically elusive.

Second, the Hotelling-Salop approach of the aforementioned papers conflates changes in the degree of competition with changes in the outside option (as changes in "transportation costs" simultaneously affect the consumer choice between any two firms, and between any given firm and not consuming the good). ${ }^{5}$ Our model isolates changes purely in the competitiveness of the market, contributing to its greater tractability. ${ }^{6}$

There is, of course, other work recognizing that consumers may not be perfectly informed about offers in competitive settings. ${ }^{7}$ The works of Verboven (1999) and Ellison (2005) depart from the benchmark of perfect consumer information by assuming that consumers observe the baseline prices offered by all firms, but have to pay a search cost to observe the price of upgrades (or add-on prices). The focus of these papers is on the strategic consequences of the hold-up problem faced by consumers once their store choices are made. By taking quality provision as exogenous, these papers ignore the mechanism design issues that are at the core of the present article. Katz (1984) studies a model of price discrimination where a measure of low-value consumers are uninformed about prices while other consumers are perfectly informed. Heterogeneity of information thus takes a very particular

\footnotetext{
${ }^{4}$ See Borenstein (1985), Wilson (1993) and Borenstein et al (1994) for numerical results in closely related settings.

${ }^{5}$ See Bénabou and Tirole (2016) for further discussion of this point.

${ }^{6}$ Relatedly, understanding the impact of entry in a spatial model typically requires modeling the detailed spatial structure of the market. Our alternative approach simply views an increase in the number of firms as stochastically increasing the number of offers each consumer receives.

${ }^{7}$ There is also work where consumers have imperfect information about offers in the absence of competition. Most closely related to our paper, Villas-Boas (2004) studies monopoly price discrimination where consumers randomly observe either some or all elements of the menu.
} 
form in this model, and price dispersion does not arise (when quantity discounting is permitted, a unique price schedule is offered in equilibrium).

Assuming perfect consumer information, Stole (1991) and Ivaldi and Martimort (1994) study duopolistic competition in nonlinear price schedules when consumers can purchase from more than one firm (common agency). ${ }^{8}$ In a related setting, Calzolari and Denicolo (2013) study the welfare effects of contracts for exclusivity and market-share discounts (i.e., discounts that depend on the seller's share of a consumer's total purchases). The analysis of these papers is relevant for markets where goods are divisible and/or exhibit some degree of complementarity, whereas our analysis is relevant for markets where exclusive purchases are prevalent (e.g., most markets for durable goods).

Price Dispersion. We borrow important insights from the seminal papers of Butters (1977), Salop and Stiglitz (1977), Varian (1980) and Burdett and Judd (1983), that study oligopolistic competition in settings where consumers are differently informed about the prices offered by firms. In these papers, there is complete information about consumer preferences, and firms compete only on prices. ${ }^{9}$ Relative to this literature, we introduce asymmetric information about consumers' tastes, and allow firms to compete on price and quality.

Competing Auctioneers. McAfee (1993), Peters (1997), Peters and Severinov (1997) and Pai (2012) study competition among principals who propose auction-like mechanisms. These papers assume that buyers perfectly observe the sellers' mechanisms, and that the meeting technology between buyers and sellers is perfectly non-rival. This last assumption is relaxed by Eeckhout and Kircher (2010), who show that posted prices prevail in equilibrium if the meeting technology is sufficiently rival. A key ingredient of these papers is that sellers face capacity constraints (each seller has one indivisible good to sell), and offer homogenous goods whose quality is exogenous. Our paper differs from this literature in three important respects. First, sellers in our model control both the price and the quality of the good to be sold. Second, we assume away capacity constraints. Third, buyers are heterogeneously informed about the offers made by sellers.

Search and Matching. Inderst (2001) embeds the setup of Mussa and Rosen (1978) in a dynamic matching environment, where sellers and buyers meet pairwise and, in each match, each side may be chosen to make a take-it-or-leave offer. His main result shows that inefficiencies vanish when frictions (captured by discounting) are sufficiently small, thus providing a foundation for perfectly competitive outcomes. ${ }^{10}$ Frictions in our model have a different nature (they are informational).

Faig and Jerez (2005) study the effect of buyers' private information in a general equilibrium model with directed search. They show that if sellers can use two-tier pricing, private information

\footnotetext{
${ }^{8}$ See Stole (2007) for a comprehensive survey of the common agency literature.

${ }^{9}$ See, however, Grossman and Shapiro (1984) where consumers not only have heterogeneous information about offers, but also about brand preferences. Firms compete in prices and advertising intensities, but do not price discriminate.

${ }^{10}$ In contrast, Inderst (2004) shows that if frictions affect agents' utilities through type-independent costs of search (or waiting), equilibrium contracts are always first-best.
} 
has no bite, and the equilibrium allocation is efficient. In turn, Guerrieri, Shimer and Wright (2010) show that private information leads to inefficiencies in a directed-search environment with common values. Our model is closer to Faig and Jerez (2005), as we study private values. In contrast to Faig and Jerez (2005), our model leads to menu dispersion and distortions.

In work subsequent to ours, Lester et al (2015) introduce information heterogeneity in a commonvalues setting where seller types are privately known. They show that an ordered equilibrium also exists in their environment, and study the welfare effects of market interventions common in insurance and financial markets. Finally, our paper is also related to Moen and Rosén (2011), who introduce private information on match quality and effort choice in a labor market with search frictions. We focus on private information about willingness to pay (which is the same for all firms), while workers have private information about the match-specific shock in their model.

\section{$2 \quad$ Model and Preliminaries}

The economy is populated by a unit-mass continuum of consumers with single-unit demands for a vertically differentiated good. If a consumer with valuation per quality $\theta$ purchases a unit of the good with quality $q$ at a price $x$, his utility is

$$
u(q, x, \theta) \equiv \theta \cdot q-x .
$$

Consumers are heterogeneous in their valuations per unit of quality: the valuation of each consumer is an iid draw from a discrete distribution with support $\left\{\theta_{l}, \theta_{h}\right\}$, where $\Delta \theta \equiv \theta_{h}-\theta_{l}>0$, and associated probabilities $p_{l}$ and $p_{h}$, with $p_{l}, p_{h}>0$ (and $p_{l}+p_{h}=1$ ). Consumers privately observe their valuations per unit of quality. The utility from not buying the good is normalized to zero.

A unit-mass continuum of firms compete by posting menus of contracts with different combinations of quality and price. Firms have no capacity constraints and share a technology that exhibits constant returns to scale. The per-unit profit of a firm which sells a good with quality $q$ at a price $x$ is

$$
x-\varphi(q),
$$

where $\varphi(q)$ is the per-unit cost to the firm of providing quality $q$. We assume that $\varphi(\cdot)$ is twice continuously differentiable, strictly increasing and strictly convex, with $\varphi(0)=\varphi^{\prime}(0)=0$. Furthermore, we require that $\lim _{q \rightarrow \infty} \varphi^{\prime}(q)=\infty$, which guarantees that surplus-maximizing qualities are interior.

We assume that firms' offers stipulate simply that consumers choose a combination of quality and price from a menu of options. Given the absence of capacity constraints, a consumer is assured to receive his choice. We thus rule out stochastic mechanisms as well as mechanisms which condition on the choices of other buyers or on the offers of other firms. ${ }^{11}$ Given our restriction to menus of

\footnotetext{
${ }^{11}$ There is no loss of generality in considering deterministic mechanisms, provided that one assumes that each con-
} 
price-quality pairs, it is without loss of generality to suppose firms' menus include only two pairs: $\mathcal{M} \equiv\left(\left(q_{l}, x_{l}\right),\left(q_{h}, x_{h}\right)\right) \subset\left(\mathbb{R}_{+} \times \mathbb{R}\right)^{2}$, where $\left(q_{k}, x_{k}\right)$ is the contract designed for the type $k \in\{l, h\} .{ }^{12}$ Furthermore, every menu has to satisfy the following incentive-compatibility constraints: For each type $k \in\{l, h\}$,

$$
I C_{k}: \quad u\left(q_{k}, x_{k}, \theta_{k}\right)=\max _{\hat{k} \in\{l, h\}} \theta_{k} \cdot q_{\hat{k}}-x_{\hat{k}} .
$$

This constraint requires that type- $k$ consumers are better off choosing the contract $\left(q_{k}, x_{k}\right)$ rather than the contract designed for type $l \neq k$.

Contracts which offer negative utility to consumers would never be selected. It is therefore without loss of generality to assume that menus are individually rational (IR), i.e. $u\left(q_{k}, x_{k}, \theta_{k}\right) \geq 0$ for each $k$. According to our convention, a firm that does not want to serve type $k$ offers an incentive compatible menu with type- $k$ contract $\left(q_{k}, x_{k}\right)=(0,0)$. A menu $\mathcal{M}$ that satisfies the IC and IR constraints is said to be implementable. The set of implementable menus is denoted by $\mathbb{I}$.

One key feature of our analysis is that there is heterogeneity in the information possessed by consumers about the menus offered by firms. To simplify the exposition, we model this heterogeneity in the baseline model according to the simultaneous-search framework of Burdett and Judd (1983). Each consumer observes the menus of a sample of firms independently and uniformly drawn from the set of all firms. For each consumer, the size of the observed sample is $j \in\{1,2, \ldots\}$ with probability $\omega_{j}(v)$. Consumers select the best contract among all menus in their samples.

The distribution over sample sizes $\Omega(v) \equiv\left\{\omega_{j}(v): j=1,2, \ldots\right\}$ is indexed by the degree of competition $v \in \mathbb{R}_{+} \cdot{ }^{13}$ We assume that, as $v$ increases, the distribution $\Omega(v)$ increases in the likelihood-ratio order, capturing the idea that consumers are more likely to observe larger samples of firms. ${ }^{14}$ The interpretation is that $v$ represents the level of informational frictions in the market. In Section 5 below we describe other matching technologies, yielding alternative interpretations. For instance, in its Example 1 the ratio of firms to consumers plays a similar role to that of $v$.

We also assume that $\omega_{1}(v) \in(0,1)$ whenever $v>0$; this rules out the possibility that all firms are local monopolists, but ensures all firms have some market power (their offers are the only offer received with positive probability). To span the entire spectrum of competitive intensity, we assume that $\omega_{1}(0)=1$ (i.e., firms are local monopolies when the degree of competition is minimal), and

sumer can contract with at most one firm. The difficulties associated with stochastic mechanisms in environments where consumers can try firms sequentially (e.g., a consumer might look for a second firm if the lottery offered by the first firm resulted in a bad outcome) are discussed in Rochet and Stole (2002).

${ }^{12}$ Assume a seller offers a menu with more than two price-quality pairs and that at least one type chooses two or more options with positive probability. It is easy to show that there is a menu, with a single option intended for each consumer type, which yields the same payoff to each type but strictly increases the seller's profit (see Lemma 1 below). ${ }^{13}$ For every $v$, we assume that $\Omega(v)$ has a finite mean.

${ }^{14}$ The likelihood-ratio order is commonly used in economics (see Jewitt (1991) for a detailed account). For discrete random variables, we say that $X$ dominates $\hat{X}$ in the sense of the likelihood-ratio order if $\frac{\rho(x)}{\hat{\rho}(x)}$ is increasing in $x$ over the union of the supports of $X$ and $\hat{X}$, where $\rho$ and $\hat{\rho}$ are the probability mass functions of $X$ and $\hat{X}$. 
$\lim _{v \rightarrow \infty} \omega_{1}(v)=0$ (i.e., consumers are sure to know at least two firms as the degree of competition grows unbounded). For a simple example satisfying these requirements, let $\Omega(v)$ be a shifted Poisson distribution with support on $\{1,2, \ldots\}$ and mean $v+1$.

It is convenient to denote by $\tilde{F}$ the probability measure over menus prevailing in the economy. In intuitive terms, this measure describes the cross-section distribution of menus offered by all firms. This measure, which has support $\mathbb{S}$ contained in the set of implementable menus $\mathbb{I}$, induces, for each type $k$, the marginal distribution over indirect utilities

$$
F_{k}\left(\tilde{u}_{k}\right) \equiv \operatorname{Prob}_{\tilde{F}}\left[\mathcal{M}: u\left(q_{k}, x_{k}, \theta_{k}\right) \leq \tilde{u}_{k}\right]
$$

We denote by $\Upsilon_{k} \subseteq \mathbb{R}_{+}$the support of indirect utilities offered to type- $k$ consumers, and by $f_{k}$ the density of $F_{k}$, whenever it exists.

A firm's expected sales to type- $k$ consumers will depend on the ranking of the indirect utility that the firm's offer yields to type- $k$ consumers (relative to other offers in the market). ${ }^{15}$ If the type- $k$ contract is $\left(q_{k}, x_{k}\right)$, then this ranking is $y_{k}=F_{k}\left(u\left(q_{k}, x_{k}, \theta_{k}\right)\right)$. We define the sales function $\Lambda\left(y_{k} \mid v\right)$ such that, if the distribution $F_{k}$ is continuous, then each firm expects sales $p_{k} \Lambda\left(y_{k} \mid v\right)$ to consumers of type $k$. In our baseline model (following Burdett and Judd (1983)), we have that

$$
\Lambda\left(y_{k} \mid v\right)=\sum_{j=1}^{\infty} j \omega_{j}(v) y_{k}^{j-1}
$$

for any type- $k$ contract with rank $y_{k} \cdot{ }^{16}$ In the case where the sample-size distribution $\Omega(v)$ is a shifted-Poisson, the sales function simplifies to $\Lambda\left(y_{k} \mid v\right)=\left(1+v y_{k}\right) \exp \left\{-v\left(1-y_{k}\right)\right\}$. In Section 5 we describe the sales functions induced by other models of information heterogeneity.

A firm that faces a measure over menus $\tilde{F}$ (inducing the marginal cdf $F_{k}$ over type- $k$ indirect utilities) chooses a menu $\left(\left(q_{l}, x_{l}\right) ;\left(q_{h}, x_{h}\right)\right) \in \mathbb{I}$ to maximize profits

$$
\sum_{k=l, h} p_{k} \Lambda\left(F_{k}\left(u\left(q_{k}, x_{k}, \theta_{k}\right)\right) \mid v\right)\left(x_{k}-\varphi\left(q_{k}\right)\right)
$$

The next definition formalizes our notion of equilibrium in terms of the probability measure over menus $\tilde{F}$.

\footnotetext{
${ }^{15}$ A firm's sales to type $k$ consumers depends neither on the offers it makes to other consumer types $l \neq k$, nor on the distribution over contracts offered to other types by competing firms. This is an immediate consequence of the fact that all menus are incentive compatible.

${ }^{16}$ At any point where $F_{k}$ has an atom, sales are determined according to a uniform rationing rule (which amounts to assuming that consumers evenly randomize across offers generating the same payoffs). Formally, if $u_{k} \in \Upsilon_{k}$ is a mass point of $F_{k}$, then the share of sales to type- $k$ agents obtained by a firm offering indirect utility $u_{k}$ is

$$
\left(F_{k}\left(u_{k}\right)-\lim _{\tilde{u}_{k} \uparrow u_{k}} F_{k}\left(\tilde{u}_{k}\right)\right)^{-1} \cdot \int_{\lim _{\tilde{u}_{k} \uparrow u_{k}} F_{k}\left(\tilde{u}_{k}\right)}^{F_{k}\left(u_{k}\right)} \Lambda(y \mid v) d y
$$

Finally, this share equals $\Lambda(1 \mid v)$ if $u_{k}>\tilde{u}_{k}$ for all $\tilde{u}_{k} \in \Upsilon_{k}$, and equals $\Lambda(0 \mid v)$ if $0 \leq u_{k}<\tilde{u}_{k}$ for all $\tilde{u}_{k} \in \Upsilon_{k}$.
} 
Definition 1 [Equilibrium] An equilibrium is a probability measure over menus $\tilde{F}$ (inducing the marginal cdf $F_{k}$ over type- $k$ indirect utilities) such that $\mathcal{M} \in$ supp $\tilde{F} \subset \mathbb{I}$ implies that $\mathcal{M}$ maximizes profits (2).

Accordingly, an equilibrium is described by a probability distribution over menus such that every menu in the support maximizes firms' profits. This equilibrium definition renders itself to different interpretations. For instance, one interpretation is that firms follow symmetric mixed strategies by randomizing over menus according to the probability $\tilde{F}$. Another interpretation is that each firm follows a pure strategy that consists in posting some menu in the support of $\tilde{F}$.

\subsection{Incentive Compatibility and Indirect Utilities}

A key step in our analysis is to formulate the firms' maximization problem in terms of the of indirect utilities offered to consumers. To this end, denote by

$$
q_{k}^{*} \equiv \arg \max _{q} \theta_{k} \cdot q-\varphi(q)
$$

the efficient quality for type- $k$ consumers, and let $S_{k}^{*} \equiv \theta_{k} \cdot q_{k}^{*}-\varphi\left(q_{k}^{*}\right)$ be the social surplus associated with the efficient quality provision. The next lemma uses the incentive constraints and the optimality of equilibrium contracts to map indirect utilities into quality levels.

Lemma 1 [Incentive Compatibility] Consider a menu $\mathcal{M}=\left\{\left(q_{l}, x_{l}\right),\left(q_{h}, x_{h}\right)\right\}$ in the support of the equilibrium probability over menus, $\tilde{F}$, and let $u_{k} \equiv u\left(q_{k}, x_{k}, \theta_{k}\right)$. Then, for all $k \in\{l, h\}$,

$$
q_{k}\left(u_{l}, u_{h}\right)=\mathbf{1}_{k}\left(u_{h}-u_{l}\right) \cdot \frac{u_{h}-u_{l}}{\triangle \theta}+\left(1-\mathbf{1}_{k}\left(u_{h}-u_{l}\right)\right) \cdot q_{k}^{*}
$$

where $\mathbf{1}_{h}(z)$ is an indicator function that equals one if and only if $z>q_{h}^{*} \cdot \triangle \theta$, and $\mathbf{1}_{l}(z)$ is an indicator function that equals one if and only if $z<q_{l}^{*} \cdot \triangle \theta$.

The result above is standard in adverse selection models. Consider some menu $\mathcal{M} \in \operatorname{supp}(\tilde{F})$ offered in equilibrium, and let $\left(u_{l}, u_{h}\right)$ be its profile of indirect utilities. Suppose for illustration that $u_{h}-u_{l}<q_{h}^{*} \cdot \triangle \theta$ (this turns out to always be the case in equilibrium). Then $\mathbf{1}_{h}\left(u_{h}-u_{l}\right)=0$, and so $q_{h}=q_{h}^{*}$ (i.e., we have efficiency at the top). This simply reflects that the low-type incentive constraint $\left(\mathrm{IC}_{l}\right)$ is always slack. The low-type quality is then efficient if $u_{h} \geq u_{l}+\Delta \theta \cdot q_{l}^{*}$, and downward distorted otherwise. This is simply because the high-type incentive constraint $\left(\mathrm{IC}_{h}\right)$ is slack in the former case, and binds otherwise.

In light of Lemma 1, we can describe each menu in the support of $\tilde{F}$ in terms of the indirect utilities $\left(u_{l}, u_{h}\right)$ induced by $\mathcal{M}$. Given $\left(u_{l}, u_{h}\right)$, one can determine via (3) the equilibrium quality levels consumed by each consumer type $\left(q_{l}, q_{h}\right)$, and hence also the prices paid $\left(x_{l}, x_{h}\right)$. 
Two natural benchmarks play an important role in the analysis that follows. The first one is the static monopolistic (or Mussa-Rosen) solution. Under this benchmark, the quality provided to low types, denote it $q_{l}^{m}$, is implicitly defined by:

$$
\varphi^{\prime}\left(q_{l}^{m}\right)=\max \left\{\theta_{l}-\frac{p_{h}}{p_{l}} \cdot \Delta \theta, 0\right\} .
$$

We interpret $q_{l}^{m}=0$ as meaning that low-type consumers are not served under the monopolistic solution. In turn, quality provision for high types is efficient: $q_{h}^{m}=q_{h}^{*}$. Finally, recall that, in the monopolistic solution, the indirect utility left to low types is zero, $u_{l}^{m}=0$ (as the IR constraint is binding), and the indirect utility left to high types is $u_{h}^{m}=q_{l}^{m} \cdot \triangle \theta$, as the constraint $\mathrm{IC}_{h}$ is binding. Written in terms of indirect utilities, the menu $\mathcal{M}^{m} \equiv\left(0, q_{l}^{m} \cdot \triangle \theta\right)$ is the monopolist (or Mussa-Rosen) menu.

The second benchmark is the competitive (or Bertrand) solution. Under this benchmark, quality provision to both types is efficient and firms derive zero profits from each contract in the menu. Written in terms of indirect utilities, the menu $\mathcal{M}^{*} \equiv\left(S_{l}^{*}, S_{h}^{*}\right)$ is the competitive (or Bertrand) menu. We can now proceed to characterizing the equilibrium of our model.

\section{Equilibrium Characterization}

We start by studying the firms' profit-maximization problem, and then characterize equilibrium. For analytical convenience, the analysis of this section is developed in the space of indirect utilities. The next section then translates the equilibrium characterization into properties of observable variables.

\subsection{Firm Problem}

For each menu $\mathcal{M}=\left(u_{l}, u_{h}\right)$ offered in equilibrium, let

$$
S_{k}\left(u_{l}, u_{h}\right) \equiv \theta_{k} \cdot q_{k}\left(u_{l}, u_{h}\right)-\varphi\left(q_{k}\left(u_{l}, u_{h}\right)\right)
$$

be the social surplus induced by $\mathcal{M}$ for each type- $k$ consumer, where the quality levels $q_{k}\left(u_{l}, u_{h}\right)$ are computed according to (3). We can then write the profit per sale to type- $k$ consumers produced by the menu $\mathcal{M}=\left(u_{l}, u_{h}\right)$ as $S_{k}\left(u_{l}, u_{h}\right)-u_{k}$.

Employing Lemma 1, we can rewrite the firm's profit-maximization problem (in response to the cdf's over indirect utilities $\left.F_{l}, F_{h}\right)$ as that of choosing a menu $\left(u_{l}, u_{h}\right)$ to maximize

$$
\pi\left(u_{l}, u_{h}\right) \equiv \sum_{k=l, h} p_{k} \Lambda\left(F_{k}\left(u_{k}\right) \mid v\right)\left(S_{k}\left(u_{l}, u_{h}\right)-u_{k}\right)
$$

subject to the constraint $u_{h} \geq u_{l} \geq 0$. This constraint guarantees that menus are individually rational. The requirement that $u_{h} \geq u_{l}$ captures incentive compatibility, as it guarantees that the 
indirect utility profile $\left(u_{l}, u_{h}\right)$ can be generated by a pair of contracts satisfying the self-selection constraint of each consumer type.

It is worth comparing Equation (6) to the profit expressions that appear in the literature assuming horizontal differentiation (where consumers have preferences over brands); see, especially, Rochet and Stole (2002). The only difference is in how expected sales are determined. In our setting, because consumers are only concerned with the utility of consumption net of transfers (and thus pick the best offer available), expected sales to each type $k$ depend on the rank $F_{k}\left(u_{k}\right)$ of the indirect utility offered by the firm (as described by the sales function $\Lambda$ ). By contrast, in Rochet and Stole (2002), sales depend on how differences in anticipated indirect utilities compare with differences in transportation costs (which describe horizontal preferences).

To better understand the firms' trade-offs, we now analyze the first-order conditions for (6). We will follow the common practice in mechanism design of assuming that $\mathrm{IC}_{l}$ is slack in equilibrium, in which case $\mathrm{IC}_{h}$ is the only constraint that may bind in equilibrium. We also assume that each $F_{k}$ is differentiable; in the appendix, we verify that these properties hold in all equilibria. First-order conditions for each firm's problem are then

$$
\underbrace{p_{h} \cdot \Lambda_{1}\left(F_{h}\left(u_{h}\right) \mid v\right) \cdot f_{h}\left(u_{h}\right) \cdot\left(S_{h}^{*}-u_{h}\right)}_{\text {sales gains }}-\underbrace{p_{h} \cdot \Lambda\left(F_{h}\left(u_{h}\right) \mid v\right)}_{\text {profit losses }}+\underbrace{p_{l} \cdot \Lambda\left(F_{l}\left(u_{l}\right) \mid v\right) \cdot \frac{\partial S_{l}}{\partial u_{h}}\left(u_{l}, u_{h}\right)}_{\text {efficiency gains }}=0
$$

for $u_{h}$, and

$$
\underbrace{p_{l} \cdot \Lambda_{1}\left(F_{l}\left(u_{l}\right) \mid v\right) \cdot f_{l}\left(u_{l}\right) \cdot\left(S_{l}\left(u_{l}, u_{h}\right)-u_{l}\right)}_{\text {sales gains }}-\underbrace{p_{l} \cdot \Lambda\left(F_{l}\left(u_{l}\right) \mid v\right)}_{\text {profit losses }}+\underbrace{p_{l} \cdot \Lambda\left(F_{l}\left(u_{l}\right) \mid v\right) \cdot \frac{\partial S_{l}}{\partial u_{l}}\left(u_{l}, u_{h}\right)}_{\text {efficiency losses }}=0
$$

for $u_{l}$. Intuitively, the firms' choice of menus balances sales, profit, and efficiency considerations.

Let us start with the first-order condition for high-type payoffs, given by Equation (7). The first two terms in (7) are familiar from models without asymmetric information on type. By increasing the indirect utility $u_{h}$, the firm makes its menu more attractive to high types, increasing sales (the first term). However, the higher indirect utility reduces profits per sale to high types (the second term). The third term captures the effect of an increase in $u_{h}$ on the quality offered to low-type consumers. When $\mathrm{IC}_{h}$ is slack (i.e., $u_{h}>u_{l}+\Delta \theta \cdot q_{l}^{*}$ ), high types have no incentive to imitate low types, and this term is zero. When $\mathrm{IC}_{h}$ binds (in which case $u_{h}=u_{l}+\Delta \theta \cdot q_{l}$ ), increasing $u_{h}$ increases the quality $q_{l}$ that can be supplied to the low type, while holding $u_{l}$ fixed. Hence,

$$
\frac{\partial q_{l}\left(u_{l}, u_{h}\right)}{\partial u_{h}}=\frac{1}{\Delta \theta}
$$

The marginal effect of increasing low-type quality on surplus per sale is $\theta_{l}-\varphi^{\prime}\left(q_{l}\right)$, and so the marginal effect of an increase in $u_{h}$ is

$$
\frac{\partial S_{l}}{\partial u_{h}}\left(u_{l}, u_{h}\right)=\frac{1}{\Delta \theta}\left(\theta_{l}-\varphi^{\prime}\left(q_{l}\right)\right)
$$


Holding $u_{l}$ fixed, the seller appropriates all of the additional surplus, and this is reflected in profits. On the other hand, when $\mathrm{IC}_{h}$ is slack, increasing $u_{h}$ does not affect the quality supplied to the low type (which is equal to the efficient level), and so the efficiency effect on profits is absent.

The first-order condition for low-type utilities is given by Equation (8). The first two terms are familiar from (7). In contrast to (7), however, increasing $u_{l}$ has the effect of tightening $\mathrm{IC}_{h}$, so the quality distortion present in the low-types' contract increases. The efficiency loss is the third term in Equation (8). It has the same magnitude as the third term in (7), but the opposite sign. Our equilibrium analysis of the next subsections will clarify how firms simultaneously resolve the efficiency-rent-extraction and the rent-extraction-sales-volume trade-offs in equilibrium.

Equations (7) and (8) capture the role of consumers' private information on preferences in determining the firms' choice of menus. For instance, they show how the optimal design of contracts for low and high types are linked as a result of (high-type) incentive constraints. To see this, suppose that instead types are public and contractual offers can be conditioned directly on each consumer's type. Then we would have $S_{l}\left(u_{l}, u_{h}\right)=S_{l}^{*}$, and the third terms in (7) and (8) would be zero. Instead, when consumer types are private information, the problems of choosing $u_{l}$ and $u_{h}$ are interdependent whenever incentive constraints bind. As the next lemma shows, this interdependency is materialized in the following crucial property of the expected profit function $\pi$.

Lemma 2 [Increasing differences] Consider any two implementable menus $\left(u_{l}^{1}, u_{h}^{1}\right)$ and $\left(u_{l}^{2}, u_{h}^{2}\right)$, with $u_{l}^{2}>u_{l}^{1}$ and $u_{h}^{2}>u_{h}^{1}$. Then we have

$$
\pi\left(u_{l}^{2}, u_{h}^{2}\right)-\pi\left(u_{l}^{2}, u_{h}^{1}\right) \geq \pi\left(u_{l}^{1}, u_{h}^{2}\right)-\pi\left(u_{l}^{1}, u_{h}^{1}\right)
$$

If some incentive constraint binds for at least one of these menus (i.e., $u_{h}^{i}-u_{l}^{i} \notin\left[q_{l}^{*} \cdot \triangle \theta, q_{h}^{*} \cdot \triangle \theta\right]$ for some $i \in\{1,2\})$, then the inequality in (9) is strict. Otherwise, (9) holds with equality.

Intuitively, the result above means that firms generating a high $u_{h}$ have a comparative advantage in generating a high $u_{l}$. To understand why this is true, let us consider the first-order conditions (7) and (8) and suppose that $\mathrm{IC}_{h}$ is binding for both menus (i.e., $u_{h}^{i}-u_{l}^{i}<\Delta \theta q_{l}^{*}$ for $\left.i \in\{1,2\}\right) .{ }^{17}$ In this case, $q_{l}=\frac{u_{h}-u_{l}}{\triangle \theta}$, and increasing $u_{h}$ from $u_{h}^{1}$ to $u_{h}^{2}$ raises the quality supplied to the low type. This increases the marginal profit of raising $u_{l}$ for two reasons. First, the sales gains from raising $u_{l}$ (which is the first term in (8)) go up as $u_{h}$ increases. Second, the efficiency losses from raising $u_{l}$ (which is the third term in (8)) go down (in absolute value) as $u_{h}$ increases. This is so because the cost of quality $\varphi$ is convex, which means that a marginal reduction in low-type quality has less effect on surplus when this quality is closer to its first-best level. These effects are summarized by

\footnotetext{
${ }^{17}$ The intuition for the case where the low types' incentive constraint binds is similar. However, we will show that this constraint does not bind in equilibrium.
} 
the cross derivative of the profit function $\pi$ at any menu for which $\mathrm{IC}_{h}$ is binding:

$$
\frac{\partial^{2} \pi\left(u_{l}, u_{h}\right)}{\partial u_{h} \partial u_{l}}=p_{l} \cdot f_{l}\left(u_{l}\right) \cdot \Lambda_{1}\left(F_{l}\left(u_{l}\right) \mid v\right)\left(\frac{\theta_{l}-\varphi^{\prime}\left(q_{l}\right)}{\Delta \theta}\right)+\frac{p_{l} \cdot \Lambda\left(F_{l}\left(u_{l}\right) \mid v\right) \cdot \varphi^{\prime \prime}\left(q_{l}\right)}{(\Delta \theta)^{2}}>0,
$$

as can be directly computed from either (7) or (8). ${ }^{18}$ The first term captures the effect of $u_{h}$ on the sales gain from raising $u_{l}$, while the second term captures the effect of $u_{h}$ on the efficiency loss from raising $u_{l}$. Both terms are positive.

In contrast, if no incentive constraints bind at some menu $\left(u_{l}, u_{h}\right)$, the profit function $\pi$ exhibits

constant differences; i.e., $\frac{\partial^{2} \pi\left(u_{l}, u_{h}\right)}{\partial u_{h} \partial u_{l}}=0$. In this case, as established by Lemma 1 , optimality requires that qualities are fixed at their efficient levels for both consumer types, and the effects of $u_{l}$ and $u_{h}$ on profits are locally separable.

Before characterizing the equilibrium, we will use Lemma 2 to establish that, in any equilibrium, the distributions over indirect utilities, $F_{l}$ and $F_{h}$, are absolutely continuous, and have support on an interval that starts at the indirect utility associated with the monopolistic (Mussa-Rosen) menu.

Lemma 3 [Support] In any equilibrium of this economy, the marginal cdf over indirect utilities for type $k \in\{l, h\}, F_{k}$, is absolutely continuous. Its support is $\Upsilon_{k}=\left[u_{k}^{m}, \bar{u}_{k}\right]$, where $\bar{u}_{k}<S_{k}^{*}$.

The lemma above has a number of important implications. First, because the distributions $F_{k}$ are absolutely continuous, no equilibria exist in which a positive mass of firms post the same menu. Second, the minimum indirect utilities offered in equilibrium are those induced by the monopoly menu. The proof, contained in the appendix, combines familiar arguments from models of price dispersion under complete information (e.g., Varian (1980)) with novel ones that account for incentive constraints.

\subsection{Ordered Equilibrium}

We construct an equilibrium in which firms that cede high indirect utilities to high types also cede high indirect utilities low types. We say that equilibria that satisfy this property are ordered.

Definition 2 [Ordered Equilibrium] An equilibrium is said to be ordered if, for any two menus $\mathcal{M}=\left(u_{l}, u_{h}\right)$ and $\mathcal{M}^{\prime}=\left(u_{l}^{\prime}, u_{h}^{\prime}\right)$ offered in equilibrium, $u_{l}<u_{l}^{\prime}$ if and only if $u_{h}<u_{h}^{\prime}$. In this case, the menu $\left(u_{l}^{\prime}, u_{h}^{\prime}\right)$ is said to be more generous than the menu $\left(u_{l}, u_{h}\right)$.

Note that menus offered in an ordered equilibrium can be described via a support function relating high-type payoffs to the low-type payoffs in any menu.

Remark 1 [Support Function] In every ordered equilibrium, the support of indirect utilities offered by firms can be described by a strictly increasing and bijective support function $\hat{u}_{l}: \Upsilon_{h} \rightarrow \Upsilon_{l}$ such that, for every menu $\mathcal{M}=\left(u_{l}, u_{h}\right)$ in $\Upsilon_{l} \times \Upsilon_{h}, u_{l}=\hat{u}_{l}\left(u_{h}\right)$.

\footnotetext{
${ }^{18}$ Differentiability of $F_{l}$ holds in equilibrium, but is not assumed in the proof of Lemma 2 .
} 
Theorem 1 characterizes the unique ordered equilibrium of the economy. We find it notationally convenient to denote the identity function by $\hat{u}_{h}\left(u_{h}\right)=u_{h}$ for all $u_{h} \in \Upsilon_{h}$.

Theorem 1 [Equilibrium Characterization] There exists a unique ordered equilibrium. In this equilibrium, the support of indirect utilities offered by firms is described by the support function $\hat{u}_{l}:\left[u_{h}^{m}, \bar{u}_{h}\right] \rightarrow\left[0, \bar{u}_{l}\right]$ that is the unique solution to the differential equation

$$
\hat{u}_{l}^{\prime}\left(u_{h}\right)=\frac{S_{l}\left(\hat{u}_{l}\left(u_{h}\right), u_{h}\right)-\hat{u}_{l}\left(u_{h}\right)}{S_{h}^{*}-u_{h}} \cdot \frac{1-\frac{p_{l}}{p_{h}} \cdot \frac{\partial S_{l}}{\partial u_{h}}\left(\hat{u}_{l}\left(u_{h}\right), u_{h}\right)}{1-\frac{\partial S_{l}}{\partial u_{l}}\left(\hat{u}_{l}\left(u_{h}\right), u_{h}\right)}
$$

with boundary condition $\hat{u}_{l}\left(u_{h}^{m}\right)=0$.

The equilibrium distribution over menus solves

$$
\frac{\Lambda\left(F_{h}\left(u_{h}\right) \mid v\right)}{\Lambda(0 \mid v)}=\frac{\sum_{k=l, h} p_{k} \cdot\left(S_{k}\left(0, u_{h}^{m}\right)-u_{k}^{m}\right)}{\sum_{k=l, h} p_{k} \cdot\left(S_{k}\left(\hat{u}_{l}\left(u_{h}\right), u_{h}\right)-\hat{u}_{k}\left(u_{h}\right)\right)},
$$

and the supremum point $\bar{u}_{h}$ is determined by $F_{h}\left(\bar{u}_{h}\right)=1$.

The existence of an ordered equilibrium is intimately related to the increasing differences property of firms' profit functions established in Lemma 2. To understand how, consider a firm that raises the indirect utility of high types $u_{h}$ (or, equivalently, reduces the price charged to high types $x_{h}$ ). As noted above, this relaxes $\mathrm{IC}_{h}$ (i.e., it relaxes the constraint $u_{h} \geq u_{l}+\Delta \theta \cdot q_{l}$ ), permitting an increase in the quality supplied to low types $q_{l}$ without a violation of incentive compatibility. If $u_{l}$ were to remain fixed, then the firm would extract all of the additional surplus associated with the increase in $q_{l}$. But since the firm now makes more profits per sale to low types, it is worthwhile sharing some of the surplus with low types in order to make more of these sales. This explains why $u_{h}$ and $u_{l}$ increase together in equilibrium.

As noted in Remark 1, the support function $\hat{u}_{l}(\cdot)$ is thus strictly increasing. This function, together with the supremum point $\bar{u}_{h}$, determines the set of menus offered in equilibrium; i.e., the support of the equilibrium distribution $\tilde{F}$. Completing the characterization of $\tilde{F}$, Equation (12) determines the marginal distribution over high-type payoffs $F_{h}$. Note that this equation is simply an indifference condition which requires that all menus in the support of $\tilde{F}$ generate the same expected profits (more generous menus, i.e., those with a higher $u_{h}$, make more sales in expectation, but smaller expected profits per sale).

A striking feature of equilibrium is that the support function $\hat{u}_{l}(\cdot)$ does not depend on the sales function $\Lambda$. This means that $\hat{u}_{l}(\cdot)$ is invariant to the sample-size distribution $\Omega(v)$, and hence to any variation in the level of competition, $v$. By contrast, the support of equilibrium menus does depend on $\Omega(v)$, but only through the supremum indirect utility $\bar{u}_{h}$, determined by the indifference condition (12). $\Omega(v)$ also plays an important role in determining the equilibrium distribution over menus, as seen from (12). 
The slope of the support function, implicitly determined by the differential equation (11), describes how the intensity of competition varies across types. A slope $\hat{u}_{l}^{\prime}\left(u_{h}\right)$ close to zero means that firms are willing to cede very little indirect utility to low types as they offer one extra unit of indirect utility to high types. By contrast, as the slope $\hat{u}_{l}^{\prime}\left(u_{h}\right)$ approaches unity, competition for the two types becomes "more balanced". Accordingly, the lower is the slope $\hat{u}_{l}^{\prime}\left(u_{h}\right)$, the fiercer is the competition for high types (relative to low types) among the firms that offer menus close to $\left(\hat{u}_{l}\left(u_{h}\right), u_{h}\right)$. The next lemma describes how the slope $\hat{u}_{l}^{\prime}(\cdot)$ varies across equilibrium menus.

Corollary 1 [Competition Across Types] The equilibrium support function is such that $0<$ $\hat{u}_{l}^{\prime}\left(u_{h}\right)<1$ for all $u_{h} \in\left(u_{h}^{m}, \bar{u}_{h}\right)$. Moreover, the slope $\hat{u}_{l}^{\prime}(\cdot)$ is increasing in $u_{h}$ (i.e., $\hat{u}_{l}(\cdot)$ is convex) and satisfies $\hat{u}_{l}^{\prime}\left(u_{h}^{m}\right)=0$.

Corollary 1 states that the slope $\hat{u}_{l}^{\prime}\left(u_{h}\right)$ is always less than unity; this means that competition for high types is fiercer than for low types at all menus offered in equilibrium. There are two reasons for this. First, purchases by high-type consumers generate more profits per sale than for low types, reflecting the fact that high-type consumers have more surplus to share with firms (i.e., $\left.S_{h}^{*}>S_{l}\left(\hat{u}_{l}\left(u_{h}\right), u_{h}\right)\right)$. Second, as noted above, increasing the high-type payoff relaxes the high-type incentive constraint $\mathrm{IC}_{h}$; when this constraint is binding, it permits higher quality to be supplied to low types in an incentive-compatible manner.

The slope of the support function determines how low-type quality varies across menus. In particular, recall that

$$
q_{l}\left(\hat{u}_{l}\left(u_{h}\right), u_{h}\right)=\frac{u_{h}-\hat{u}_{l}\left(u_{h}\right)}{\Delta \theta}
$$

whenever $u_{h}-\hat{u}_{l}\left(u_{h}\right) \leq \triangle \theta \cdot q_{l}^{*}$ (i.e., when $\mathrm{IC}_{h}$ binds). Because $\hat{u}_{l}^{\prime}\left(u_{h}\right)<1$, the quality provided to low types is strictly increasing in $u_{h}$ (and so is the low-type surplus $S_{l}\left(\hat{u}_{l}\left(u_{h}\right), u_{h}\right)$ ). It then follows that there is a threshold level of $u_{h}$, call it $u_{h}^{c}$, above which low-type quality is efficient. The threshold $u_{h}^{c}$ is the the unique value of $u_{h}$ solving $u_{h}-\hat{u}_{l}\left(u_{h}\right)=\triangle \theta \cdot q_{l}^{*}$.

The corollary above also establishes that the slope $\hat{u}_{l}^{\prime}(\cdot)$ is increasing in $u_{h}$. The reason is that low-type quality increases with $u_{h}$, which implies that sales to low types become more profitable the more generous is the firm. This results in more generous firms competing more fiercely for low types (relative to high types). ${ }^{19}$

The last property established by Corollary 1 is that the slope of the support function is zero in a neighborhood of the Mussa-Rosen menu. To gain intuition, suppose that $u_{h}^{m}>0$. For menus in a neighborhood of the monopoly menu $\left(0, u_{h}^{m}\right)$, increasing $u_{h}$ has only a second-order effect on the profitability of a sale, since $u_{h}^{m}$ is an interior maximizer of these profits. Increasing $u_{l}$, however,

\footnotetext{
${ }^{19}$ There is also a second reason why competition becomes more balanced as $u_{h}$ increases. Because the marginal surplus created by additional low-type quality is smaller the more efficient is quality provision, firms gain less by raising $u_{h}$ (through the relaxation of $\mathrm{IC}_{h}$ ) the higher is $u_{h}$.
} 


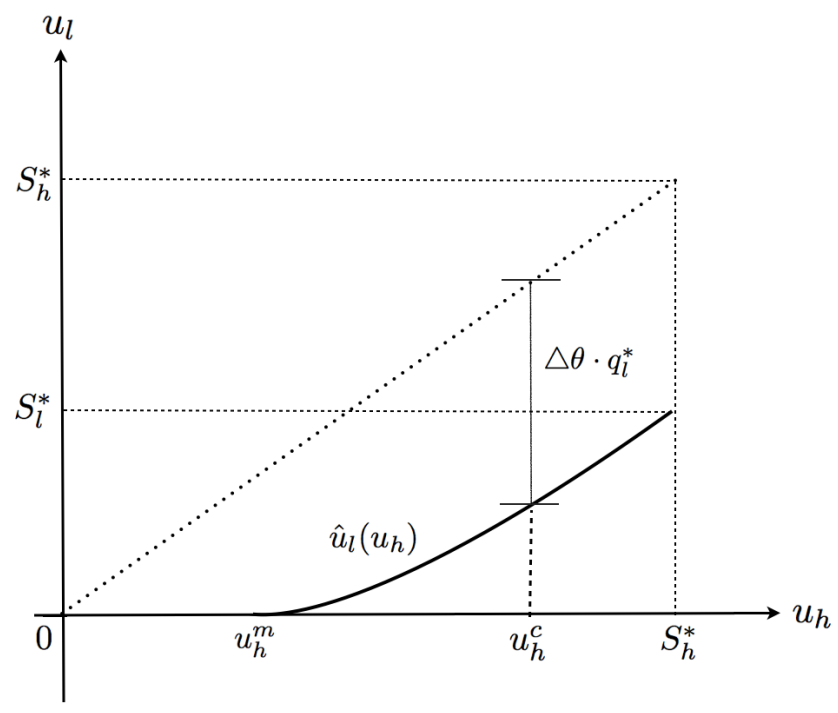

Figure 1: The equilibrium support function $\hat{u}_{l}(\cdot)$. The dotted line is the 45-degree line.

leads to a first-order loss in profits per sale. As such, competing for high types is arbitrarily less costly than competing for low types for firms offering a menu close to the monopolistic one. This implies $\hat{u}_{l}^{\prime}\left(u_{h}^{m}\right)=0$ in equilibrium.

Figure 1 illustrates these observations. This figure represents the entire graph of the support function, $\left\{\left(\hat{u}_{l}\left(u_{h}\right), u_{h}\right): u_{h} \in\left[u_{h}^{m}, S_{h}^{*}\right)\right\}$. Which of these offers are made in equilibrium depends on the supremum point $\bar{u}_{h}$.

Before developing some testable implications of our model, it is useful to understand how the degree of competition in the market affects the equilibrium distribution over menus. To this end, consider the indifference condition (12) from Proposition 1. Its right-hand side is independent of the degree of competition $v$ (similarly to the support function), while its left-hand side increases with $v{ }^{20}$ It then follows that, as the degree of competition increases, (i) firms become more likely to offer more generous menus, and (ii) the support of equilibrium menus expands. To see the latter, note that expected profits fall as competition increases. Hence, the firm which makes the largest number of expected sales, by offering the most generous menu $\left(\hat{u}_{l}\left(\bar{u}_{h}\right), \bar{u}_{h}\right)$, must be yielding more rent to consumers in equilibrium (i.e., $\bar{u}_{h}$ must increase with competition).

To formalize these results, and to state the key empirical predictions of our theory in the next section, we shall say that a random variable increases probabilistically if its distribution increases in the sense of first-order stochastic dominance.

Corollary 2 [Comparative Statics] The indirect utility $u_{k}$ obtained by each consumer type $k \in$ $\{l, h\}$ increases probabilistically with competition (i.e., as $v$ increases). Moreover, the top of the support of these indirect utilities $\bar{u}_{k}$ increases with $v$.

\footnotetext{
${ }^{20}$ This follows from the fact that $\frac{\Lambda(y \mid v)}{\Lambda(0 \mid v)}$ increases with $v$ for all $y \in(0,1]$, as implied by Equation $(1)$ and that $\Omega(v)$ increases in the likelihood-ratio order with $v$.
} 
The next remark clarifies when the ordered equilibrium is unique in the class of all possible equilibria.

Remark 2 [Equilibrium Uniqueness] In deriving testable predictions below, we focus on the unique ordered equilibrium characterized in Theorem 1. As we show in Appendix B, little (if anything) is lost by restricting attention to this equilibrium. Namely, when the degree of competition is not too large, the ordered equilibrium is the unique equilibrium. By contrast, if the degree of competition is sufficiently large, there are equilibria which are not ordered. However, all equilibria (including the non-ordered ones) lead to the same marginal distributions over indirect utilities $F_{k}(\cdot)$, and the same ex-ante profits for firms.

\section{Economic Implications}

For analytical convenience, the equilibrium characterization of the previous section was developed in the space of indirect utilities. In this section, we employ this characterization to derive testable implications in terms of prices, qualities and markups. We then relate these implications to the available empirical evidence.

\subsection{Competing on price and quality}

Purchasing decisions depend on consumer preferences as well as on price and quality differentials across products. Absent asymmetric information about consumer preferences, all firms would offer the same efficient quality level to each consumer type, although different prices. Under asymmetric information, a firm's choice of how much utility to leave to high types affects its ability to provide quality to low types (as the high-type incentive constraint, $\mathrm{IC}_{h}$, must be satisfied). As a consequence, firms' offers to low types differ on both price and quality provision, which work as substitute instruments for increasing sales.

Our theory helps to explain how firms select either one of these instruments as a function of the degree of competition in the market. To explore this important question, it is convenient to write the prices of the low and high quality goods as a function of indirect utilities:

$$
\begin{aligned}
x_{l}\left(u_{h}\right) & \equiv \theta_{l} \cdot q_{l}\left(\hat{u}_{l}\left(u_{h}\right), u_{h}\right)-\hat{u}_{l}\left(u_{h}\right), \text { and } \\
x_{h}\left(u_{h}\right) & \equiv \theta_{h} \cdot q_{h}^{*}-u_{h}
\end{aligned}
$$

for $u_{h} \in \Upsilon_{h}$. The next result is then a consequence of Corollary 1. To state it, recall that $u_{h}^{m}$ is the high-type indirect utility at the monopolistic menu, and that $u_{h}^{c}$ solves $u_{h}-\hat{u}_{l}\left(u_{h}\right)=\triangle \theta \cdot q_{l}^{*}$.

Corollary 3 [Equilibrium Prices] The price of the high-quality good $x_{h}\left(u_{h}\right)$ is strictly decreasing in $u_{h}$ over $\left[u_{h}^{m}, S_{h}^{*}\right)$. There exists $u_{h}^{d} \in\left(u_{h}^{m}, u_{h}^{c}\right]$ such that the price of the low-quality good $x_{l}\left(u_{h}\right)$ is strictly increasing in $u_{h}$ if $u_{h} \leq u_{h}^{d}$, and strictly decreasing over $\left(u_{h}^{d}, S_{h}^{*}\right)$. 


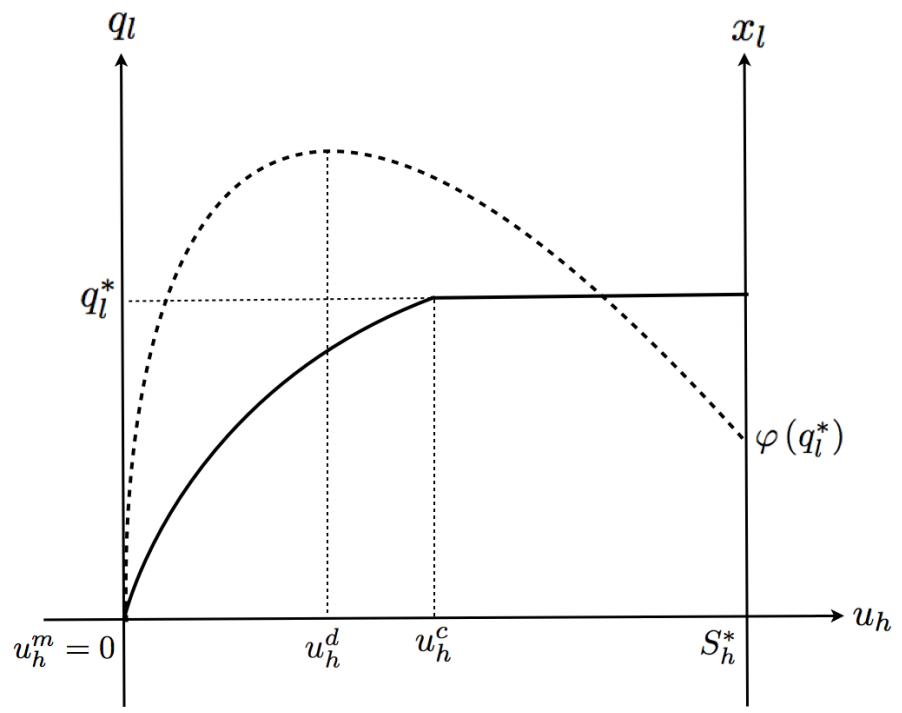

Figure 2: The low-type quality schedule (full curve and left-side Y-axis)) and the low-type price (dotted curve and right-side Y-axis) as a function of the generosity of the menu, $u_{h}$.

As established in Corollary 1, firms that offer menus close to the Mussa-Rosen one compete much more fiercely for high than for low types, as implied by $\hat{u}_{l}^{\prime}\left(u_{h}^{m}\right)=0$. This results in the relaxation of the high-type incentive constraint $\mathrm{IC}_{h}$, leading to an increase in the quality of the low-type good relative to the Mussa-Rosen menu. Also because $\hat{u}_{l}^{\prime}\left(u_{h}^{m}\right)=0$, most of the additional surplus from higher low-type quality is appropriated by the firms. This implies that prices have to increase. Hence, firms offering the least generous menus (i.e., $u_{h}<u_{h}^{d}$ ) compete for additional consumers by increasing both the quality and the price of the low-quality option.

As the generosity of menus increases, firms compete more evenly for both consumer types, as they are willing to cede relatively more utility to the low type (reflecting the fact that $\hat{u}_{l}(\cdot)$ is convex). This implies that quality increases with generosity at a decreasing rate. If $u_{h}^{d}<u_{h}^{c}$, then $x_{l}(\cdot)$ decreases with $u_{h}$ over the interval $\left(u_{h}^{d}, u_{h}^{c}\right)$, although the low-type quality $q_{l}\left(\hat{u}_{l}\left(u_{h}\right), u_{h}\right)$ increases in $u_{h}$. For still more generous menus, namely those with $u_{h}>u_{h}^{c}$, the low-type quality remains constant at its efficient level. As a result, the price of the low-quality good necessarily decreases in $u_{h}$. Taken together, these observations imply the price of the low-quality good is a $\cap$-shaped function of the menu generosity, as indexed by $u_{h}$.

Finally, because high-type quality is efficiently provided for all levels of $u_{h}$, the price of the high-quality good $x_{h}\left(u_{h}\right)$ strictly decreases in $u_{h}$. Figure 2 summarizes the findings of Corollary 3.

Combined with the comparative statics of Corollary 2, Corollary 3 leads to interesting predictions on how prices react to changes in the degree of competition in the market.

Proposition 1 [Price-Increasing Competition] As the degree of competition increases, the prices for the high-quality good decrease and the quality levels of the low-quality good increase probabilistically. Moreover, there exists $v^{d}>0$ such that, if the degree of competition is low (i.e., $v<v^{d}$ ), the 
prices for the low-quality good increase probabilistically as $v$ increases to $\hat{v}<v^{d}$.

Intuitively, more competition makes it more likely that firms offer high indirect utility to high types while competing less aggressively for low types. As incentive constraints are relaxed, low-type qualities increase (probabilistically), and so do low-type prices. Figure 2 nicely illustrates this result. Consider first the case where $v<v^{d}$. Because more competition shifts to the right the distribution of high-type indirect utilities $u_{h}$, and low-type prices increase in $u_{h}$, it follows that low-type prices have to increase (probabilistically) following an increase in $v$.

By contrast, when $v>v^{d}$, the effect of additional competition on the price of the low-quality good depends on features of the market, such as the level of competition and the proportion of high types. It is helpful to consider the limiting cases of monopoly and perfect competition (equivalently, to consider the limits $v \rightarrow 0$ and $v \rightarrow+\infty$ in our model). For instance, suppose that the proportion of high types, $p_{h}$, is small. Then, as we go from monopoly to perfect competition, the price of the low-quality good falls. This is because the low-type quality at the monopoly menu, $q_{l}^{m}$, is close to the efficient level $q_{l}^{*}$. Hence, while quality increases little in response to competition, the low type's rent goes from zero under monopoly to the entire surplus $S_{l}^{*}$ at the competitive outcome. Conversely, if $p_{h}$ is sufficiently large, then the change in the low type's quality is large, and the price paid by the low type increases as we move from monopoly to perfect competition.

Our finding that increased competition can raise prices is not without empirical counterparts. For instance, Chu (2010) finds that cable companies in the US reacted to new competition by satellite television by raising both price and quality (as determined by the available channels) in some markets, with consumers benefiting overall from the higher-priced offerings. ${ }^{21}$ Miravete and Roller (2004) examine the market for cell-phone plans in the 1980s and find that, while prices per minute for high-consumption users are lower in markets with competition, there is (approximately) no difference in prices for low-consumption users. Gerardi and Shapiro (2009) study the 90th and 10th percentiles of the distribution of airlines' prices on given routes (as noted in the Introduction, that airlines offer different prices on the same route can be substantially accounted for by variation in tickets' conditions). On so-called "big-city" routes, they find the 10th percentile of prices fall on average less than half as much as the 90th percentile of prices with increases in competition. The muted relationship between competition and the prices charged to low-paying consumers in Miravete and Roller and Gerardi and Shapiro seems consistent with the findings in Proposition $1 .^{22}$

The empirical literature also suggests a further prediction of our model; namely, that the difference between firms' highest prices $\left(x_{h}\left(u_{h}\right)\right)$ and lowest prices $\left(x_{l}\left(u_{h}\right)\right)$ should decrease with compe-

\footnotetext{
${ }^{21}$ See also Byrne (2014), who uses Canadian data to study how the entry of satellite television affected the pricing and quality provision of cable television in Canada. His results are comparable to those of Chu (2010).

${ }^{22}$ Although data on quality provision is scarce, some papers support the prediction that baseline quality increases with competition. Besides the work by Chu cited above, Mazzeo (2003) provide some direct evidence suggesting quality increases in response to competition.
} 
tition. To see why, we can decompose the difference in prices into differences in consumption utility and differences in payoffs of the consumers purchasing high- and low-quality options. In particular, we can write the price differential for a menu with high-type utility $u_{h}$ as

$$
\begin{aligned}
\Delta_{p}\left(u_{h}\right) & \equiv x_{h}\left(u_{h}\right)-x_{l}\left(u_{h}\right) \\
& =\underbrace{\left(\theta_{h} \cdot q_{h}^{*}-\theta_{l} \cdot q_{l}\left(\hat{u}_{l}\left(u_{h}\right), u_{h}\right)\right)}_{\text {Difference in consumption utility }}-\underbrace{\left(u_{h}-\hat{u}_{l}\left(u_{h}\right)\right)}_{\text {Difference in rents }} .
\end{aligned}
$$

Recall that both the low-type quality $q_{l}\left(\hat{u}_{l}\left(u_{h}\right), u_{h}\right)$ and the payoff differential $u_{h}-\hat{u}_{l}\left(u_{h}\right)$ are increasing in $u_{h}$. Together with Corollary 2 this implies the following result.

Proposition 2 [Competition and Price Differentials] As the degree of competition increases, the price differential $\Delta_{p}\left(u_{h}\right)$ decreases probabilistically.

The logic behind this result is familiar from Proposition 1. High-quality prices always decrease with more competition. On the other hand, the price of the low-quality good either (i) increases (when competition is originally low, following large quality improvements), or (ii) decreases less sharply (when competition is originally high, following small or null quality improvements). The former reflects that quality improvements are a superior way (in terms of profits) to compete for consumers than price reductions.

Much of the existing evidence on the role of competition in markets with price discrimination is in line with this prediction. ${ }^{23}$ The studies of Miravete and Roller (2004) and Gerardi and Shapiro (2009) mentioned above are clear examples. Another is Busse and Rysman (2005), who find that, while prices for yellow-pages advertisements are lower on average in more competitive markets, this price reduction is most pronounced for the largest (and hence most expensive) ads.

\subsection{Distributional Effects of Competition}

Our theory also generates predictions concerning the welfare of different consumer types, and the profitability of sales to different types. Competition in our model is beneficial for both consumer types (even when the price of the low-type option increases with competition), as implied by Corollary 2. How the different types fare in relative terms can then be understood by studying

$$
\Delta_{u} \equiv \int_{\Upsilon_{h}} u_{h} d F_{h}-\int_{\Upsilon_{l}} u_{l} d F_{l}
$$

which is the difference (in expectation) of the indirect utility offered by firms to high and low types in equilibrium. Corollaries 1 and 2 imply that $\Delta_{u}$ increases with the degree of competition $v .^{24}$ This

\footnotetext{
${ }^{23}$ For a recent review of this literature, see Crawford (2012).

${ }^{24}$ Note that $\Delta_{u}=\int_{\Upsilon_{h}}\left(u_{h}-\hat{u}_{l}\left(u_{h}\right)\right) d F_{h}$, after a change of variables. The result then follows, as $u_{h}-\hat{u}_{l}\left(u_{h}\right)$ is increasing in $u_{h}$ and $F_{h}$ increases according to first-order stochastic dominance as $v$ increases (by Corollaries 1 and 2).
} 
implies that, on average, an increase in competition leads to larger gains to high-type consumers. ${ }^{25}$

Again, this prediction is consistent with many of the studies that examine the effects of competition on consumer welfare in markets with price discrimination. Miravete and Roller (2004) and Economides, Seim and Viard (2008) find that high-consumption users gain the most from increases in competition in cellular phone markets. Chu (2010) finds that those consumers with the highest value for quality in television packages gained most when satellite television began to compete with incumbent cable providers. Other studies, such as Busse and Rysman (2005) and Gerardi and Shapiro (2009) suggest that high-paying consumers have the most to gain from competition (due to lower prices), but do not estimate consumer preferences.

These results also have a natural counterpart in the arena of incentive-based compensation. Bénabou and Tirole (2016) argue that the rise in incentive pay (often manifested in large bonus payments) for bankers and CEOs can be naturally interpreted as a consequence of increasing competition for top talent. For instance, globalization has increased the geographical range of firms a given manager or banker may consider working for (or have information about). The rise in incentive pay has naturally benefited most those individuals with the greatest talent, capable of generating the highest profits for their chosen firms. Our theory, which emphasizes agents' heterogeneous information about available offers, can be readily reframed to apply to these kinds of labor-market settings, and would predict the observed distributional effects of competition. ${ }^{26}$ See Section 6 for more discussion on the labor-market application of our theory.

It is also interesting to compare how firms' profits from the different types depend on the intensity of competition. One natural way to do so is to consider the impact of competition on the markup difference, which is the difference in profits per sale for high and low types. For a menu with high-type utility $u_{h}$, this can be written

$$
\begin{aligned}
\Delta_{m}\left(u_{h}\right) & \equiv\left[x_{h}\left(u_{h}\right)-\varphi\left(q_{h}^{*}\right)\right]-\left[x_{l}\left(u_{h}\right)-\varphi\left(q_{l}\left(\hat{u}_{l}\left(u_{h}\right), u_{h}\right)\right)\right] \\
& =\underbrace{\left(S_{h}^{*}-S_{l}\left(\hat{u}_{l}\left(u_{h}\right), u_{h}\right)\right)}_{\text {Difference in surplus }}-\underbrace{\left(u_{h}-\hat{u}_{l}\left(u_{h}\right)\right)}_{\text {Difference in rents }} .
\end{aligned}
$$

Recall that the low-type surplus $S_{l}\left(\left(\hat{u}_{l}\left(u_{h}\right), u_{h}\right)\right.$ is increasing in $u_{h}$ (because low-type quality is increasing in $u_{h}$ ), while the difference in rents $u_{h}-\hat{u}_{l}\left(u_{h}\right)$ is also increasing in $u_{h}$. This, together with our finding that $u_{h}$ increases probabilistically with competition (see Corollary 2), then implies the following.

\footnotetext{
${ }^{25}$ The result in the text refers to the expected difference in the utility offered to each consumer type. It is straightforward to show the expected difference in the utility accepted by different consumer types also increases in $v$.

${ }^{26}$ In the reframed model, high agent types would correspond to those individuals with the greatest ability to generate high profits for their chosen firms, and these types would gain the most from competition among firms for the same reasons we have described above.
} 
Proposition 3 [Competition and Markups] As the degree of competition increases, the markup difference decreases probabilistically.

In other words, markups decrease faster for high types than for low types as competition intensifies. Intuitively, this result reflects two facts. First, competition is the fiercest for high-types, and takes the exclusive form of price reductions. Second, much (in many cases, all) of the gains that low types obtain from more competition take the form of higher provision of quality, rather than lower prices. This contributes to moderate the effect of competition on low-type markups.

Although researchers often lack data on marginal costs, the empirical work examining the relationship between mark-ups and competition seems broadly in line with Proposition 3 . Under assumptions on the structure of yellow-pages advertising, Busse and Rysman (2005) find that decreases in mark-ups associated with competition are greatest for the largest sizes of ads in yellow-pages phone books. Miravete and Roller (2004) estimate price-cost margins using a structural model, and find that marginal costs fall in response to competition (possibly due to improved efficiency in markets with competition). They argue that competition favors high-end users more than low-end users, as the markup difference across calling plans typically decreases as competition intensifies.

\subsection{Competition and Preference Heterogeneity}

Consumer preference heterogeneity is another important determinant of how competition impacts price and qualities. In this subsection, we describe how differences in consumer preferences help to explain variations in quality provision and pricing across markets.

The next proposition addresses the following question: For markets with the same degree of competition, how does quality provision depend on the distribution of consumer preferences?

Proposition 4 [Quality Provision and Preference Heterogeneity] The quality levels of the low-type good probabilistically increase as the share of consumers with low willingness to pay $\left(p_{l}\right)$ increases.

This result combines the effects of changes in $p_{l}$ on both the support function and the equilibrium distributions over indirect utilities. Crucially, an increase in $p_{l}$ induces the support function to shift downwards; equivalently, for each $u_{l}$, the associated $u_{h}$ increases. This reflects the fact that, as the mass of low-type consumers increases, the marginal gains from increasing $u_{h}$ due to the relaxation of $\mathrm{IC}_{h}$ go up. Therefore, as we move to markets with a greater fraction of low-type consumers, for each $u_{h}$, the low-type quality offered by menus of generosity $u_{h}$ has to increase.

In addition, the distribution over high-type indirect utilities shifts to the right as $p_{l}$ increases. To understand why, recall that markup differences $\Delta_{m}\left(u_{h}\right)$ decrease in $u_{h}$. This implies that, as $p_{l}$ goes up, the profits of the most generous firms are the ones to decrease the least. Therefore, to sustain 
indifference, firms have to be more likely in equilibrium to offer menus of high generosity. These two effects together guarantee that low-type qualities are higher (probabilistically) in markets with more low-type consumers. We are unaware of empirical work documenting the correlation across markets between consumer tastes for quality and the quality of the low-type good.

Inspired by the empirical literature, the next proposition explores two other predictions of our model. First, for markets with the same degree of competition, how do price differentials depend on the distribution of consumer preferences? Second, in which markets should we expect a greater impact of competition on price differentials?

To answer these questions, it is convenient to denote by $\tilde{\Delta}_{p}(y)$ the price differential of rank $y$, that is, $\tilde{\Delta}_{p}(y) \equiv x_{h}\left(u_{h}\right)-x_{l}\left(u_{h}\right)$ such that $y=F_{h}\left(u_{h}\right)$. By tracking the price differential provided by firms in each quantile of the distribution of indirect utilities, we are able to describe in a transparent way the interplay between pricing and consumer heterogeneity.

Proposition 5 [Price Differentials and Preference Heterogeneity] For any $y \in(0,1)$, the price differential of rank $y, \tilde{\Delta}_{p}(y)$, decreases in $v$ and $p_{l}$. Moreover, if the degree of competition is sufficiently high (i.e., whenever $v>\bar{v}$ for some $\bar{v}$ ), the marginal impact of $v$ on $\tilde{\Delta}_{p}(y)$ (in absolute terms) is decreasing in $p_{l}$.

As established by the proposition above, the price differential of rank $y$ is decreasing in both $v$ and $p_{l}$, for any $y \in(0,1)$. That it decreases in $v$ follows immediately from Proposition 2 . That $\tilde{\Delta}_{p}(y)$ decreases in $p_{l}$ follows from two facts. First, the low-type quality level of rank $y$ (namely $\hat{q}_{l}(y) \equiv q_{l}\left(\hat{u}_{l}\left(u_{h}\right), u_{h}\right)$ such that $\left.y=F_{h}\left(u_{h}\right)\right)$ increases in $p_{l}$, as implied by Proposition 4. Second, the price differential of rank $y$ is a decreasing function of the low-type quality $\hat{q}_{l}(y)$ (see Equation $(13))$.

More interesting, perhaps, is that the impact of competition on price differentials is stronger in markets with fewer low-type consumers. As such, the degree of competition and the fraction of low types work as substitutes for reducing price differentials. To get intuition, recall from the discussion following Proposition 4 that, as $p_{l}$ increases, the utility enjoyed by high-type consumers goes up probabilistically, or, equivalently, high-type prices go down. Together with the fact that low-type qualities are higher in markets with more low-type consumers (as established by Proposition 4), this means that competition is fiercer for low types the higher is $p_{l}$. This works to moderate the impact of competition on price differentials, as the surplus to be shared with consumers from low-type sales is smaller.

In line with this prediction, Gerardi and Shapiro (2009) find that the compression of an airline's prices associated with increased competition is greatest on "big-city" routes, likely to have the greatest number of high-paying business travelers. 


\section{Extensions}

\subsection{Other Models of Information Heterogeneity}

A key feature of our analysis is that consumers are heterogeneously informed about the offers prevailing in the market. To simplify the exposition, we modeled information heterogeneity following the "simultaneous-search" framework proposed by Burdett and Judd (1983). Our results are, however, robust to other matching technologies, as we now describe.

One notable example of a matching technology under which our results readily apply is the "urn-ball" model of Butters (1977).

Example 1 [Butters (1977)] Let the menu offered by each firm be observed at random by exactly one consumer. The analysis of Butters (1977) implies that, when the number of firms and consumers in the market is large (with ratio $\eta$ ), the expected sales to type-k consumers of a firm offering an indirect utility of rank $y_{k}$ (relative to the other offers in the market) is given by $p_{k} \Lambda\left(y_{k} \mid \eta\right)$, where the sales function $\Lambda\left(y_{k} \mid \eta\right)$ has the form

$$
\Lambda\left(y_{k} \mid \eta\right)=\exp \left\{-\eta\left(1-y_{k}\right)\right\}
$$

The parameter $\eta$, describing the ratio of firms to consumers, plays an analogous role to the degree of competition $v$ in the Burdett-Judd specification of the baseline model.

Another important example is the "on-the-job search" model of Burdett and Mortensen (1998).

Example 2 [Burdett and Mortensen (1998)] Consider a dynamic economy in continuous time in which consumers receive ads (each ad describes the menu of a particular firm) according to independent Poisson processes with arrival rate $\lambda$. Consumers must make purchasing decisions as soon as an ad arrives, and there is no recall. Each matched consumer purchases continuously from the seller until the match is dissolved. This can occur exogenously due to an event which arrives at Poisson rate $\gamma$. Alternatively, consumers may switch firms if they receive (at rate $\lambda$ ) an ad describing a more attractive menu. The analysis of Burdett and Mortensen (1998) implies that, at the steady state of this economy, the expected sales to type- $k$ consumers of a firm offering an indirect utility of rank $y_{k}$ (relative to the other offers in the market) is given by $p_{k} \Lambda\left(y_{k} \mid \lambda\right)$, where the sales function $\Lambda\left(y_{k} \mid \lambda\right)$ has the form

$$
\Lambda\left(y_{k} \mid \lambda\right)=\gamma\left[\frac{1}{\gamma+\lambda\left(1-y_{k}\right)}\right]\left[\frac{1}{\gamma+r+\lambda\left(1-y_{k}\right)}\right] .
$$

The parameter $\lambda$, describing the arrival rate of a new ad, plays an analogous role to the degree of competition $v$ in the Burdett-Judd specification of the baseline model.

The examples above share a number of features. First, the mass of sales is linear in the mass of type- $k$ consumers in the market. Second, sales functions depend on $u_{k}$ only through the rank in the 
distribution of indirect utilities to type $k, F_{k}\left(u_{k}\right)$. This "ranking property" reflects the assumption that consumers are concerned only for the utility of consumption net of transfers (and thus pick the best offer available based on these features), and not with other characteristics of a firm's offer such as transportation costs or the firm's identity.

These two features, together with some other technical requirements detailed below, define a class of matching technologies under which all results from Sections 3 and 4 hold as stated.

Assumption 1 Let $\tilde{F}$ be a measure over menus with supp $\tilde{F} \subset \mathbb{I}$, and marginal cdf over type- $k$ indirect utilities $F_{k}$, with support $\Upsilon_{k}$. At any continuity point $u_{k} \in \Upsilon_{k}$ of $F_{k}$, the expected sales to type- $k$ consumers of a firm offering an indirect utility of rank $y_{k}=F_{k}\left(u_{k}\right)$ is given by $p_{k} \Lambda\left(y_{k} \mid v\right)$, where the sales function $\Lambda(y \mid v)$ is continuously differentiable, bounded, strictly increasing in $y$ with derivative bounded away from zero, and is such that $\frac{\Lambda(y \mid v)}{\Lambda(0 \mid v)}$ is strictly increasing in $v$ for any $y>0 .{ }^{27}$

This last requirement means that, relative to the least generous menu available in the market, the proportional gains in sales from offering a contract whose indirect utility lies in some quantile $y>0$ increases with the degree of competition $v$. The matching technologies of Burdett and Judd (1983) and of the Examples 1 and 2 satisfy Assumption 1. We refer the reader to a previous version of this article (Garrett et al (2014)) for other examples, as well as for a detailed proof of Theorem 1 that covers any matching technology satisfying Assumption 1.

\subsection{Continuum of Types}

The equilibrium characterization described above proceeded under the assumption of two consumer types (with no restrictions on the probability distribution). In a previous version of this article (Garrett et al (2014)), we extend our characterization to the case of a continuum of types with a uniform distribution and quadratic costs. This extension exhibits the (arguably, realistic) feature that qualities are distorted for almost every consumer type in every equilibrium menu. This is unlike the binary model considered here, where quality is efficiently provided with positive probability (for high types). Importantly, we show that our main insights remain true (pertaining to the existence of an ordered equilibrium, and its implications for pricing and quality provision) in this continuum-type setting. ${ }^{28}$

\footnotetext{
${ }^{27}$ At any point where $F_{k}$ is discontinuous (i.e., has an atom), sales are determined according to uniform rationing rule described in Footnote 14.

${ }^{28}$ The chief difficulty for analyzing other specifications stems from the fact that closed-form solutions are difficult to obtain. We have numerically calculated equilibria for the discrete-type case with various number of types and different distributions over consumer types, obtaining results similar to those reported above.
} 


\subsection{Information Acquisition by Consumers}

In order to isolate the effects of competition on the firms' pricing and quality provision, the analysis above assumed that consumer information is exogenous. In reality, information might often be endogenous, as consumers may invest in information acquisition, so as to learn the offers available in the market.

It is possible to incorporate information acquisition by consumers in our model of competitive nonlinear pricing. A natural alternative is to assume that, after learning their willingness to pay for quality, each consumer can make an investment that shifts her sample-size distribution according to first-order stochastic dominance. We explore this extension in a previous version of this article (Garrett et al (2014)), and show that high-type consumers invest more in information acquisition than low types. As a result, relative to the case where information is exogenous, consumer information acquisition makes high types "over-represented" in equilibrium, i.e., firms behave as if high-type consumers were more frequent relative to low types than as implied by their actual masses.

\section{Conclusion}

This paper studies imperfect competition in price-quality schedules in a market with informational frictions. On the one hand, consumers have private information about their willingness to pay for quality. On the other, consumers are imperfectly informed about the offers in the market, which is the source of firms' market power. While firms are ex-ante identical, equilibrium menus are dispersed and can be ranked in terms of their generosity to all consumer types. Our analysis illuminates how firms of different generosity employ price reductions and/or quality improvements to compete for consumers.

We build on the characterization of equilibrium to deliver a number of empirical implications that explore changes in market fundamentals. Namely, (i) we study how prices and qualities react to changes in competition, (ii) we analyze the distributional effects of competition across consumer types, and (iii) we assess the impact of variations in consumer tastes and competition on the price differentials within firms' menus. These predictions find support in a number of markets, such as those for cell phone plans, yellow-pages advertising, airline tickets and cable television.

Labor-Market Application. While we focused on sales of products with variable quality, our results extend to other contexts where information heterogeneity makes sense. A natural application, for instance, is to labor markets where workers have private information about their productivities, and are heterogeneously informed about the job offers available in the market. Contracts might pay wages based on the worker's output. In such settings, our results indicate dispersion over offers, with firms endogenously segmenting themselves relative to (i) the indirect utility left to all worker types, and (ii) the efficiency of effort provision induced by their contracts. We expect that changes in labor 
market fundamentals generate empirical predictions analogous to those derived above.

Directions for Further Research. For the sake of tractability, we have assumed that firms' capacities are unconstrained, so they are able to fill all orders. Capacity constraints raise the possibility that those firms offering the most generous menus sell out, a possibility that consumers should in turn anticipate. An examination of these "congestion effects" when consumer tastes are private information and information is heterogeneous seems difficult but worthwhile. ${ }^{29}$

A perhaps more tractable alternative to modeling capacity constraints is to assume that the marginal benefit of an additional consumer is decreasing in the measure of consumers already served by each firm. If firms are heterogeneous in costs, we conjecture that market segmentation would occur in equilibrium, and more cost-effective firms would serve on average higher-valuation consumers.

Finally, we assumed that consumers observe the entire menu of qualities offered by each firm. In practice, consumers may fail to consider all of the options that a firm offers; i.e., information imperfections may pertain also to a consumer's ability to observe the entire menu. This possibility has been explicitly recognized in empirical work (e.g., Sovinsky Goeree (2008)). In theoretical work, Villas-Boas (2004) studies a monopolist whose consumers may (randomly) observe only the option designed for the high or low type; extending the analysis to a competitive setting raises additional challenges.

\section{Acknowledgements}

We are grateful to Jean Tirole for extensive comments at the early stages of this project. We also thank Yeon-Koo Che, Andrew Clausen, Jacques Crémer, Wouter Dessein, Jan Eeckhout, Renaud Foucart, Ed Hopkins, Bruno Jullien, Tatiana Kornienko, Volker Nocke, Wojciech Olszewski, Michael Peters, Patrick Rey, Andrew Rhodes, Mike Riordan, Maher Said, Ron Siegel, Bruno Strulovici, André Veiga, and Yaron Yehezkel for very helpful conversations. For useful feedback, we thank seminar participants at Bilkent, Columbia, FGV-EPGE, the LMU of Munich, Melbourne, Monash, UNSW, Queensland, École Polytechnique, Northwestern, Oxford, Bonn, Edinburgh, Stonybrook, the 2013 Toulouse-Northwestern IO conference, the 2013 UBC-UHK Theory conference (Hong Kong), the 2014 CEPR Applied IO conference (Athens), INSPER, the 2014 EARIE conference (Milan), Mannheim, PSE and Pompeu Fabra. The usual disclaimer applies.

\section{References}

[1] Armstrong, M. and J. Vickers, 2001. "Competitive Price Discrimination." Rand Journal of Economics, 32, 579-605.

\footnotetext{
${ }^{29}$ See Lester (2011) for a related model without private information on consumer tastes.
} 
[2] Berry, S., J. Levinsohn and A. Pakes, 1995. "Automobile Prices in Market Equilibrium." Econometrica, 63, 841-890.

[3] Bénabou, R. and J. Tirole, 2016. "Bonus Culture: Competitive Pay, Screening, and Multitasking." Journal of Political Economy (forthcoming).

[4] Borenstein, S., 1985. "Price Discrimination in Free-Entry Markets." Rand Journal of Economics, $16,380-397$.

[5] Borenstein, S. and N. Rose, 1994. "Competition and Price Dispersion in the U.S. Airline Industry." Journal of Political Economy, 102, 653-683.

[6] Butters, G., 1977. "Equilibrium Distributions of Sales and Advertising Prices." Review of Economic Studies, 44, 465-491.

[7] Burdett, K., and D. Mortensen, 1998. "Wage Differentials, Employer Size, and Unemployment." International Economic Review, 39, 257-273.

[8] Burdett, K., and D. Judd, 1983. "Equilibrium Price Dispersion.” Econometrica, 51, 955-970.

[9] Busse, M. and M. Rysman, 2005. "Competition and Price Discrimination in Yellow Pages Advertising." Rand Journal of Economics, 36, 378-390.

[10] Byrne, D., 2015. "Testing Models of Differentiated Products Markets: Consolidation in the Cable TV Industry." International Economic Review, 56, 805-850.

[11] Calzolari, G., and V. Denicolo, 2013. "Competition with Exclusive Contracts and Market-Share Discounts." American Economic Review, 103, 2384-2411.

[12] Champsaur, P. and J.-C. Rochet, 1989. "Multi-Product Duopolists". Econometrica, 57, 533-557.

[13] Chandra, A. and M. Tappata, 2011. "Consumer Search and Dynamic Price Dispersion: An Application to Gasoline Markets." Rand Journal of Economics, 42, 681-704.

[14] Chu, C. S., 2010. "The Effect of Satellite Entry on Cable Television Prices and Product Quality." Rand Journal of Economics, 41, 730-764.

[15] Clemons, E., I.-H. Hann and L. Hitt, 2002. "Price Dispersion and Differentiation in Online Travel: An Empirical Investigation." Management Science, 48, 534-549.

[16] Crawford, G., 2012. "Accommodating Endogenous Product Choices: A Progress Report." International Journal of Industrial Organization, 30, 315-320. 
[17] Draganska, M., and D. Klapper, 2011. "Choice Set Heterogeneity and The Role of Advertising: An Analysis with Micro and Macro Data." Journal of Marketing Research, 48, 653-669.

[18] Dupuit, J., 1849. "De l'Influence des Péages sur l'Utilité des Voies de Communication", Annales des Ponts et Chaussées, s. II, 1st semester, pp. 170-248; English translation of the last section "On Tolls and Transport Charges", by E. Henderson, International Economic Papers (1962), n. 11, pp. 7-31.

[19] Economides, N., K. Seim and V. Brian Viard, 2008. "Quantifying the Benefits of Entry into Local Phone Service." Rand Journal of Economics, 39, 699-730.

[20] Eeckhout, J., and P. Kircher, 2010. "Sorting Versus Screening: Search Frictions and Competing Mechanisms." Journal of Economic Theory, 145, 1354-1385.

[21] Ellison, G., 2005. "A Model of Add-on Pricing." Quarterly Journal of Economics, 120, 585-367.

[22] Faig, M. and B. Jerez, 2005. "A Theory of Commerce." Journal of Economic Theory, 122, 60-99.

[23] Garrett, D., R. Gomes and L. Maestri, 2014. "Competitive Screening Under Heterogeneous Information." Discussion Paper 10036, Centre for Economic Policy Research, London.

[24] Gerardi, K. and A. Shapiro, 2009. "Does Competition Reduce Price Dispersion? New Evidence From the Airline Industry." Journal of Political Economy, 117, 1-37.

[25] Goldman, M., H. Leland, and D. Sibley. 1984. "Optimal Nonuniform Pricing." Review of Economic Studies, 51, 305-320.

[26] Grossman, G. M. and C. Shapiro, 1984. "Informative Advertising with Differentiated Products." Review of Economic Studies, 51, 63-81.

[27] Guerrieri, V., R. Shimer and R. Wright, 2010. "Equilibrium Price Dispersion." Econometrica, $78,1823-1862$.

[28] Inderst, R., 2001. "Screening in a Matching Market." Review of Economic Studies, 68, 849-868.

[29] Inderst, R., 2004. "Contractual Distortions in a (Labor) Market with Frictions." Journal of Economic Theory, 116, 155-176.

[30] Ivaldi, M. and D. Martimort, 1994. "Competition Under Nonlinear Pricing." Annales d'Économie et de Statistique, 34, 71-114.

[31] Jewitt, I., 1991. "Applications of Likelihood Ratio Orderings in Economics." In: Stochastic Orders and Decision Under Risk: Papers from the International Workshop Held in Hamburg, May 16-20, 1989 (eds. K. Mosler and M. Scarsini), Institute of Mathematical Statistics, Hayward. 
[32] Katz, M. L., 1984. "Price Discrimination and Monopolist Competition." Econometrica, 52, 1453-1471.

[33] Lester, B., 2011. "Information and Prices with Capacity Constraints." American Economic Review, 101, 1591-1600.

[34] Lester, B., A. Shourideh, V. Venkateswaran and A. Zetlin-Jones, 2015. "Screening and Adverse Selection in Frictional Markets." Working Paper.

[35] McAfee, P., 1993. "Mechanism Design by Competing Sellers." Econometrica, 78, 1823-1862.

[36] Maskin, E., and J. Riley, 1984. "Monopoly with Incomplete Information." Rand Journal of Economics, 15, 171-196.

[37] Mazzeo, M., 2003. "Competition and Service Quality in the US Airline Industry." Review of Industrial Organization, 22, 275-296.

[38] Miravete, E. and L.-H. Roller, 2004. "Estimating Price-Cost Markups under Nonlinear Pricing Competition." Journal of the European Economic Association, 2, 526-535.

[39] Moen, A. and A. Rosén, 2011. "Incentives in Competitive Search Equilibrium." Review of Economic Studies, 98, 733-761.

[40] Mussa, M. and S. Rosen, 1978. "Monopoly and Product Quality." Journal of Economic Theory, $18,301-317$.

[41] Pai, M., 2012. "Competing Auctioneers." Working Paper.

[42] Peters, M., 1997. "A Competitive Distribution of Auctions." Review of Economic Studies, 64, 97-123.

[43] Peters, M., and S. Severinov, 1997. "Competition among Sellers Who Offer Auctions Instead of Prices." Journal of Economic Theory, 75, 141-179.

[44] Rochet, J.-C., and L. Stole, 1997. "Competitive Nonlinear Pricing." Working paper.

[45] Rochet, J.-C., and L. Stole, 2002. "Nonlinear Pricing with Random Participation." Review of Economic Studies, 69, 277-311.

[46] Salop, S., and J. Stiglitz, 1977. "Bargains and Rip-Offs: A Model of Monopolistically Competitive Price Discrimination." Review of Economic Studies, 44, 493-510.

[47] Sengupta, A. and S. Wiggins, 2014. "Airline Pricing, Price Dispersion, and Ticket Characteristics on and off the Internet." American Economic Journal: Economic Policy, 6, 272-307. 
[48] Sovinsky Goeree, M., 2008. "Limited Information and Advertising in the U.S. Personal Computer Industry." Econometrica, 76, 1017-1074.

[49] Spulber, D., 1989. "Product Variety and Competitive Discounts." Journal of Economic Theory, $48,510-525$.

[50] Stole, L., 1991. "Mechanism Design and Common Agency". Working Paper.

[51] Stole, L., 1995. "Nonlinear Pricing and Oligopoly." Journal of Economics \& Management Strategy, 4, 529-562.

[52] Stole, L., 2007. "Price Discrimination and Competition." In: Handbook of Industrial Organization, vol. 3 (eds. M. Armstrong and R. Porter), North-Holland.

[53] Varian, H., 1980. "A Model of Sales.” American Economic Review, 70, 651-659.

[54] Verboven, F., 1999. "International Price Discrimination in the European Car Market." Rand Journal of Economics, 27, 240-268.

[55] Villas-Boas, M., 2004. "Communication Strategies and Product Line Design." Marketing Science, $23,304-316$.

[56] Wilson, R., 1993. Nonlinear Pricing. Oxford University Press, Oxford.

[57] Yang, H., and Ye, L., 2008. "Nonlinear Pricing, Market Coverage and Competition." Theoretical Economics, 3, 123-153.

\section{Appendix A: Main Proofs}

Throughout all the appendices, we find convenient to define

$$
\Phi_{k}(u) \equiv p_{k} \Lambda\left(F_{k}(u) \mid v\right)
$$

for $k \in\{l, h\}$.

Proof of Lemma 1. If the low type is offered the quality $q_{l}$, then payoffs must satisfy $I C_{h}$, i.e.,

$$
u_{h} \geq u_{l}+\Delta \theta q_{l}
$$

On the other hand, $I C_{l}$ requires that

$$
u_{l} \geq u_{l}-\Delta \theta q_{h} .
$$

The firm would like to make its offer as efficient as possible subject to the payoffs it delivers to the consumer. 
If $u_{h}-u_{l}<\bar{\Delta}_{l} \equiv \Delta \theta q_{l}^{*}$, then offering the efficient quality $q_{l}^{*}$ for the low type is inconsistent with (15), and the firm does best to choose the highest possible value. That is, the firm chooses quality $q_{l}\left(u_{l}, u_{h}\right)$ which satisfies (15) with equality, or

$$
q_{l}\left(u_{l}, u_{h}\right) \equiv \frac{u_{h}-u_{l}}{\Delta \theta}
$$

If $u_{h}-u_{l} \geq \bar{\Delta}_{l}$, then the constraint (15) does not bind, and the firm chooses low-type quality efficiently: $q_{l}\left(u_{l}, u_{h}\right) \equiv q_{l}^{*}$. Similarly, let $\bar{\Delta}_{h} \equiv \Delta \theta q_{h}^{*}$. If $u_{h}-u_{l}>\bar{\Delta}_{h}$, then asking the quality $q_{h}^{*}$ for the high type violates (16), and so the best the firm can do is to choose $q_{h}\left(u_{l}, u_{h}\right)$ defined by

$$
q_{h}\left(u_{l}, u_{h}\right) \equiv \frac{u_{h}-u_{l}}{\Delta \theta}
$$

If $u_{h}-u_{l}<\bar{\Delta}_{h}$, the firm offers the high-type an efficient quality: $q_{h}\left(u_{l}, u_{h}\right) \equiv q_{h}^{*}$. Q.E.D.

Proof of Lemma 2. To see this claim, note that $\pi\left(u_{l}, u_{h}^{2}\right)-\pi\left(u_{l}, u_{h}^{1}\right)$ equals (recall our definition of $\Phi_{k}$ given in (14))

$$
\begin{gathered}
\Phi_{l}\left(u_{l}\right)\left(S_{l}\left(u_{l}, u_{h}^{2}\right)-S_{l}\left(u_{l}, u_{h}^{1}\right)\right) \\
+\left(\Phi_{h}\left(u_{h}^{2}\right)-\Phi_{h}\left(u_{h}^{1}\right)\right)\left(S_{h}\left(u_{l}, u_{h}^{2}\right)-u_{h}^{2}\right) \\
+\Phi_{h}\left(u_{h}^{1}\right)\left(\begin{array}{c}
S_{h}\left(u_{l}, u_{h}^{2}\right)-u_{h}^{2} \\
-\left(S_{h}\left(u_{l}, u_{h}^{1}\right)-u_{h}^{1}\right)
\end{array}\right) .
\end{gathered}
$$

The cross-partial $\frac{\partial^{2}}{\partial u_{l} \partial u_{h}} S_{l}\left(u_{l}, u_{h}\right)$ is positive if $u_{h}-u_{l}<\Delta \theta q_{l}^{*}$ and zero otherwise. Thus the first line of (17) is strictly increasing over $u_{l}$ such that $u_{h}^{1}-u_{l} \leq \Delta \theta q_{l}^{*}$ and constant otherwise. The function $S_{h}\left(\cdot, u_{h}^{2}\right)$ is strictly increasing if $q_{h}\left(u_{l}, u_{h}^{2}\right)>q_{h}^{*}$ and constant otherwise. Thus the second line in (17) is increasing in $u_{l}$. The cross-partial $\frac{\partial^{2}}{\partial u_{l} \partial u_{h}} S_{h}\left(u_{l}, u_{h}\right)$ is positive if $u_{h}-u_{l}>\Delta \theta q_{h}^{*}$ and is zero otherwise. Thus the third term is strictly increasing over $u_{l}$ such that $u_{h}^{2}-u_{l} \geq \Delta \theta q_{h}^{*}$ and constant otherwise. These arguments imply the result. Q.E.D.

Proof of Lemma 3. See Section 9 in the Online Appendix. Q.E.D.

Proof of Theorem 1. We proceed in three steps. First, we construct the support function $\hat{u}_{l}(\cdot)$. In the second step, we derive the equilibrium distribution over menus. In the last step, we show that firms cannot benefit from deviating to an out-of-equilibrium menu.

In order to better explain the Theorem, we relegate some technical steps to Section 9 in the Online Appendix (Claims 1- 5).

\section{Step 1 Constructing the support function}

Because of the ranking property of kernels, it follows that in any ordered equilibrium with support function $\hat{u}_{l}(\cdot)$,

$$
\Lambda\left(F_{h}\left(u_{h}\right) \mid v\right)=\Lambda\left(F_{l}\left(\hat{u}_{l}\left(u_{h}\right)\right) \mid v\right) .
$$


The equation above implies that sales to each type $k$ are proportional to the probability of that type $p_{k}$. Accordingly, the support function $\hat{u}_{l}(\cdot)$ describes the locus of indirect utility pairs $\left(\hat{u}_{l}\left(u_{h}\right), u_{h}\right)$ such that the proportion of sales to each type is constant.

Claim 1 shows that $\Phi_{h}(\cdot)$ and $\Phi_{l}(\cdot)$ (defined in (14)) are continuously differentiable, what justifies the first-order conditions (7) and (8). Claim 2 guarantees that if we differentiate (18) we obtain:

$$
\hat{u}_{l}^{\prime}\left(u_{h}\right)=\frac{\Lambda_{1}\left(F_{h}\left(u_{h}\right) \mid v\right) \cdot f_{h}\left(u_{h}\right)}{\Lambda\left(F_{h}\left(u_{h}\right) \mid v\right)} \cdot\left[\frac{\Lambda_{1}\left(F_{l}\left(\hat{u}_{l}\left(u_{h}\right)\right) \mid v\right) \cdot f_{l}\left(\hat{u}_{l}\left(u_{h}\right)\right)}{\Lambda\left(F_{l}\left(\hat{u}_{l}\left(u_{h}\right)\right) \mid v\right)}\right]^{-1} .
$$

Intuitively, the slope of the support function, $\hat{u}_{l}^{\prime}\left(u_{h}\right)$, equals the ratio between the semi-elasticities of sales with respect to indirect utilities for each type of consumer.

The first-order conditions (7) and (8) provide an alternative expression for these semi-elasticities. Evaluated at the locus $\left(\hat{u}_{l}\left(u_{h}\right), u_{h}\right)$, with the help of (18), equations $(7)$ and (8) can be rewritten as

$$
p_{k} \cdot \frac{\Lambda_{1}\left(F_{k}\left(\hat{u}_{k}\left(u_{h}\right)\right) \mid v\right) \cdot f_{k}\left(\hat{u}_{k}\left(u_{h}\right)\right)}{\Lambda\left(F_{k}\left(\hat{u}_{k}\left(u_{h}\right)\right) \mid v\right)} \cdot\left(S_{k}\left(\hat{u}_{l}\left(u_{h}\right), u_{h}\right)-u_{k}\right)=p_{k}-p_{l} \cdot \frac{\partial S_{l}}{\partial u_{k}}\left(\hat{u}_{l}\left(u_{h}\right), u_{h}\right),
$$

for $k=h$ and $k=l$, respectively. In equilibrium, the optimality of firms' menus requires that the support function $\hat{u}_{l}(\cdot)$ simultaneously satisfies the first-order conditions (20) and equation (19). Combining these two equations leads to the differential equation (11) which describes how the utility of the low type relates to the utility of the high type in the equilibrium menus.

From Lemma 3, we know that the least generous menu in equilibrium is the Mussa and Rosen menu $\left(0, u_{h}^{m}\right)$. Hence, we require that the solution to (11) satisfy the initial condition $\hat{u}_{l}\left(u_{h}^{m}\right)=0$. Next we invoke Claim 3 to assert the existence and uniqueness of the differential equation (11) subject to $\hat{u}_{l}\left(u_{h}^{m}\right)=0$. Moreover, Claim 3 shows that $\hat{u}_{l}^{\prime}\left(u_{h}\right)>0$ for all $u_{h} \in\left[u_{h}^{m}, \bar{u}_{h}\right]$. This guarantees that the menus $\left(\hat{u}_{l}\left(u_{h}\right), u_{h}\right)$ are indeed ordered.

Finally, Claim 4 verifies that the constraint $\mathrm{IC}_{l}$ is never binding in any menu $\left(\hat{u}_{l}\left(u_{h}\right), u_{h}\right)$. Indeed, we are able to show that, for all $u_{h} \in\left[u_{h}^{m}, \bar{u}_{h}\right]$,

$$
u_{h}-\hat{u}_{l}\left(u_{h}\right) \leq \bar{u}_{h}-\hat{u}_{l}\left(\bar{u}_{h}\right)<S_{h}^{*}-S_{l}^{*}<\triangle \theta \cdot q_{h}^{*}
$$

which, by Lemma 1 , implies that $\mathrm{IC}_{l}$ is slack at any equilibrium menu.

\section{Step 2 Constructing the distribution over menus}

In view of the support function $\hat{u}_{l}(\cdot)$, we can describe the equilibrium distribution over menus in terms of the distribution of indirect utilities to high type consumers, $F_{h}(\cdot)$. For that we choose, for each $u_{h}$, the quantile $F_{h}\left(u_{h}\right)$ in a way that all menus offered in equilibrium lead to the same expected profits as the Mussa-Rosen menu $\mathcal{M}^{m}$. This is reflected in the indifference condition (12). The argument in Claim 5 shows that the profits conditional on sale

$$
p_{l}\left(S_{l}\left(\hat{u}_{l}\left(u_{h}\right), u_{h}\right)-\hat{u}_{l}\left(u_{h}\right)\right)+p_{h}\left(S_{h}\left(\hat{u}_{l}\left(u_{h}\right), u_{h}\right)-u_{h}\right)
$$


are strictly decreasing in $u_{h}$. Hence, if we define $F_{h}(\cdot)$ to satisfy (12).we obtain an increasing and absolutely continuous function.

In order to complete the construction of $F_{h}(\cdot)$, we need to determine the support of high type indirect utilities, $\Upsilon_{h}$. By Lemma $3, \Upsilon_{h}$ is a closed interval of the form $\left[u_{h}^{m}, \bar{u}_{h}\right]$, so we are only left to compute the upper limit of $\Upsilon_{h}, \bar{u}_{h}$. Claim 5 shows that there exists a unique $\bar{u}_{h}<S_{h}^{*}$ for which $F_{h}\left(\bar{u}_{h}\right)=1$.

\section{Step 3 Verifying the optimality of equilibrium menus}

It now remains to check that firms have no incentive to deviate from the putative equilibrium strategies. By construction, all menus $\left(u_{l}, u_{h}\right)$ such that $u_{h} \in\left[u_{h}^{m}, \bar{u}_{h}\right]$ and $u_{l}=\hat{u}_{l}\left(u_{h}\right)$ yield the same profit. Moreover, it is easy to show that we may restrict attention to menus $\left(u_{l}^{\prime}, u_{h}^{\prime}\right) \in\left[u_{h}^{m}, \bar{u}_{h}\right] \times$ $\left[u_{l}^{m}, \hat{u}_{l}\left(\bar{u}_{h}\right)\right]$. Hence, consider a menu $\left(u_{l}^{\prime}, u_{h}^{\prime}\right) \in\left[u_{h}^{m}, \bar{u}_{h}\right] \times\left[u_{l}^{m}, \hat{u}_{l}\left(\bar{u}_{h}\right)\right]$ such that $u_{l}^{\prime} \neq \hat{u}_{l}\left(u_{h}^{\prime}\right)$. We have that

$$
\begin{aligned}
\pi\left(\hat{u}_{l}\left(u_{h}^{\prime}\right), u_{h}^{\prime}\right)-\pi\left(u_{l}^{\prime}, u_{h}^{\prime}\right) & =\int_{u_{l}^{\prime}}^{\hat{u}_{l}\left(u_{h}^{\prime}\right)} \frac{\partial \pi\left(\tilde{u}_{l}, u_{h}^{\prime}\right)}{\partial u_{l}} d \tilde{u}_{l} \\
& =\int_{u_{l}^{\prime}}^{\hat{u}_{l}\left(u_{h}^{\prime}\right)} \frac{\partial \pi\left(\tilde{u}_{l}, u_{h}^{\prime}\right)}{\partial u_{l}}-\frac{\partial \pi\left(\tilde{u}_{l}, \hat{u}_{l}^{-1}\left(\tilde{u}_{l}\right)\right)}{\partial u_{l}} d \tilde{u}_{l} \\
& =\int_{u_{l}^{\prime}}^{\hat{u}_{l}\left(u_{h}^{\prime}\right)} \int_{\hat{u}_{l}^{-1}\left(\tilde{u}_{l}\right)}^{u_{h}^{\prime}} \frac{\partial^{2} \pi\left(\tilde{u}_{l}, \tilde{u}_{h}\right)}{\partial u_{h} \partial u_{l}} d \tilde{u}_{h} d \tilde{u}_{l} \\
& \geq 0 .
\end{aligned}
$$

The second equality follows because $\frac{\partial \pi\left(u_{l}, u_{h}\right)}{\partial u_{l}}=0$ along the curve $\left\{\left(\hat{u}_{l}\left(u_{h}\right), u_{h}\right): u_{h} \in\left[u_{h}^{m}, \bar{u}_{h}\right]\right\}$. The inequality follows because $\frac{\partial^{2} \pi\left(\tilde{u}_{l}, \tilde{u}_{h}\right)}{\partial u_{h} \partial u_{l}} \geq 0$ for all $\left(\tilde{u}_{l}, \tilde{u}_{h}\right)$ by Lemma 2 . Thus a deviation to menu $\left(u_{l}^{\prime}, u_{h}^{\prime}\right)$ is unprofitable. This completes the proof of the Theorem 1. Q.E.D.

Proof of Corollary 1. The proof that $0<\hat{u}_{l}^{\prime}\left(u_{h}\right)<1$ can be found in the proof of Claim 3 in Section 9 in the Online Appendix. The proof that $\hat{u}_{l}(\cdot)$ is convex can be found in the proof of Corollary 3 below. Finally, the proof of $\hat{u}_{l}^{\prime}\left(u_{h}^{m}\right)=0$ follows from evaluating (11) at $\left(0, u_{h}^{m}\right)$. Q.E.D.

Proof of Corollary 2 Denote by $F_{k}$ and $\hat{F}_{k}$ (with supports $\Upsilon_{k}$ and $\hat{\Upsilon}_{k}$ ) the distributions over indirect utilities in the ordered equilibrium associated with the degree of competition is $v$ and $\hat{v}$, respectively. We will show that if $v>\hat{v}$ then $F_{k}$ first-order stochastically dominates $\hat{F}_{k}$, and $\hat{\Upsilon}_{k}$ is a proper subset of $\Upsilon_{k}$, for $k \in\{l, h\}$.

We first show that $F_{h}\left(u_{h}\right) \leq \hat{F}_{h}\left(u_{h}\right)$ for all $u_{h}$ and hence $F_{h}$ stochastically dominates $\hat{F}_{h}$. Since the support function does not depend on the degree of competition, the last claim implies that $F_{l}$ stochastically dominates $\hat{F}_{l}$. Towards a contradiction, take $\tilde{u}_{h}$ such that $F_{h}\left(\tilde{u}_{h}\right)>\hat{F}_{h}\left(\tilde{u}_{h}\right)$. Without 
loss assume that $\tilde{u}_{h} \in \Upsilon_{h}$ (otherwise, replace $\tilde{u}_{h}$ with $\max \Upsilon_{h}$ ). Therefore, we have:

$$
\begin{gathered}
\Lambda(0 \mid v)\left[p_{l} S_{l}\left(0, u_{h}^{m}\right)+p_{h}\left(S_{h}\left(0, u_{h}^{m}\right)-u_{h}^{m}\right)\right] \\
=\Lambda\left(F_{h}\left(\tilde{u}_{h}\right) \mid v\right)\left[p_{l}\left(S_{l}\left(\tilde{u}_{h}, \hat{u}_{l}\left(\tilde{u}_{h}\right)\right)-\hat{u}_{l}\left(\tilde{u}_{h}\right)\right)+p_{h}\left(S_{h}\left(\tilde{u}_{h}, \hat{u}_{l}\left(\tilde{u}_{h}\right)\right)-\tilde{u}_{h}\right)\right]
\end{gathered}
$$

and

$$
\begin{gathered}
\Lambda(0 \mid \hat{v})\left[p_{l} \cdot S_{l}\left(0, u_{h}^{m}\right)+p_{h}\left(S_{h}\left(0, u_{h}^{m}\right)-u_{h}^{m}\right)\right] \\
=\Lambda\left(\hat{F}_{h}\left(\tilde{u}_{h}\right) \mid \hat{v}\right)\left[p_{l}\left(S_{l}\left(\tilde{u}_{h}, \hat{u}_{l}\left(\tilde{u}_{h}\right)\right)-\hat{u}_{l}\left(\tilde{u}_{h}\right)\right)+p_{h}\left(S_{h}\left(\tilde{u}_{h}, \hat{u}_{l}\left(\tilde{u}_{h}\right)\right)-\tilde{u}_{h}\right)\right]
\end{gathered}
$$

and hence

$$
\frac{\Lambda\left(\hat{F}_{h}\left(\tilde{u}_{h}\right) \mid \hat{v}\right)}{\Lambda(0 \mid \hat{v})}=\frac{\Lambda\left(F_{h}\left(\tilde{u}_{h}\right) \mid v\right)}{\Lambda(0 \mid v)} .
$$

On the other hand, $F_{h}\left(\tilde{u}_{h}\right)>\hat{F}_{h}\left(\tilde{u}_{h}\right)$ implies $\frac{\Lambda\left(F_{h}\left(\tilde{u}_{h}\right) \mid v\right)}{\Lambda(0 \mid v)}>\frac{\Lambda\left(\hat{F}_{h}\left(\tilde{u}_{h}\right) \mid v\right)}{\Lambda(0 \mid v)}$.

Since $v>\hat{v}$ we have $\frac{\Lambda\left(\hat{F}_{h}\left(\tilde{u}_{h}\right) \mid v\right)}{\Lambda(0 \mid v)}>\frac{\Lambda\left(\hat{F}_{h}\left(\tilde{u}_{h}\right) \mid \hat{v}\right)}{\Lambda(0 \mid \hat{v})}$. To see this, notice that for a fixed $y \in(0,1)$ we have:

$$
\begin{aligned}
\frac{\Lambda(y \mid v)}{\Lambda(0 \mid v)}-\frac{\Lambda(y \mid \hat{v})}{\Lambda(0 \mid \hat{v})} & =\sum_{j=1}^{\infty} j\left(\frac{\omega_{j}(v)}{\omega_{1}(v)}\right) y^{j-1}-\sum_{j=1}^{\infty} j\left(\frac{\omega_{j}(\hat{v})}{\omega_{1}(\hat{v})}\right) y^{j-1} \\
& =\sum_{j=1}^{\infty} j y^{j-1}\left[\left(\frac{\omega_{j}(v)}{\omega_{1}(v)}\right)-\left(\frac{\omega_{j}(\hat{v})}{\omega_{1}(\hat{v})}\right)\right] .
\end{aligned}
$$

By the assumption that $\Omega(v)$ dominates $\Omega(\hat{v})$ in the sense of likelihood-ratio order, it follows that if $\left(\frac{\omega_{j}(v)}{\omega_{j}(\hat{v})}\right)$ is increasing in $j$. Hence, for all $j$, we have $\left(\frac{\omega_{j}(v)}{\omega_{j}(v)}\right) \geq\left(\frac{\omega_{1}(v)}{\omega_{1}(v)}\right)$, which implies $\left(\frac{\omega_{j}(v)}{\omega_{1}(v)}\right)-\left(\frac{\omega_{j}(\hat{v})}{\omega_{1}(\hat{v})}\right) \geq 0$ for all $j$, with a strict inequality for at least one $j>1$. Thus we have $\frac{\Lambda\left(F_{h}\left(\tilde{u}_{h}\right) \mid v\right)}{\Lambda(0 \mid v)}>\frac{\Lambda\left(\hat{F}_{h}\left(\tilde{u}_{h}\right) \mid \hat{v}\right)}{\Lambda(0 \mid \hat{v})}$, which contradicts $(21)$.

Since $F_{h}$ stochastically dominates $\hat{F}_{h}$ it follows that $\hat{\Upsilon}_{k} \subset \Upsilon_{k}$. Assume towards a contradiction that $\hat{\Upsilon}_{k}=\Upsilon_{k}$. In this case, let $\bar{u}_{h}$ the largest indirect utility that is provided to the high type in both equilibria. By an argument similar to the one above, we obtain

$$
\frac{\Lambda\left(\hat{F}_{h}\left(\bar{u}_{h}\right) \mid \hat{v}\right)}{\Lambda(0 \mid \hat{v})}=\frac{\Lambda(1 \mid \hat{v})}{\Lambda(0 \mid \hat{v})}=\frac{\Lambda(1 \mid v)}{\Lambda(0 \mid v)}=\frac{\Lambda\left(F_{h}\left(\bar{u}_{h}\right) \mid v\right)}{\Lambda(0 \mid v)}
$$

which cannot happen when $v>\hat{v}$. Q.E.D.

Proof of Corollary 3. Because the high-type quality is constant at $q_{h}^{*}$, it is immediate that $x_{h}(\cdot)$ is decreasing in $u_{h}$. The same is true regarding the low-type price $x_{l}(\cdot)$ at any $u_{h}>u_{h}^{c}$ (since the low-type quality is constant at $q_{l}^{*}$ ). So take $u_{h} \in\left[u_{h}^{m}, u_{h}^{c}\right]$ and note that

$$
x_{l}\left(u_{h}\right)=\theta_{l} \frac{u_{h}-\hat{u}_{l}\left(u_{h}\right)}{\Delta \theta}-\hat{u}_{l}\left(u_{h}\right) .
$$

Consider $\hat{u}_{l}^{\prime}\left(u_{h}\right)=h\left(\hat{u}_{l}\left(u_{h}\right), u_{h}\right)$, where $h$ is given by

$$
h\left(u_{l}, u_{h}\right)=\frac{S_{l}\left(u_{l}, u_{h}\right)-u_{l}}{S_{h}^{*}-u_{h}} \cdot \frac{1-\frac{p_{l}}{p_{h}} \frac{\partial S_{l}}{\partial u_{h}}\left(u_{l}, u_{h}\right)}{1-\frac{\partial S_{l}}{\partial u_{l}}\left(u_{l}, u_{h}\right)},
$$


and note that $h\left(0, u_{h}^{m}\right)=0$ (which implies that $\left.\hat{u}_{l}^{\prime}\left(u_{h}^{m}\right)=0\right)$. Therefore, since $\hat{u}_{l}(\cdot)$ and $h(\cdot, \cdot)$ are continuous,

$$
x_{l}^{\prime}\left(u_{h}\right)=\theta_{l} \frac{1-\hat{u}_{l}^{\prime}\left(u_{h}\right)}{\Delta \theta}-\hat{u}_{l}^{\prime}\left(u_{h}\right)=\theta_{l} \frac{1-h\left(\hat{u}_{l}\left(u_{h}\right), u_{h}\right)}{\Delta \theta}-h\left(\hat{u}_{l}\left(u_{h}\right), u_{h}\right)>0
$$

for all $u_{h}$ sufficiently close to $u_{h}^{m}$.

Recall that there is a unique threshold $u_{h}^{c}$, above which low-type quality is efficient. The threshold $u_{h}^{c}$ is the the unique value of $u_{h}$ solving $u_{h}-\hat{u}_{l}\left(u_{h}\right)=\triangle \theta \cdot q_{l}^{*}$. Trivially we have $x_{l}^{\prime}\left(u_{h}\right)<0$ for all $u_{h} \geq u_{h}^{c}$. We will now show that $\hat{u}_{l}(\cdot)$ is convex for $u_{h}<u_{h}^{c}$. Note that the convexity of $\hat{u}_{l}(\cdot)$ and the facts that $x_{l}^{\prime}\left(u_{h}^{m}\right)>0$ and $x_{l}^{\prime}\left(u_{h}^{c}\right)<0$ imply that there exists a unique $u_{h}^{d} \in\left(u_{h}^{m}, u_{h}^{c}\right]$ such that $x_{l}^{\prime}\left(u_{h}\right)>0$ if and only if $u_{h}<u_{h}^{d}$. To see why $\hat{u}_{l}(\cdot)$ is convex, let us differentiate (11) to obtain that

$$
\hat{u}_{l}^{\prime \prime}\left(u_{h}\right)=\frac{\frac{d}{d u_{h}} S_{l}\left(\hat{u}_{l}\left(u_{h}\right), u_{h}\right)+\hat{u}_{l}^{\prime}\left(u_{h}\right) \cdot\left(\frac{1}{\nabla\left(u_{h}\right)}-1\right)}{S_{h}^{*}-u_{h}}+\frac{S_{l}\left(\hat{u}_{l}\left(u_{h}\right), u_{h}\right)-\hat{u}_{l}\left(u_{h}\right)}{S_{h}^{*}-u_{h}} \cdot \nabla^{\prime}\left(u_{h}\right),
$$

where

$$
\nabla\left(u_{h}\right) \equiv \frac{1-\frac{p_{l}}{p_{h}} \frac{\partial S_{l}}{\partial u_{h}}\left(\hat{u}_{l}\left(u_{h}\right), u_{h}\right)}{1-\frac{\partial S_{l}}{\partial u_{l}}\left(\hat{u}_{l}\left(u_{h}\right), u_{h}\right)} .
$$

Recall from the proof of Claim 3 (in the paragraph before Equation $(40)$ ) that $\nabla\left(u_{h}\right) \in(0,1)$ for $u_{h}<u_{h}^{c}$ and that $\frac{d}{d u_{h}} S_{l}\left(\hat{u}_{l}\left(u_{h}\right), u_{h}\right)>0$. Moreover, straightforward differentiation shows that $\nabla^{\prime}\left(u_{h}\right)>0$. Coupled together, these facts imply that $\hat{u}_{l}^{\prime \prime}\left(u_{h}\right)>0$ for $u_{h}<u_{h}^{c}$, as claimed. Q.E.D.

Proof of Proposition 1. Follows directly from Corollary 3. Q.E.D.

Proof of Proposition 2. Recall that we have $x_{l}\left(u_{h}\right) \equiv \theta_{l} \cdot q_{l}\left(\hat{u}_{l}\left(u_{h}\right), u_{h}\right)-\hat{u}_{l}\left(u_{h}\right)$ and $x_{h}\left(u_{h}\right) \equiv$ $\theta_{h} \cdot q_{h}^{*}-u_{h}$.

First assume that $u_{h}<u_{h}^{c}$. In this case, since $\Delta_{p}\left(u_{h}\right) \equiv x_{h}\left(u_{h}\right)-x_{l}\left(u_{h}\right)$, we have

$$
\begin{aligned}
\Delta_{p}^{\prime}\left(u_{h}\right) & =-1-\left[\theta_{l} \frac{1-h\left(\hat{u}_{l}\left(u_{h}\right), u_{h}\right)}{\Delta \theta}-h\left(\hat{u}_{l}\left(u_{h}\right), u_{h}\right)\right] \\
& =-\left(\frac{\theta_{h}}{\Delta \theta}\right)\left[1-h\left(\hat{u}_{l}\left(u_{h}\right), u_{h}\right)\right]<0,
\end{aligned}
$$

because $h\left(\hat{u}_{l}\left(u_{h}\right), u_{h}\right)<1$.

Next assume that $u_{h} \geq u_{h}^{c}$. In this case, we have $\Delta_{p}\left(u_{h}\right)=\hat{u}_{l}\left(u_{h}\right)-u_{h}$ and hence $\Delta_{p}^{\prime}\left(u_{h}\right)=$ $-\left[1-h\left(\hat{u}_{l}\left(u_{h}\right), u_{h}\right)\right]<0$. We conclude that $\Delta_{p}\left(u_{h}\right)$ is strictly decreasing in $u_{h}$, which immediately implies the proposition. Q.E.D.

Proof of Proposition 3. To show the result, it suffices to show that the markup difference is strictly decreasing in $u_{h}$. The markup difference can be written as: $\left[S_{h}^{*}-u_{h}\right]-\left[S_{l}\left(\hat{u}_{l}\left(u_{h}\right), u_{h}\right)-\hat{u}_{l}\left(u_{h}\right)\right]$. 
First notice that $\frac{d\left[S_{h}^{*}-u_{h}\right]}{d u_{h}}=-1$. Moreover, we have

$$
\begin{aligned}
& \frac{d}{d u_{h}}\left[S_{l}\left(\hat{u}_{l}\left(u_{h}\right), u_{h}\right)-\hat{u}_{l}\left(u_{h}\right)\right] \\
= & \frac{d S_{l}\left(q_{l}\left(\hat{u}_{l}\left(u_{h}\right), u_{h}\right)\right)}{d q_{l}}\left(\frac{\partial q_{l}\left(\hat{u}_{l}\left(u_{h}\right), u_{h}\right)}{\partial u_{l}} \hat{u}_{l}^{\prime}\left(u_{h}\right)+\frac{\partial q_{l}\left(\hat{u}_{l}\left(u_{h}\right), u_{h}\right)}{\partial u_{h}}\right)-h\left(\hat{u}_{l}\left(u_{h}\right), u_{h}\right) \\
= & \frac{d S_{l}\left(q_{l}\left(\hat{u}_{l}\left(u_{h}\right), u_{h}\right)\right)}{d q_{l}} \frac{\partial q_{l}\left(\hat{u}_{l}\left(u_{h}\right), u_{h}\right)}{\partial u_{h}}\left(1-h\left(\hat{u}_{l}\left(u_{h}\right), u_{h}\right)\right)-h\left(\hat{u}_{l}\left(u_{h}\right), u_{h}\right) .
\end{aligned}
$$

Therefore we obtain

$$
\begin{aligned}
& \frac{d\left(\left[S_{h}^{*}-u_{h}\right]-\left[S_{l}\left(\hat{u}_{l}\left(u_{h}\right), u_{h}\right)-\hat{u}_{l}\left(u_{h}\right)\right]\right)}{d u_{h}} \\
= & -\left(1-h\left(\hat{u}_{l}\left(u_{h}\right), u_{h}\right)\right)-\frac{d S_{l}\left(q_{l}\left(\hat{u}_{l}\left(u_{h}\right), u_{h}\right)\right)}{d q_{l}} \frac{\partial q_{l}\left(\hat{u}_{l}\left(u_{h}\right), u_{h}\right)}{\partial u_{h}}\left(1-h\left(\hat{u}_{l}\left(u_{h}\right), u_{h}\right)\right)<0,
\end{aligned}
$$

which proves the Proposition. Q.E.D.

\section{A New Indexation of Contracts}

For $k \in\{l, h\}$, let $w_{k}\left(u_{k}\right) \equiv \frac{\Lambda\left(F_{k}\left(u_{k}\right) \mid v\right)}{\Lambda(0 \mid v)}$ be the ratio between the sales to type $k$ of an offer with payoff $u_{k}$ and the sales of the monopoly offer (with payoff $\left.u_{k}^{m}\right)$. Since the monopolist's offer $\left(0, u_{h}^{m}\right)$ is always the less generous offer made in equilibrium (hence it yields the sales $\Lambda(0 \mid v)$ ), every offer $\left(u_{l}, u_{h}\right)$ that is optimal must satisfy:

$$
w_{l}\left(u_{l}\right) p_{l}\left(S_{l}\left(u_{l}, u_{h}\right)-u_{l}\right)+w_{h}\left(u_{h}\right) p_{h}\left(S_{h}^{*}-u_{h}\right)=p_{l} S_{l}\left(u_{l}^{m}, u_{h}^{m}\right)+p_{h}\left[S_{h}^{*}-u_{h}^{m}\right]
$$

Recall that our sale function depends only on the ranking $y_{k}=F_{k}\left(u_{k}\right)$. Therefore, for every $w \in\left[1, \frac{\Lambda(1 \mid v)}{\Lambda(0 \mid v)}\right]$, there is a unique $y \in[0,1]$ such that $w=\frac{\Lambda(y \mid v)}{\Lambda(0 \mid v)}$. Hence, for all $w \in\left[1, \frac{\Lambda(1 \mid v)}{\Lambda(0 \mid v)}\right]$, we may define $y(w)$ implicitly by: $w=\frac{\Lambda(y(w) \mid v)}{\Lambda(0 \mid v)}$. Moreover, in any ordered equilibrium we have $w_{l}\left(u_{l}\right)=w_{h}\left(u_{h}\right)$ and the ranking of the menu $\left(y_{k}=F_{k}\left(u_{k}\right)\right)$ is a strictly increasing function of $u_{k}$. Thus, since $w \rightarrow y(w)$ is strictly increasing, so is its inverse, which implies that the mapping $u_{k} \rightarrow w\left(u_{k}\right)$ is strictly increasing. It thus follows that we can index contracts by $w$ and rewrite (23) as

$$
w p_{l}\left(S_{l}\left(u_{l}(w), u_{h}(w)\right)-u_{l}(w)\right)+w p_{h}\left(S_{h}^{*}-u_{h}(w)\right)=p_{l} S_{l}\left(u_{l}^{m}, u_{h}^{m}\right)+p_{h}\left[S_{h}^{*}-u_{h}^{m}\right],
$$

for every $w \in\left[1, \frac{\Lambda(1 \mid v)}{\Lambda(0 \mid v)}\right]$.

Proof of Proposition 4. From the discussion right above this proof, we know that there is a one-to-one mapping between the ranking of the offer $y=F_{k}\left(u_{k}\right)$ and the variable $w$. Hence, take $w \in\left[1, \frac{\Lambda(1 \mid v)}{\Lambda(0 \mid v)}\right)$, consider an increase in $p_{l}$ from $p_{l}^{a}$ to $p_{l}^{b}$ and let, for $r \in\{a, b\}$ and $k \in\{l, h\}$, $u_{k}^{r}(w)$ be the indirect utility yielded by an offer with generosity $w$ to type $k$ in the unique ordered equilibrium in which the probability that consumer is a low type is $p_{l}^{r}$. Claim 7 (see Section 9 in the Online Appendix) shows that $u_{h}^{b}(w)>u_{h}^{a}(w)$. 
First assume that $u_{h}^{a}(w) \leq u_{h}^{b}(0)$. In this case, we have

$$
u_{h}^{b}(w)-u_{l}^{b}(w)>u_{h}^{b}(0)-u_{l}^{b}(0)=u_{h}^{b}(0) \geq u_{h}^{a}(w) \geq u_{h}^{a}(w)-u_{l}^{a}(w),
$$

where the first inequality used the fact that $\hat{u}_{l}^{\prime}\left(u_{h}\right)<1$ for any equilibrium (see Corollary 1 ).

Next assume that $u_{h}^{a}(w)>u_{h}^{b}(0)$. In this case, there exists $\tilde{w} \in(1, w)$ such that $u_{h}^{b}(\tilde{w})=u_{h}^{a}(w)$. It follows that

$$
u_{h}^{b}(w)-u_{l}^{b}(w)>u_{h}^{b}(\tilde{w})-u_{l}^{b}(\tilde{w})=u_{h}^{b}(\tilde{w})-\hat{u}_{l}^{b}\left(u_{h}^{b}(\tilde{w})\right),
$$

where, for $r \in\{a, b\}$, we write $\hat{u}_{l}^{r}(\cdot)$ for the support function of the ordered equilibrium in which the probability that the consumer is a low type is $p_{l}^{r}$. Claim 6 (stated and proved in Section 9 in the Online Appendix) shows that $\frac{\partial \hat{u}_{l}\left(u_{h}, p_{l}\right)}{\partial p_{l}}<0$ and hence $\hat{u}_{l}^{a}\left(u_{h}^{b}(\tilde{w})\right)>\hat{u}_{l}^{b}\left(u_{h}^{b}(\tilde{w})\right)$, which implies $u_{h}^{b}(\tilde{w})-\hat{u}_{l}^{b}\left(u_{h}^{b}(\tilde{w})\right)>u_{h}^{b}(\tilde{w})-\hat{u}_{l}^{a}\left(u_{h}^{b}(\tilde{w})\right)$. Finally, since $u_{h}^{b}(\tilde{w})=u_{h}^{a}(w)$ the last inequality implies $u_{h}^{b}(\tilde{w})-\hat{u}_{l}^{b}\left(u_{h}^{b}(\tilde{w})\right)>u_{h}^{a}(w)-\hat{u}_{l}^{a}\left(u_{h}^{a}(w)\right)=u_{h}^{a}(w)-u_{l}^{a}(w)$. Combining this inequality with (26) we obtain

$$
u_{h}^{b}(w)-u_{l}^{b}(w)>u_{h}^{a}(w)-u_{l}^{a}(w) .
$$

Therefore, we always have $u_{h}^{b}(w)-u_{l}^{b}(w)>u_{h}^{a}(w)-u_{l}^{a}(w)$. Since (3) implies that $q_{l}\left(u_{l}, u_{h}\right)$ is a nondecreasing function of the difference $\left(u_{h}-u_{l}\right)$, we conclude that for each $w$ (and hence for each ranking $y(w))$, the low-type quality is weakly more efficient in equilibrium $p_{l}^{b}$. Q.E.D.

Proof of Proposition 5. The price differential satisfies

$$
\Delta_{p}\left(u_{h}\right)=\left[\theta_{h} \cdot q_{h}^{*}-\theta_{l} \cdot q_{l}\left(\hat{u}_{l}\left(u_{h}\right), u_{h}\right)\right]-\left[u_{h}-\hat{u}_{l}\left(u_{h}\right)\right]
$$

From Corollary 1 we have $\hat{u}_{l}^{\prime}\left(u_{h}\right)<1$ and hence $\left[u_{h}-\hat{u}_{l}\left(u_{h}\right)\right]$ strictly increases with $u_{h}$. Next (3) implies that $q_{l}\left(\hat{u}_{l}\left(u_{h}\right), u_{h}\right)$ increases with the difference $\left[u_{h}-\hat{u}_{l}\left(u_{h}\right)\right]$ and hence $q_{l}\left(\hat{u}_{l}\left(u_{h}\right), u_{h}\right)$ increases with $u_{h}$. This implies that $\Delta_{p}\left(u_{h}\right)$ strictly decreases in $u_{h}$. Indexing the contracts for $w$ instead of $u_{h}$, we immediately see that $\Delta_{p}(w)$ is strictly decreasing in $w$.

Now define $y(w, v)$ implicitly by $\left(\frac{\Lambda(y(w, v) \mid v)}{\Lambda(0 \mid v)}\right)=w$. Take $v^{\prime \prime}>v^{\prime}$ and notice that $\left(\frac{\Lambda\left(y\left(w, v^{\prime}\right) \mid v^{\prime \prime}\right)}{\Lambda\left(0 \mid v^{\prime \prime}\right)}\right)>$ $\left(\frac{\Lambda\left(y\left(w, v^{\prime}\right) \mid v^{\prime \prime}\right)}{\Lambda\left(0 \mid v^{\prime \prime}\right)}\right)=w$, which implies that $y\left(w, v^{\prime \prime}\right)<y\left(w, v^{\prime}\right)$. Hence $y\left(\tilde{w}, v^{\prime \prime}\right)=y\left(w, v^{\prime}\right)$ implies $\tilde{w}>w$. Therefore, since we have shown that $\Delta_{p}(w)$ is strictly decreasing in $w$, we conclude that $\tilde{\Delta}_{p}(y)$ is strictly decreasing in $v$.

Next we will show that $\tilde{\Delta}_{p}(y)$ is decreasing in $p_{l}$. Fix $y \in(0,1)$ and notice that the $w$ that solves the equation $\left(\frac{\Lambda(y \mid v)}{\Lambda(0 \mid v)}\right)=w$ does not depend on $p_{l}$. Hence, consider an increase in $p_{l}$ from $p_{l}^{a}$ to $p_{l}^{b}$. Using the notation introduced in the proof of Proposition 4, the argument that we used in that proof implies that $u_{h}^{b}(w)-u_{l}^{b}(w)>u_{h}^{a}(w)-u_{l}^{a}(w)$. Thus if, for $r \in\{a, b\}$, we let $\Delta_{p}^{r}(y)$ be the price differential when the probability that the consumer is a low type is $p_{l}^{r}$, we have

$\Delta_{p}^{b}(y)-\Delta_{p}^{a}(y)=\theta_{l}\left[q_{l}\left(u_{l}^{a}(w), u_{h}^{a}(w)\right)-q_{l}\left(u_{l}^{b}(w), u_{h}^{b}(w)\right)\right]+\left[\left(u_{h}^{a}(w)-u_{l}^{a}(w)\right)-\left(u_{h}^{b}(w)-u_{l}^{b}(w)\right)\right]$, 
which is less than zero, since

$$
q_{l}\left(u_{l}^{a}(w), u_{h}^{a}(w)\right) \leq q_{l}\left(u_{l}^{b}(w), u_{h}^{b}(w)\right)
$$

and

$$
u_{h}^{a}(w)-u_{l}^{a}(w) \leq u_{h}^{b}(w)-u_{l}^{b}(w),
$$

as shown in the proof of Proposition 4.

Finally, we show that if the degree of competition is sufficiently high $(v>\bar{v})$, the marginal impact of $v$ on $\tilde{\Delta}_{p}(y)$ (in absolute terms) is decreasing in $p_{l}$. Let, for $k \in\{l, h\}$ and $y \in(0,1), u_{k}^{y}$ be defined by $F_{k}\left(u_{k}^{y}\right)=y$. Note first that there exists $\bar{v}$ such that for $v \geq \bar{v}$ we have $u_{h}^{y}-u_{l}^{y}>\Delta \theta q_{l}^{*}$. Then, for all such $v$, we have

$$
\begin{aligned}
\frac{\partial \tilde{\Delta}_{p}(y)}{\partial v}=\frac{\partial\left(u_{h}^{y}-u_{l}^{y}\right)}{\partial v} & =\frac{\partial u_{h}^{y}}{\partial v}\left(1-\frac{\frac{\partial u_{l}^{y}}{\partial v}}{\frac{\partial u_{h}^{y}}{\partial v}}\right) \\
& =\frac{\partial u_{h}^{y}}{\partial v}\left(1-\hat{u}_{l}^{\prime}\left(u_{h}^{y}\right)\right) \\
& =\frac{\partial u_{h}^{y}}{\partial v}\left(1-\frac{S_{l}\left(\hat{u}_{l}\left(u_{h}^{y}\right), u_{h}^{y}\right)-\hat{u}_{l}\left(u_{h}^{y}\right)}{S_{h}^{*}-u_{h}^{y}} \cdot \frac{1-\frac{p_{l}}{p_{h}} \cdot \frac{\partial S_{l}}{\partial u_{h}^{y}}\left(\hat{u}_{l}\left(u_{h}^{y}\right), u_{h}^{y}\right)}{1-\frac{\partial S_{l}}{\partial u_{l}^{y}}\left(\hat{u}_{l}\left(u_{h}^{y}\right), u_{h}^{y}\right)}\right) \\
& =\frac{\partial u_{h}^{y}}{\partial v}\left(1-\frac{S_{l}\left(\hat{u}_{l}\left(u_{h}^{y}\right), u_{h}^{y}\right)-\hat{u}_{l}\left(u_{h}^{y}\right)}{S_{h}^{*}-u_{h}^{y}}\right) .
\end{aligned}
$$

where the third equality uses (11) and the final equality uses the fact the incentive constraints are slack at the quantile $y$ for large enough $v$.

Next, consider $p_{l}^{\# \#}, p_{l}^{\#}$ such that $p_{l}^{\# \#}<p_{l}^{\#}$. Therefore we have

$$
\begin{aligned}
& \frac{d}{d p_{l}}\left(\frac{S_{l}^{*}-\hat{u}_{l}\left(u_{h}^{y}\left(p_{l}\right), p_{l}\right)}{S_{h}^{*}-u_{h}^{y}\left(p_{l}\right)}\right) \\
= & \left(\frac{-\frac{\partial \hat{u}_{l}\left(u_{h}^{y}\left(p_{l}\right), p_{l}\right)}{\partial u_{h}^{y}}\left[S_{h}^{*}-u_{h}^{y}\left(p_{l}\right)\right]\left(u_{h}^{y}\right)^{\prime}\left(p_{l}\right)+\left(u_{h}^{y}\right)^{\prime}\left(p_{l}\right)\left[S_{l}^{*}-\hat{u}_{l}\left(u_{h}^{y}\left(p_{l}\right), p_{l}\right)\right]-\frac{\partial \hat{u}_{l}\left(u_{h}^{y}\left(p_{l}\right), p_{l}\right)}{\partial p_{l}}\left[S_{h}^{*}-u_{h}^{y}\left(p_{l}\right)\right]}{\left[S_{h}^{*}-u_{h}^{y}\left(p_{l}\right)\right]^{2}}\right) \\
= & \left(\frac{-\frac{\partial \hat{u}_{l}\left(u_{h}^{y}\left(p_{l}\right), p_{l}\right)}{\partial p_{l}}\left[S_{h}^{*}-u_{h}^{y}\left(p_{l}\right)\right]}{\left[S_{h}^{*}-u_{h}^{y}\left(p_{l}\right)\right]^{2}}\right)>0,
\end{aligned}
$$

where the second line uses $-\frac{\partial \hat{u}_{l}\left(u_{h}^{y}\left(p_{l}\right), p_{l}\right)}{\partial u_{h}^{y}}=\frac{S_{l}^{*}-\hat{u}_{l}\left(u_{h}^{y}\right)}{S_{h}^{*}-u_{h}^{y}}$ and $\frac{\partial \hat{u}_{l}\left(u_{h}^{y}\left(p_{l}\right), p_{l}\right)}{\partial p_{l}}<0$ follows from Claim 6 . Thus we have

$$
\frac{\partial}{\partial p_{l}}\left(1-\frac{S_{l}\left(\hat{u}_{l}\left(u_{h}^{y}\right), u_{h}^{y}\right)-\hat{u}_{l}\left(u_{h}^{y}\right)}{S_{h}^{*}-u_{h}^{y}}\right)<0 .
$$

Now, let $w_{k}=\frac{\Lambda\left(F_{k}\left(u_{k}\right) \mid v\right)}{\Lambda(0 \mid v)}$ be the ratio of sales for an offer with payoff $u_{k}$ to the sales for the monopoly offer to type $k$ (with payoff $u_{k}^{m}$ ). Here we find convenient to index all contracts by the ratio of sales. 
Let $u_{k}\left(w_{k}\right)$ be the indirect utility of type $k$ such that the sales ratio is $w_{k}$. It is easily verified that, for all large enough $v$, incentive constraints are slack when the sales ratio is $w_{k}=\frac{\Lambda(y \mid v)}{\Lambda(0 \mid v)}$ for each $k$. It follows that we can write the expected profits by

$$
w_{l} p_{l}\left(S_{l}^{*}-u_{l}^{y}\left(w_{l}\right)\right)+w_{h} p_{h}\left(S_{h}^{*}-u_{h}^{y}\left(w_{h}\right)\right)
$$

for all $\left(w_{l}, w_{h}\right)$ in a sufficiently small neighborhood of $\left(\frac{\Lambda(y \mid v)}{\Lambda(0 \mid v)}, \frac{\Lambda(y \mid v)}{\Lambda(0 \mid v)}\right)$. A first-order condition with respect to $w_{h}$ yields

$$
u_{h}^{\prime}\left(\frac{\Lambda(y \mid v)}{\Lambda(0 \mid v)}\right)=\frac{S_{h}^{*}-u_{h}^{y}\left(w_{h}\right)}{w_{h}}=\frac{S_{h}^{*}-u_{h}^{y}\left(\frac{\Lambda(y \mid v)}{\Lambda(0 \mid v)}\right)}{\frac{\Lambda(y \mid v)}{\Lambda(0 \mid v)}} .
$$

Hence

$$
\frac{\partial u_{h}^{y}}{\partial v}=u_{h}^{\prime}\left(\frac{\Lambda(y \mid v)}{\Lambda(0 \mid v)}\right) \frac{d}{d v}\left[\frac{\Lambda(y \mid v)}{\Lambda(0 \mid v)}\right]=\left(S_{h}^{*}-u_{h}^{y}\left(\frac{\Lambda(y \mid v)}{\Lambda(0 \mid v)}\right)\right) \frac{d}{d v}\left[\frac{\Lambda(y \mid v)}{\Lambda(0 \mid v)}\right]>0,
$$

where $\frac{d}{d v}\left[\frac{\Lambda(y \mid v)}{\Lambda(0 \mid v)}\right]>0$ holds by our assumptions on the matching function. Again consider $p_{l}^{\# \#}, p_{l}^{\#}$ such that $p_{l}^{\# \#}<p_{l}^{\#}$, and index payoffs accordingly. Let $w=\frac{\Lambda(y \mid v)}{\Lambda(0 \mid v)}$. Claim 7 (in Section 9 in the Online Appendix) shows that $u_{h}^{\# \#}(w)<u_{h}^{\#}(w)$, i.e. $S_{h}^{*}-u_{h}^{y}\left(\frac{\Lambda(y \mid v)}{\Lambda(0 \mid v)}\right)$ is larger when $p_{l}$ is smaller. Thus using (29) we conclude that

$$
\frac{\partial^{2} u_{h}^{y}}{\partial p_{l} \partial v}<0
$$

Combining (28), (29) and (30) we obtain

$$
\frac{\partial^{2} \tilde{\Delta}_{p}(y)}{\partial p_{l} \partial v}=\frac{\partial^{2}\left(u_{h}^{y}-u_{l}^{y}\right)}{\partial p_{l} \partial v}=\frac{\partial^{2} u_{h}^{y}}{\partial v \partial p_{l}}\left(1-\frac{\frac{\partial u_{l}^{y}}{\partial v}}{\frac{\partial u_{h}^{y}}{\partial v}}\right)+\left(\frac{\partial u_{h}^{y}}{\partial v}\right)\left[\frac{\partial}{\partial p_{l}}\left(1-\frac{\frac{\partial u_{l}^{y}}{\partial v}}{\frac{\partial u_{h}^{y}}{\partial v}}\right)\right]<0 .
$$

Q.E.D. 


\section{Online Appendix (NOT FOR PUBLICATION)}

\section{Appendix B: Uniqueness}

This appendix describes when the ordered equilibrium of Theorem 1 is the only equilibrium. Recall from Lemma 2 that a firm's expected profits $\pi$ satisfy strict increasing differences when the incentive constraint $\mathrm{IC}_{h}$ binds (i.e., for menus with $u_{h} \leq u_{h}^{c}$, where recall that $u_{h}^{c}$ is the efficiency threshold specified in the previous subsection). In this case, we argued that higher indirect utilities $u_{h}$ must imply higher indirect utilities to low types $u_{l}$, i.e. the equilibrium menus must be ordered. Hence, if $\mathrm{IC}_{h}$ binds for all equilibrium menus, ordering is enough to uniquely pin down equilibrium.

However, if $\mathrm{IC}_{h}$ is slack, firms offering high indirect utilities $u_{h}$ to high types no longer have a comparative advantage in offering high utilities $u_{l}$ to low types, and so equilibrium menus need not be ordered. A multiplicity of equilibria then arises due to the possible non-ordering of menus for which the incentive constraint $\mathrm{IC}_{h}$ is slack (i.e., menus for which $u_{h}>u_{h}^{c}$ ). We summarize these observations as follows.

Theorem 2 [Equilibrium Uniqueness] There exists a threshold $v^{c}>0$ on the degree of competition such that:

1. if $v \leq v^{c}$, the top of the support of $F_{h}, \bar{u}_{h}$, satisfies $\bar{u}_{h} \leq u_{h}^{c}$. The downward incentive constraint $\left(I C_{h}\right)$ is then binding for all menus offered in the ordered equilibrium. In this case, the only equilibrium is the ordered equilibrium.

2. if $v>v^{c}$, then $\bar{u}_{h}>u_{h}^{c}$, and the downward incentive constraint $\left(I C_{h}\right)$ is slack for all menus in the ordered equilibrium with $u_{h}>u_{h}^{c}$, and binding for $u_{h} \leq u_{h}^{c}$. In this case, there exist multiple equilibria that differ only in the menus for which $u_{h}>u_{h}^{c}$ (i.e., the efficient menus). However, all equilibria (including the non-ordered ones) lead to the same marginal distributions over indirect utilities $F_{k}(\cdot)$, and the same ex-ante profits for firms.

The proof, presented below, shows that in any equilibrium, when the degree of competition is small (i.e., $v \leq v^{c}$ ), the support of utilities of type- $k$ consumers, $\Upsilon_{k}$, is contained in $\left[u_{k}^{m}, u_{k}^{c}\right]$. Using the increasing differences property (see Lemma 2), we show that this implies that all equilibria are equal to the ordered equilibrium.

By contrast, when the degree of competition is large (i.e., $v>v^{c}$ ), some menus offered in the ordered equilibrium exhibit non-binding incentive constraints. Consider such a menu $\left(\hat{u}_{l}\left(u_{h}\right), u_{h}\right)$, in which case $u_{h} \in\left(u_{h}^{c}, \bar{u}_{h}\right]$. For this menu, the profit function $\pi\left(u_{l}, u_{h}\right)$ is locally modular, i.e. its cross-partial derivative is zero. As a result, for some (small) $\varepsilon>0$, both the menus $\left(\hat{u}_{l}\left(u_{h}-\varepsilon\right), u_{h}\right)$ and $\left(\hat{u}_{l}\left(u_{h}\right), u_{h}-\varepsilon\right)$ are profit-maximizing for the firm. Based on the ordered equilibrium, we can 
thus construct a non-ordered equilibrium by replacing the menus $\left(\hat{u}_{l}\left(u_{h}\right), u_{h}\right)$ and $\left(\hat{u}_{l}\left(u_{h}-\varepsilon\right), u_{h}-\varepsilon\right)$ by their non-ordered counterparts $\left(\hat{u}_{l}\left(u_{h}-\varepsilon\right), u_{h}\right)$ and $\left(\hat{u}_{l}\left(u_{h}\right), u_{h}-\varepsilon\right)$. Theorem 2 confirms that this is the unique source of multiplicity of equilibria in our economy.

Proof of Theorem 2. For the unique ordered distribution described in Theorem 1, there is a value $v^{c}$ such that $v \leq v^{c}$ implies $\bar{u}_{h} \leq u_{h}^{c}$, while $v>v^{c}$ implies $\bar{u}_{h}>u_{h}^{c}$. What remains to show is that, for $v \leq v^{c}$, the only equilibrium is the ordered equilibrium (i.e., Part 1 of the Theorem) as well as the uniqueness claims in Part 2 (i.e., regarding menus with payoffs $u_{h} \leq u_{h}^{c}$ and regarding the marginal distributions $F_{k}$ ).

Let $\tilde{F}$ be any distribution over menus which describes a (not necessarily ordered) equilibrium. Let the marginal distributions over indirect utilities be given by $F_{k}$ with supports $\Upsilon_{k}$ as given in Lemma 3. We begin with the following lemma.

Lemma 4 Consider two equilibrium menus $\left(u_{l}, u_{h}\right),\left(u_{l}^{\prime}, u_{h}^{\prime}\right) \in \Upsilon_{l} \times \Upsilon_{h}$. If $u_{h}^{\prime}>u_{h}$, then either $u_{l}^{\prime} \geq u_{l}$ or both $I C_{h}$ and $I C_{l}$ are slack for both menus (i.e., $u_{h}-u_{l}, u_{h}^{\prime}-u_{l}^{\prime} \in\left[q_{l}^{*} \Delta \theta, q_{h}^{*} \Delta \theta\right]$ ).

Proof. Suppose $u_{h}^{\prime}>u_{h}$ and $u_{l}^{\prime}<u_{l}$, while either $u_{h}-u_{l} \notin\left[q_{l}^{*} \Delta \theta, q_{h}^{*} \Delta \theta\right]$ or $u_{h}^{\prime}-u_{l}^{\prime} \notin\left[q_{l}^{*} \Delta \theta, q_{h}^{*} \Delta \theta\right]$. By Lemma 2, we have

$$
\pi\left(u_{l}, u_{h}^{\prime}\right)+\pi\left(u_{l}^{\prime}, u_{h}\right)>\pi\left(u_{l}^{\prime}, u_{h}^{\prime}\right)+\pi\left(u_{l}, u_{h}\right)
$$

contradicting the optimality of $\left(u_{l}, u_{h}\right)$ or $\left(u_{l}^{\prime}, u_{h}^{\prime}\right)$. Q.E.D.

An immediate implication of this lemma is that if $\left(u_{l}, u_{h}\right)$ is a menu for which $I C_{l}$ or $I C_{h}$ binds (i.e., $\left.u_{h}-u_{l} \notin\left[q_{l}^{*} \Delta \theta, q_{h}^{*} \Delta \theta\right]\right)$, then there exists no other equilibrium menu $\left(u_{l}^{\prime}, u_{h}^{\prime}\right)$ for which $u_{l}^{\prime}<u_{l}$ and $u_{h}^{\prime}>u_{h}$ or $u_{l}^{\prime}>u_{l}$ and $u_{h}^{\prime}<u_{h}$. Since $F_{l}$ and $F_{h}$ are absolutely continuous by Lemma 3 , we can conclude hence that $F_{l}\left(u_{l}\right)=F_{h}\left(u_{h}\right)$.

Next, note that there exists $\varepsilon>0$ such that $I C_{h}$ binds for all $u_{h} \leq u_{h}^{m}+\varepsilon$. Thus, for every menu $\left(u_{l}, u_{h}\right)$ with $u_{h} \leq u_{h}^{m}+\varepsilon$, we have $F_{l}\left(u_{l}\right)=F_{h}\left(u_{h}\right)$. Define a strictly increasing and continuous function $\kappa$ by $\kappa\left(u_{h}\right) \equiv F_{l}^{-1}\left(F_{h}\left(u_{h}\right)\right.$ ) (here we use Lemma 3 which guarantees both the continuity of $F_{l}$ and $F_{h}$ and that both are strictly increasing). Using Lemma 4, it is easy to see that there can be no menu $\left(u_{l}, u_{h}\right)$ with $u_{l}<\kappa\left(u_{h}^{m}+\varepsilon\right)$ but $u_{l} \neq \kappa\left(u_{h}\right)$. Thus, we have established that, for any equilibrium menu $\left(u_{l}, u_{h}\right)$, with $u_{h}<u_{h}^{m}+\varepsilon$ or $u_{l}<\kappa\left(u_{h}^{m}+\varepsilon\right), u_{l}=\kappa\left(u_{h}\right)$. The arguments in Step 1 of the proof of Theorem 1 then imply that $\kappa(\cdot)=\hat{u}_{l}(\cdot)$ on $\left[u_{h}^{m}, u_{h}^{m}+\varepsilon\right)$.

We can extend the above argument to show that all menus $\left(u_{l}, u_{h}\right)$ with $u_{h}<u_{h}^{c}$ or $u_{l}<\hat{u}_{l}\left(u_{h}^{c}\right)$ must also be given by $\left(\hat{u}_{l}\left(u_{h}\right), u_{h}\right)$ for some $u_{h}<u_{h}^{c}$. To see this, let

$$
\breve{u}_{h} \equiv \sup \left\{u_{h}: \forall \text { eqm menus }\left(u_{l}^{\prime}, u_{h}^{\prime}\right), u_{h}^{\prime}<u_{h} \text { or } u_{l}^{\prime}<\hat{u}_{l}\left(u_{h}\right) \text { implies } u_{l}^{\prime}=\hat{u}_{l}\left(u_{h}^{\prime}\right)\right\} \text {. }
$$

As argued above, $\breve{u}_{h}>u_{h}^{m}$. Suppose with a view to contradiction that $\breve{u}_{h}<u_{h}^{c}$. Since we must have $u_{l} \geq \hat{u}_{l}\left(\breve{u}_{h}\right)$ for any equilibrium menu with $u_{h} \geq \breve{u}_{h}$, there must exist $\eta>0$ sufficiently small 
that $I C_{h}$ binds for all $u_{h} \leq \breve{u}_{h}+\eta$ (indeed, this must follow because $I C_{h}$ binds at $\left.\left(\hat{u}_{l}\left(\breve{u}_{h}\right), \breve{u}_{h}\right)\right)$. The same arguments as above then imply that, for any equilibrium menu $\left(u_{l}, u_{h}\right)$ with $u_{h}<\breve{u}_{h}+\eta$ or $u_{l}<\hat{u}_{l}\left(\breve{u}_{h}+\eta\right), u_{l}=\hat{u}_{l}\left(u_{h}\right)$. Hence, $\breve{u}_{h}$ cannot be the supremum in (31), our contradiction.

Thus, we have established that $\breve{u}_{h} \geq u_{h}^{c}$. This establishes Part 1 of the proposition: In case $v \leq v^{c}$, we have $u_{h} \leq u_{h}^{c}$ for all equilibrium menus, as implied by the requirement that all menus generate the same expected profits. This also establishes our claim in Part 2 that non-ordered equilibria differ only in menus for which $u_{h}>u_{h}^{c}$ (the existence of such non-ordered equilibria is straightforward and left to the reader).

To establish our remaining claims, we consider menus for which $u_{h} \geq u_{h}^{c}$ and $u_{l} \geq \hat{u}_{l}\left(u_{h}^{c}\right)$. We show that (recall our definition of $\Phi_{k}$ given in (14))

$$
\begin{aligned}
\Phi_{h}^{\prime}\left(u_{h}\right) & =\frac{\Phi_{h}\left(u_{h}\right)}{S_{h}^{*}-u_{h}} \\
\Phi_{l}^{\prime}\left(u_{l}\right) & =\frac{\Phi_{l}\left(u_{l}\right)}{S_{l}^{*}-u_{l}}
\end{aligned}
$$

for these values of $u_{h}$ and $u_{l}$. This implies that $\Phi_{l}$ and $\Phi_{h}$ are precisely those functions determined in Theorem 1; hence, the marginal distributions $F_{k}$ are identical in any equilibrium. As a result, as shown in the proof of Theorem 1, neither incentive constraint can bind for equilibrium menus with $u_{h} \geq u_{h}^{c}$ and $u_{l} \geq \hat{u}_{l}\left(u_{h}^{c}\right)$ (a binding incentive constraint at $\left(u_{l}, u_{h}\right)$ would imply $F_{l}\left(u_{l}\right)=F_{h}\left(u_{h}\right)$, but then $u_{l}=\hat{u}_{l}\left(u_{h}\right)$ and neither incentive constraint binds at $\left(\hat{u}_{l}\left(u_{h}\right), u_{h}\right)$ as shown in the proof of Theorem 1).

It is easy to see that the equilibrium menu with high-type payoff $u_{h}^{c}$ is unique and equal to $\left(\hat{u}_{l}\left(u_{h}^{c}\right), u_{h}^{c}\right) \cdot{ }^{30}$ Neither of the incentive constraints $I C_{l}$ or $I C_{h}$ bind at this menu. This allows us to establish that (32) and (33) hold at $\left(\hat{u}_{l}\left(u_{h}^{c}\right), u_{h}^{c}\right)$. We consider (32) as the case of (33) is analogous. We use a similar argument to that in Step 1 of the proof of Theorem 1 . For any $\varepsilon \in \mathbb{R}$ such that $u_{h}^{c}+\varepsilon \in \Upsilon_{h}$, let $\left(u_{l, \varepsilon}, u_{h}^{c}+\varepsilon\right)$ be a corresponding equilibrium menu. The same arguments as in the proof of Theorem 1 imply

$$
\begin{aligned}
& \frac{\left(\begin{array}{c}
\Phi_{l}\left(u_{l, \varepsilon}\right)\left[S_{l}\left(u_{l, \varepsilon}, u_{h}^{c}\right)-S_{l}\left(u_{l, \varepsilon}, u_{h}^{c}+\varepsilon\right)\right] \\
+\Phi_{h}\left(u_{h}^{c}\right)\left[S_{h}\left(u_{l, \varepsilon}, u_{h}^{c}\right)-S_{h}\left(u_{l, \varepsilon}, u_{h}^{c}+\varepsilon\right)+\varepsilon\right]
\end{array}\right)}{\varepsilon\left[S_{h}\left(u_{l, \varepsilon}, u_{h}^{c}+\varepsilon\right)-u_{h}^{c}-\varepsilon\right]} \\
\leq & \frac{\Phi_{h}\left(u_{h}^{c}+\varepsilon\right)-\Phi_{h}\left(u_{h}^{c}\right)}{\varepsilon} \\
\leq & \frac{\left(\begin{array}{c}
\Phi_{l}\left(\hat{u}_{l}\left(u_{h}^{c}\right)\right)\left[S_{l}\left(\hat{u}_{l}\left(u_{h}^{c}\right), u_{h}^{c}\right)-S_{l}\left(\hat{u}_{l}\left(u_{h}^{c}\right), u_{h}^{c}+\varepsilon\right)\right] \\
+\Phi_{h}\left(u_{h}^{c}\right)\left[S_{h}\left(\hat{u}_{l}\left(u_{h}^{c}\right), u_{h}^{c}\right)-S_{h}\left(\hat{u}_{l}\left(u_{h}^{c}\right), u_{h}^{c}+\varepsilon\right)+\varepsilon\right]
\end{array}\right)}{\varepsilon\left[S_{h}\left(\hat{u}_{l}\left(u_{h}^{c}\right), u_{h}^{c}+\varepsilon\right)-u_{h}^{c}-\varepsilon\right]} .
\end{aligned}
$$

\footnotetext{
${ }^{30}$ By the previous argument, any equilibrium menu $\left(u_{l}, u_{h}^{c}\right)$ must satisfy $u_{l} \geq \hat{u}_{l}\left(u_{h}^{c}\right)$. If $u_{l}>\hat{u}_{l}\left(u_{h}^{c}\right)$, then $I C_{h}$ binds at $\left(u_{l}, u_{h}^{c}\right)$ implying that $F_{l}\left(u_{l}\right)=F_{h}\left(u_{h}^{c}\right)$, a contradiction (since $F_{h}\left(u_{h}^{c}\right)=F_{l}\left(\hat{u}_{l}\left(u_{h}^{c}\right)\right)$ by the previous argument and continuity of $F_{l}$ and $F_{h}$ ).
} 
We then use that ${ }^{31}$

$$
\lim _{\varepsilon \rightarrow 0} \frac{S_{l}\left(u_{l, \varepsilon}, u_{h}^{c}\right)-S_{l}\left(u_{l, \varepsilon}, u_{h}^{c}+\varepsilon\right)}{\varepsilon}=\lim _{\varepsilon \rightarrow 0} \frac{S_{l}\left(\hat{u}_{l}\left(u_{h}^{c}\right), u_{h}^{c}\right)-S_{l}\left(\hat{u}_{l}\left(u_{h}^{c}\right), u_{h}^{c}+\varepsilon\right)}{\varepsilon}=0
$$

and

$$
S_{h}\left(u_{l, \varepsilon}, u_{h}^{c}\right)-S_{h}\left(u_{l, \varepsilon}, u_{h}^{c}+\varepsilon\right)=S_{h}\left(\hat{u}_{l}\left(u_{h}^{c}\right), u_{h}^{c}\right)-S_{h}\left(\hat{u}_{l}\left(u_{h}^{c}\right), u_{h}^{c}+\varepsilon\right)=0
$$

to conclude that

$$
\Phi_{h}^{\prime}\left(u_{h}^{c}\right)=\frac{\Phi_{h}\left(u_{h}^{c}\right)}{S_{h}^{*}-u_{h}^{c}} .
$$

Next, observe that there exists $\eta>0$ such that incentive constraints are slack for any equilibrium menu with $u_{h} \in\left[u_{h}^{c}, u_{h}^{c}+\eta\right]$. This is obtained from (i) the above observation that if $\left(u_{l}, u_{h}\right)$ is a menu for which an incentive constraint $I C_{k}$ binds, then $F_{l}\left(u_{l}\right)=F_{h}\left(u_{h}\right)$, and (ii) $u_{h}^{c}-\hat{u}_{l}\left(u_{h}^{c}\right)=q_{l}^{*} \Delta \theta$ together with $\Phi_{h}^{\prime}\left(u_{h}^{c}\right)<\Phi_{l}^{\prime}\left(\hat{u}_{l}\left(u_{h}^{c}\right)\right)$ (equivalently, $\left.F_{h}^{\prime}\left(u_{h}^{c}\right)<F_{l}^{\prime}\left(\hat{u}_{l}\left(u_{h}^{c}\right)\right)\right)$.

As with the derivatives $\Phi_{h}^{\prime}\left(u_{h}^{c}\right)$ and $\Phi_{l}^{\prime}\left(\hat{u}_{l}\left(u_{h}^{c}\right)\right)$, one obtains (32) and (33) on $\left[u_{h}^{c}, u_{h}^{c}+\eta\right]$. We then use again that $F_{l}\left(u_{l}\right)=F_{h}\left(u_{h}\right)$ for any menu $\left(u_{l}, u_{h}\right)$ for which an incentive constraint binds to obtain that the constraints must be slack for any equilibrium menu with $u_{h} \geq u_{h}^{c}$. To see this, let

$$
u_{h}^{\#}=\sup \left\{u_{h}: I C_{l} \text { and } I C_{h} \text { are slack for all eqm. menus }\left(u_{l}^{\prime}, u_{h}^{\prime}\right) \text { with } u_{h}^{\prime} \in\left[u_{h}^{c}, u_{h}\right]\right\} \text {. }
$$

The above property, together with continuity of $F_{l}$ and $F_{h}$, implies that, if $u_{h}^{\#}<\bar{u}_{h}$, then $u_{h}^{\#}-u_{l}^{\#} \notin$ $\left(\Delta \theta q_{l}^{*}, \Delta \theta q_{h}^{*}\right)$ for $u_{l}^{\#}$ satisfying $F_{l}\left(u_{l}^{\#}\right)=F_{h}\left(u_{h}^{\#}\right)$. However, $F_{l}$ and $F_{h}$ must agree with functions derived in Theorem 1 on, respectively, $\left[u_{l}^{m}, \hat{u}_{l}\left(u_{h}^{\#}\right)\right]$ and $\left[u_{h}^{m}, u_{h}^{\#}\right]$. Hence $u_{l}^{\#}=\hat{u}_{l}\left(u_{h}^{\#}\right)$. This contradicts our finding in the proof of Theorem 1 that $u_{h}^{\#}-\hat{u}_{l}\left(u_{h}^{\#}\right) \in\left(\Delta \theta q_{l}^{*}, \Delta \theta q_{h}^{*}\right)$. Q.E.D.

\section{Appendix C: Omitted Proofs}

Proof of Lemma 3. We divide the proof in five steps.

Step 1 No mass points in the distribution of high-type offers.

We begin by showing that $F_{h}$ has no mass points. Assume towards a contradiction there is an atom of firms offering $\tilde{u}_{h}$.

We first show that, if a firm makes an equilibrium offer $\left(\tilde{u}_{l}, \tilde{u}_{h}\right)$, for some value $\tilde{u}_{l}$, then $S_{h}\left(\tilde{u}_{l}, \tilde{u}_{h}\right)-\tilde{u}_{h}>0$. Suppose not. Then it must be that $S_{l}\left(\tilde{u}_{l}, \tilde{u}_{h}\right)-\tilde{u}_{l} \leq 0$ (in case $S_{h}\left(\tilde{u}_{l}, \tilde{u}_{h}\right)-\tilde{u}_{h} \leq 0$

\footnotetext{
${ }^{31}$ This follows after noticing that, for any $\nu>0$, there exists $\iota>0$ such that, for all $|\varepsilon|<\iota, u_{h}^{c}-u_{l, \varepsilon} \in\left(\Delta \theta q_{l}^{*}-\nu, \Delta \theta q_{h}^{*}\right]$. This follows after noticing that either both incentive constraints are slack at $\left(u_{l, \varepsilon}, u_{h}^{c}+\varepsilon\right)$, or one of $I C_{l}$ and $I C_{h}$ bind, in which case $u_{l, \varepsilon}=F_{l}^{-1}\left(F_{h}\left(u_{h}^{c}+\varepsilon\right)\right)$, which tends to $\hat{u}_{l}\left(u_{h}^{c}\right)$ as $\varepsilon \rightarrow 0$.
} 
and $S_{l}\left(\tilde{u}_{l}, \tilde{u}_{h}\right)-\tilde{u}_{l}>0$, offering only the option designed for the low type improves the seller's expected profit because high types accept such an offer with positive probability). Hence, $\pi\left(\tilde{u}_{l}, \tilde{u}_{h}\right) \leq 0$. This contradicts seller optimization. Indeed, the seller could offer a menu which yields the Mussa and Rosen utilities $\left(u_{l}^{m}, u_{h}^{m}\right)$ and obtain a payoff at least as large as $\left(S_{h}^{*}-u_{h}^{m}\right) \Phi_{h}(0)>0$.

Next, notice that $S_{l}\left(\tilde{u}_{l}, \tilde{u}_{h}\right)-\tilde{u}_{l} \geq 0$. If not, the seller can profit by offering the menu $\left(q_{l}, x_{l}\right)=$ $(0,0)$ and $\left(q_{h}, x_{h}\right)=\left(q_{h}^{*}, \theta_{h} q_{h}^{*}-\tilde{u}_{h}\right)$. Irrespective of whether the low type finds it incentive compatible to choose the option $(0,0)$, the seller is guaranteed an expected profit at least as high as under the original menu.

These two observations imply that $\pi\left(\tilde{u}_{l}+\varepsilon, \tilde{u}_{h}+\varepsilon\right)>\pi\left(\tilde{u}_{l}, \tilde{u}_{h}\right)$ for $\varepsilon>0$ sufficiently small, contradicting the optimality of $\left(\tilde{u}_{l}, \tilde{u}_{h}\right)$. To see this, note that $\pi\left(\tilde{u}_{l}+\varepsilon, \tilde{u}_{h}+\varepsilon\right)$ must be bounded below by

$$
\begin{aligned}
& \pi\left(\tilde{u}_{l}, \tilde{u}_{h}\right)-\varepsilon\left[\Phi_{h}\left(\tilde{u}_{h}+\varepsilon\right)+\Phi_{l}\left(\tilde{u}_{l}+\varepsilon\right)\right] \\
& +\left(S_{h}\left(\tilde{u}_{l}, \tilde{u}_{h}\right)-\tilde{u}_{h}-\varepsilon\right)\left[\Phi_{h}\left(\tilde{u}_{h}+\varepsilon\right)-\Phi_{h}\left(\tilde{u}_{h}\right)\right],
\end{aligned}
$$

where $\Phi_{k}$ is defined in (14). Since $\Phi_{h}\left(\tilde{u}_{h}+\varepsilon\right)-\Phi_{h}\left(\tilde{u}_{h}\right)$ is bounded above zero as $\varepsilon \searrow 0$, and since $S_{h}\left(\tilde{u}_{l}, \tilde{u}_{h}\right)-\tilde{u}_{h}>0$, the expression above is greater than $\pi\left(\tilde{u}_{l}, \tilde{u}_{h}\right)$ whenever $\varepsilon$ is sufficiently small.

Step 2 No mass points in the distribution of low-type offers.

First, we show that there are no mass points in $F_{l}$ at any $u_{l}>0$. Suppose towards a contradiction that $F_{l}$ has a mass point at some $\tilde{u}_{l}>0$. Take a firm that offers $\left(\tilde{u}_{l}, \tilde{u}_{h}\right)$. Since, as reasoned above, $S_{l}\left(\tilde{u}_{l}, \tilde{u}_{h}\right)-\tilde{u}_{l} \geq 0$, we can consider two cases.

Case 1: $S_{l}\left(\tilde{u}_{l}, \tilde{u}_{h}\right)-\tilde{u}_{l}>0$.

As noted in Step 1, the expected profit conditional on selling to a high type must also be positive. Notice that in this case $\pi\left(\tilde{u}_{l}+\varepsilon, \tilde{u}_{h}+\varepsilon\right)$ is bounded below by

$$
\begin{aligned}
& \pi\left(\tilde{u}_{l}, \tilde{u}_{h}\right)-\varepsilon\left[\Phi_{h}\left(\tilde{u}_{h}+\varepsilon\right)+\Phi_{l}\left(\tilde{u}_{l}+\varepsilon\right)\right] \\
& +\left(S_{l}\left(\tilde{u}_{l}, \tilde{u}_{h}\right)-\tilde{u}_{l}-\varepsilon\right)\left(\Phi_{l}\left(\tilde{u}_{l}+\varepsilon\right)-\Phi_{l}\left(\tilde{u}_{l}\right)\right) .
\end{aligned}
$$

Since $\Phi_{l}$ has a mass point at $\tilde{u}_{l}$, and since $S_{l}\left(\tilde{u}_{l}, \tilde{u}_{h}\right)-\tilde{u}_{l}>0$, the expression above is strictly greater than $\pi\left(\tilde{u}_{l}, \tilde{u}_{h}\right)$ for $\varepsilon>0$ sufficiently small.

Case 2: $S_{l}\left(\tilde{u}_{l}, \tilde{u}_{h}\right)-\tilde{u}_{l}=0$. Let $\left\{\left(q_{l}, x_{l}\right),\left(q_{h}, x_{h}\right)\right\}=\left\{\left(q_{l}\left(\tilde{u}_{l}, \tilde{u}_{h}\right), x_{l}\left(\tilde{u}_{l}, \tilde{u}_{h}\right)\right),\left(q_{h}\left(\tilde{u}_{l}, \tilde{u}_{h}\right), x_{h}\left(\tilde{u}_{l}, \tilde{u}_{h}\right)\right)\right\}$ be the menu offered by the firm. Consider a deviation to the menu $\left\{\left(q_{l}, x_{l}+\varepsilon\right),\left(q_{h}, x_{h}\right)\right\}$ for some $\varepsilon \in\left(0, \tilde{u}_{l}\right)$. This menu generates the same expected profits from high types and is accepted with positive probability by low types. Moreover, since $S_{h}\left(\tilde{u}_{l}, \tilde{u}_{h}\right)-\tilde{u}_{h}>0$ (see Step 1 ), the seller makes positive profits whether a low-type buyer chooses the option $\left(q_{l}, x_{l}+\varepsilon\right)$ or $\left(q_{h}, x_{h}\right)$. That is, expected profits from low types are strictly positive under the deviating offer. 
Finally, we show that there can be no mass point in $F_{l}$ at zero. Assume towards a contradiction that $F_{l}(0)>0$. From Step 1 (i.e., since there are no mass points in the distribution of high-type offers), menus $\left(u_{l}, u_{h}\right) \in\{0\} \times[\varepsilon, \infty)$ are then offered with positive probability. It is easy to see that there is $\chi>0$ such that $S_{l}\left(0, u_{h}\right)>\chi$ for all $u_{h} \in[\varepsilon, \infty)$. Therefore, for small $\eta>0$ the difference $\pi\left(\eta, u_{h}\right)-\pi\left(0, u_{h}\right)$ is

$$
\begin{gathered}
\left(\Phi_{l}(\eta)-\Phi_{l}(0)\right)\left[S_{l}\left(\eta, u_{h}\right)-\eta\right] \\
-\Phi_{l}(0)\left(S_{l}\left(0, u_{h}\right)-S_{l}\left(\eta, u_{h}\right)-\eta\right) .
\end{gathered}
$$

We can take $\eta^{*}$ such that $\eta \in\left(0, \eta^{*}\right)$ implies that the first line of $(34)$ is at least $\left(\Phi_{l}\left(0_{+}\right)-\Phi_{l}(0)\right)\left(\frac{\chi}{2}\right)>$ 0 . Moreover, the second line of (34) converges to 0 as $\eta \searrow 0$, which shows a profitable deviation.

Step 3 The supports $\Upsilon_{k}$ are intervals.

Suppose for a contradiction that one or both of the supports are disconnected sets. Assume that $\Upsilon_{l}$ is disconnected. Then there are $u_{l}^{\prime}$ and $u_{l}^{\prime \prime}$ in $\Upsilon_{l}$ with $u_{l}^{\prime}<u_{l}^{\prime \prime}$ such that $\left(u_{l}^{\prime}, u_{l}^{\prime \prime}\right) \cap \Upsilon_{l}=\emptyset$. Consider values $u_{h}^{\prime}$ and $u_{h}^{\prime \prime}$ such that $\left(u_{l}^{\prime}, u_{h}^{\prime}\right)$ and $\left(u_{l}^{\prime \prime}, u_{h}^{\prime \prime}\right)$ are optimal. From Steps 1 and 2 and Lemma 2 we may assume that $\Phi_{l}\left(u_{l}^{\prime}\right)=\Phi_{l}\left(u_{l}^{\prime \prime}\right), \Phi_{h}\left(u_{h}^{\prime}\right)=\Phi_{h}\left(u_{h}^{\prime \prime}\right)$ and $u_{h}^{\prime} \leq u_{h}^{\prime \prime}$.

If $u_{h}^{\prime}<u_{h}^{\prime \prime}$ then there is $\varepsilon>0$ for which $\pi\left(u_{l}^{\prime \prime}-\varepsilon, u_{h}^{\prime \prime}-\varepsilon\right)>\pi\left(u_{l}^{\prime \prime}, u_{h}^{\prime \prime}\right)$. Thus assume that $u_{h}^{\prime}=u_{h}^{\prime \prime}$. For any $\varepsilon \in\left(0, u_{l}^{\prime \prime}-u_{l}^{\prime}\right)$, optimality requires $\pi\left(u_{l}^{\prime \prime}-\varepsilon, u_{h}^{\prime \prime}\right) \leq \pi\left(u_{l}^{\prime \prime}, u_{h}^{\prime \prime}\right)$. This implies that $q_{h}\left(u_{l}^{\prime \prime}, u_{h}^{\prime \prime}\right)>q_{h}^{*}$, i.e. $I C_{l}$ binds. Thus $\frac{\partial^{2} S_{h}\left(u_{l}, u_{h}\right)}{\partial u_{l}^{2}}<0$ at $\left(u_{l}^{\prime \prime}, u_{h}^{\prime \prime}\right)$, which implies (using $\Phi_{l}\left(u_{l}^{\prime}\right)=$ $\left.\Phi_{l}\left(u_{l}^{\prime \prime}\right)\right)$ that $\pi\left(\lambda u_{l}^{\prime}+(1-\lambda) u_{l}^{\prime \prime}, u_{h}^{\prime \prime}\right)>\lambda \pi\left(u_{l}^{\prime}, u_{h}^{\prime \prime}\right)+(1-\lambda) \pi\left(u_{l}^{\prime \prime}, u_{h}^{\prime \prime}\right)$ for $\lambda \in(0,1)$. Hence, $\left(u_{l}^{\prime \prime}, u_{h}^{\prime \prime}\right)$ is not optimal. The proof that $\Upsilon_{h}$ is connected is analogous and omitted.

Step 4 The minimum of the supports $\Upsilon_{l}$ and $\Upsilon_{h}$ are, respectively, $u_{l}^{m}=0$ and $u_{h}^{m}$.

Let $\underline{u}_{l}$ and $\underline{u}_{h}$ be the minimum of the supports of $\Upsilon_{l}$ and $\Upsilon_{h}$ respectively. It follows from Steps 1 and 2 and from Lemma 2 that $\left(\underline{u}_{l}, \underline{u}_{h}\right)$ is an optimal menu. IR requires $\underline{u}_{l} \geq 0$, and we next show that $\underline{u}_{l}=0$. To see this, suppose that $\underline{u}_{l}>0$ and note that $\underline{u}_{h} \geq \underline{u}_{l}$. Since $\Phi_{l}(0)=\Phi_{l}\left(\underline{u}_{l}\right)$ and $\Phi_{h}\left(\underline{u}_{h}-\underline{u}_{l}\right)=\Phi_{h}\left(\underline{u}_{h}\right)$, we have $\pi\left(0, \underline{u}_{h}-\underline{u}_{l}\right)>\pi\left(\underline{u}_{l}, \underline{u}_{h}\right)$, a contradiction. Hence indeed $\underline{u}_{l}=0$ and so $\underline{u}_{h} \geq 0$ maximizes

$$
\Phi_{l}(0) S_{l}\left(0, u_{h}\right)+\Phi_{h}(0)\left(S_{h}\left(0, u_{h}\right)-u_{h}\right) .
$$

Since $u_{h}^{m}$ is the only maximizer of (35), the claim follows. We have thus established that, for each $k \in\{l, h\}$, the support $\Upsilon_{k}$ is equal to $\left[u_{k}^{m}, \bar{u}_{k}\right]$, where $\bar{u}_{k}>u_{k}^{m}$.

Step $5 F_{l}$ and $F_{h}$ are absolutely continuous.

We will show that $F_{h}$ is Lipschitz continuous (the proof that $F_{l}$ is absolutely continuous is analogous and omitted). Notice that from 2. in Assumption 1 it suffices to show that $\Phi_{h}$ is Lipschitz 
continuous. For that, it is enough to show that there are positive values $K$ and $\delta$ such that, for all $u_{h} \in \Upsilon_{h}$ and all $\varepsilon \in(0, \delta), \Phi_{h}\left(u_{h}+\varepsilon\right)-\Phi_{h}\left(u_{h}\right)<K \varepsilon$.

First, we claim that we may find a constant $\underline{S}_{h}>0$ such that we have $S_{h}\left(u_{l}^{\prime}, u_{h}^{\prime}\right)-u_{h}^{\prime} \geq \underline{S}_{h}$ for every optimal menu $\left(u_{l}^{\prime}, u_{h}^{\prime}\right)$. The claim follows by the same logic as in Step 1. If the claim does not hold, we may find a sequence of optimal menus $\left(u_{l}^{n}, u_{h}^{n}\right)$ such that $S_{h}\left(u_{l}^{n}, u_{h}^{n}\right)-u_{h}^{n} \leq \frac{1}{n}$. Taking a subsequence if necessary, assume that $\left(u_{l}^{n}, u_{h}^{n}\right) \rightarrow\left(u_{l}^{*}, u_{h}^{*}\right)$. By the continuity of $\Phi_{k}$ (Steps 1 and 2) and the continuity of $S_{k}$ (for $k \in\{l, h\}$ ) we conclude that $\left(u_{l}^{*}, u_{h}^{*}\right)$ is optimal and that $S_{h}\left(u_{l}^{*}, u_{h}^{*}\right)-u_{h}^{*}=0$. However, we showed in Step 1 that such a menu cannot be optimal.

Next, let $\delta>0$ and define $\xi_{h} \equiv \sup _{\left(\tilde{u}_{l}, \tilde{u}_{h}\right) \in\left\{\left[0, \bar{u}_{l}\right] \times\left[u_{h}^{m}, \bar{u}_{h}+\delta\right]: \tilde{u}_{h} \geq \tilde{u}_{l}\right\}}\left|\frac{\partial S_{h}\left(\tilde{u}_{l}, \tilde{u}_{h}\right)}{\partial u_{h}}\right|$. Take any equilibrium menu $\left(u_{l}, u_{h}\right) \in \Upsilon_{l} \times \Upsilon_{h}$. Notice that, for $\varepsilon \in(0, \delta), \pi\left(u_{l}, u_{h}+\varepsilon\right)$ is

$$
\begin{gathered}
\Phi_{l}\left(u_{l}\right)\left[S_{l}\left(u_{l}, u_{h}+\varepsilon\right)-u_{l}\right]+\Phi_{h}\left(u_{h}+\varepsilon\right)\left[S_{h}\left(u_{l}, u_{h}+\varepsilon\right)-u_{h}-\varepsilon\right] \\
\geq\left[\begin{array}{c}
\Phi_{l}\left(u_{l}\right)\left[S_{l}\left(u_{l}, u_{h}\right)-u_{l}\right]+\Phi_{h}\left(u_{h}\right)\left[S_{h}\left(u_{l}, u_{h}\right)-u_{h}\right] \\
-\Phi_{h}\left(\bar{u}_{h}\right)\left(\xi_{h}+1\right) \varepsilon+\left[\Phi_{h}\left(u_{h}+\varepsilon\right)-\Phi_{h}\left(u_{h}\right)\right]\left(\underline{S}_{h}-\left(\xi_{h}+1\right) \varepsilon\right)
\end{array}\right] .
\end{gathered}
$$

Since $\pi\left(u_{l}, u_{h}+\varepsilon\right) \leq \pi\left(u_{l}, u_{h}\right)$ we have:

$$
\frac{\Phi_{h}\left(u_{h}+\varepsilon\right)-\Phi_{h}\left(u_{h}\right)}{\varepsilon} \leq \frac{\Phi_{h}\left(\bar{u}_{h}\right)\left(\xi_{h}+1\right)}{\underline{S}_{h}-\left(\xi_{h}+1\right) \varepsilon}<\frac{\Phi_{h}\left(\bar{u}_{h}\right)\left(\xi_{h}+1\right)}{\underline{S}_{h}-\left(\xi_{h}+1\right) \delta} .
$$

Since Part 3 of Assumption 1 implies $\Phi_{h}\left(\bar{u}_{h}\right)<+\infty$, it is then easy to see that our claim holds provided $K$ is sufficiently large and $\delta$ sufficiently small. Q.E.D.

Claim 1 The functions $\Phi_{h}(\cdot)$ and $\Phi_{l}(\cdot)$ are continuously differentiable.

Proof We first show that $\Phi_{h}(\cdot)$ and $\Phi_{l}(\cdot)$ are continuously differentiable. By Assumption 1.2 , this implies that each $F_{k}\left(u_{k}\right)$ is continuously differentiable as well. Hence, the firm's profits $\pi\left(u_{l}, u_{h}\right)$ as defined by (6) are continuously differentiable, with first-order conditions given by $(7)$ and (8).

We focus on the claim that $\Phi_{h}(\cdot)$ is continuously differentiable, as the case of $\Phi_{l}(\cdot)$ is analogous. Let $u_{h} \in \Upsilon_{h}$ and suppose that $u_{l}=\hat{u}_{l}\left(u_{h}\right)$, so that $\left(u_{l}, u_{h}\right)$ is an optimal menu. Note that for any $\varepsilon \in \mathbb{R}$, we have

$$
\begin{aligned}
& \Phi_{l}\left(u_{l}\right)\left[S_{l}\left(u_{l}, u_{h}+\varepsilon\right)-u_{l}\right]+\Phi_{h}\left(u_{h}+\varepsilon\right)\left[S_{h}\left(u_{l}, u_{h}+\varepsilon\right)-u_{h}-\varepsilon\right] \\
= & \Phi_{l}\left(u_{l}\right)\left[S_{l}\left(u_{l}, u_{h}\right)-u_{l}\right]+\Phi_{h}\left(u_{h}\right)\left[S_{h}\left(u_{l}, u_{h}\right)-u_{h}\right] \\
& +\Phi_{l}\left(u_{l}\right)\left[S_{l}\left(u_{l}, u_{h}+\varepsilon\right)-S_{l}\left(u_{l}, u_{h}\right)\right]+\Phi_{h}\left(u_{h}\right)\left[S_{h}\left(u_{l}, u_{h}+\varepsilon\right)-\varepsilon-S_{h}\left(u_{l}, u_{h}\right)\right] \\
& +\left[\Phi_{h}\left(u_{h}+\varepsilon\right)-\Phi_{h}\left(u_{h}\right)\right]\left[S_{h}\left(u_{l}, u_{h}+\varepsilon\right)-u_{h}-\varepsilon\right] .
\end{aligned}
$$

Since $\pi\left(u_{l}, u_{h}\right) \geq \pi\left(u_{l}, u_{h}+\varepsilon\right)$, we have

$$
\begin{aligned}
& {\left[\Phi_{h}\left(u_{h}+\varepsilon\right)-\Phi_{h}\left(u_{h}\right)\right]\left[S_{h}\left(u_{l}, u_{h}+\varepsilon\right)-u_{h}-\varepsilon\right] } \\
\leq & \Phi_{l}\left(u_{l}\right)\left[S_{l}\left(u_{l}, u_{h}\right)-S_{l}\left(u_{l}, u_{h}+\varepsilon\right)\right]+\Phi_{h}\left(u_{h}\right)\left[S_{h}\left(u_{l}, u_{h}\right)-S_{h}\left(u_{l}, u_{h}+\varepsilon\right)+\varepsilon\right] .
\end{aligned}
$$


Next, for any $\varepsilon \in \mathbb{R}$ such that $u_{h}+\varepsilon \in \Upsilon_{h}$, let $u_{l, \varepsilon}=\hat{u}_{l}\left(u_{h}+\varepsilon\right)$. Thus, we have

$$
\begin{aligned}
& \Phi_{l}\left(u_{l, \varepsilon}\right)\left[S_{l}\left(u_{l, \varepsilon}, u_{h}+\varepsilon\right)-u_{l, \varepsilon}\right]+\Phi_{h}\left(u_{h}+\varepsilon\right)\left[S_{h}\left(u_{l, \varepsilon}, u_{h}+\varepsilon\right)-u_{h}-\varepsilon\right] \\
= & \Phi_{l}\left(u_{l, \varepsilon}\right)\left[S_{l}\left(u_{l, \varepsilon}, u_{h}\right)-u_{l, \varepsilon}\right]+\Phi_{h}\left(u_{h}\right)\left[S_{h}\left(u_{l, \varepsilon}, u_{h}\right)-u_{h}\right] \\
& +\Phi_{l}\left(u_{l, \varepsilon}\right)\left[S_{l}\left(u_{l, \varepsilon}, u_{h}+\varepsilon\right)-S_{l}\left(u_{l, \varepsilon}, u_{h}\right)\right]+\Phi_{h}\left(u_{h}\right)\left[S_{h}\left(u_{l, \varepsilon}, u_{h}+\varepsilon\right)-\varepsilon-S_{h}\left(u_{l, \varepsilon}, u_{h}\right)\right] \\
& +\left[\Phi_{h}\left(u_{h}+\varepsilon\right)-\Phi_{h}\left(u_{h}\right)\right]\left[S_{h}\left(u_{l, \varepsilon}, u_{h}+\varepsilon\right)-u_{h}-\varepsilon\right] .
\end{aligned}
$$

Since $\pi\left(u_{l, \varepsilon}, u_{h}+\varepsilon\right) \geq \pi\left(u_{l, \varepsilon}, u_{h}\right)$, we have

$$
\begin{aligned}
& {\left[\Phi_{h}\left(u_{h}+\varepsilon\right)-\Phi_{h}\left(u_{h}\right)\right]\left[S_{h}\left(u_{l, \varepsilon}, u_{h}+\varepsilon\right)-u_{h}-\varepsilon\right] } \\
\geq & \Phi_{l}\left(u_{l, \varepsilon}\right)\left[S_{l}\left(u_{l, \varepsilon}, u_{h}\right)-S_{l}\left(u_{l, \varepsilon}, u_{h}+\varepsilon\right)\right]+\Phi_{h}\left(u_{h}\right)\left[S_{h}\left(u_{l, \varepsilon}, u_{h}\right)-S_{h}\left(u_{l, \varepsilon}, u_{h}+\varepsilon\right)+\varepsilon\right] .
\end{aligned}
$$

For the right derivative we now consider $\varepsilon>0$ (the case of the left derivative is analogous). For any $\varepsilon$ sufficiently small, we have $S_{h}\left(u_{l}, u_{h}+\varepsilon\right)-u_{h}-\varepsilon>0$ (to see this, consider the argument in Step 1 of the proof of Lemma 3). For all such $\varepsilon$, we have

$$
\begin{aligned}
\frac{\left(\begin{array}{c}
\Phi_{l}\left(u_{l, \varepsilon}\right)\left[S_{l}\left(u_{l, \varepsilon}, u_{h}\right)-S_{l}\left(u_{l, \varepsilon}, u_{h}+\varepsilon\right)\right] \\
+\Phi_{h}\left(u_{h}\right)\left[S_{h}\left(u_{l, \varepsilon}, u_{h}\right)-S_{h}\left(u_{l, \varepsilon}, u_{h}+\varepsilon\right)+\varepsilon\right]
\end{array}\right)}{\varepsilon\left[S_{h}\left(u_{l, \varepsilon}, u_{h}+\varepsilon\right)-u_{h}-\varepsilon\right]} & \leq \frac{\Phi_{h}\left(u_{h}+\varepsilon\right)-\Phi_{h}\left(u_{h}\right)}{\varepsilon} \\
& \leq \frac{\left(\begin{array}{c}
\Phi_{l}\left(u_{l}\right)\left[S_{l}\left(u_{l}, u_{h}\right)-S_{l}\left(u_{l}, u_{h}+\varepsilon\right)\right] \\
+\Phi_{h}\left(u_{h}\right)\left[S_{h}\left(u_{l}, u_{h}\right)-S_{h}\left(u_{l}, u_{h}+\varepsilon\right)+\varepsilon\right]
\end{array}\right)}{\varepsilon\left[S_{h}\left(u_{l}, u_{h}+\varepsilon\right)-u_{h}-\varepsilon\right]} .
\end{aligned}
$$

Next, note that $\hat{u}_{l}(\cdot)$ must be continuous by Lemma 3 , since each $F_{k}$ is continuous and $F_{l}\left(\hat{u}_{l}\left(u_{h}\right)\right)=$ $F_{h}\left(u_{h}\right)$ for all $u_{h}$. Hence $u_{l, \varepsilon} \searrow u_{l}$ as $\varepsilon \searrow 0$, implying that the right derivative of $\Phi_{h}\left(u_{h}\right)$ is equal to

$$
\frac{-\Phi_{l}\left(u_{l}\right) \frac{\partial S_{l}\left(u_{l}, u_{h}\right)}{\partial u_{h}}+\Phi_{h}\left(u_{h}\right)\left(1-\frac{\partial S_{h}\left(u_{l}, u_{h}\right)}{\partial u_{h}}\right)}{S_{h}\left(u_{l}, u_{h}\right)-u_{h}}
$$

The left derivative can similarly be shown to take the same value, i.e., $\Phi_{h}\left(u_{h}\right)$ is differentiable at $u_{h}$. Using our assumption that $I C_{l}$ is slack, we can thus conclude that

$$
\begin{aligned}
\Phi_{h}^{\prime}\left(u_{h}\right) & =\frac{-\Phi_{l}\left(u_{l}\right) \frac{\partial S_{l}\left(u_{l}, u_{h}\right)}{\partial u_{h}}+\Phi_{h}\left(u_{h}\right)}{S_{h}^{*}-u_{h}} \\
\Phi_{l}^{\prime}\left(u_{l}\right) & =\frac{\Phi_{l}\left(u_{l}\right)\left(1-\frac{\partial S_{l}\left(u_{l}, u_{h}\right)}{\partial u_{l}}\right)}{S_{l}\left(u_{l}, u_{h}\right)-u_{l}} .
\end{aligned}
$$

Recall that $\bar{u}_{h}<S_{h}^{*}$ by Lemma 3. Moreover, we must have $S_{l}\left(u_{l}, u_{h}\right)-u_{l}>0$ whenever $u_{h}>0$ (this follows from the argument in Step 2, Case 2 of Lemma 3). Hence, both derivatives are finite over $u_{h} \in\left(u_{h}^{m}, \bar{u}_{h}\right)$. Q.E.D.

Claim 2 The mapping $\hat{u}_{l}\left(u_{h}\right)$ is differentiable and satisfies (19). 
Proof Note from $(37)$ that $\Phi_{l}^{\prime}\left(u_{l}\right)$ is strictly positive at $u_{l}=\hat{u}_{l}\left(u_{h}\right)$ for any $u_{h} \in\left(u_{h}^{m}, \bar{u}_{h}\right)$. Thus, by the implicit function theorem, $\hat{u}_{l}^{\prime}\left(u_{h}\right)=\frac{\Phi_{h}^{\prime}\left(u_{h}\right)}{\Phi_{l}^{\prime}\left(\hat{u}_{l}\left(u_{h}\right)\right)}$, which is precisely (19). Q.E.D.

Claim 3 The ordinary differential equation differential equation (11) subject to $\hat{u}_{l}\left(u_{h}^{m}\right)=0$ admits a unique solution. Moreover, we have $\hat{u}_{l}^{\prime}\left(u_{h}\right)>0$ for all $u_{h} \in\left[u_{h}^{m}, S_{h}^{*}\right)$.

Proof As described above, (7), (8) and (19) imply that the support function $\hat{u}_{l}$ must satisfy

$$
\hat{u}_{l}^{\prime}\left(u_{h}\right)=h\left(\hat{u}_{l}\left(u_{h}\right), u_{h}\right),
$$

where

$$
h\left(u_{l}, u_{h}\right)=\frac{S_{l}\left(u_{l}, u_{h}\right)-u_{l}}{S_{h}^{*}-u_{h}} \cdot \frac{1-\frac{p_{l}}{p_{h}} \frac{\partial S_{l}}{\partial u_{h}}\left(u_{l}, u_{h}\right)}{1-\frac{\partial S_{l}}{\partial u_{l}}\left(u_{l}, u_{h}\right)},
$$

and where we impose the boundary condition $\hat{u}_{l}\left(u_{h}^{m}\right)=0$. We now show that there exists a unique solution $\hat{u}_{l}(\cdot)$ on $\left[u_{h}^{m}, S_{h}^{*}\right)$.

For any $\varepsilon \in\left(0, S_{h}^{*}\right)$, the function $h(\cdot, \cdot)$ is Lipschitz continuous on

$$
\Gamma(\varepsilon) \equiv\left\{\left(u_{l}, u_{h}\right) \in\left[0, S_{l}^{*}\right] \times\left[u_{h}^{m}, S_{h}^{*}-\varepsilon\right): u_{l}<u_{h}\right\} .
$$

Hence, by the Picard-Lindelof theorem, for any $\varepsilon \in\left(0, S_{h}^{*}\right)$, and for any $\left(u_{l}, u_{h}\right)$ in the interior of $\Gamma(\varepsilon)$, there is a unique local solution to $\hat{u}_{l}^{\prime}\left(u_{h}\right)=h\left(\hat{u}_{l}\left(u_{h}\right), u_{h}\right)$. Local uniqueness will extend to global uniqueness, guaranteeing that the equilibrium we construct is the only ordered equilibrium.

Now consider $\hat{u}_{l}^{\prime}\left(u_{h}\right)=h\left(\hat{u}_{l}\left(u_{h}\right), u_{h}\right)$ with initial condition $\hat{u}_{l}\left(u_{h}^{m}\right)=0$ and note the existence of $\eta>0$ such that a unique solution exists on $\left[u_{h}^{m}, u_{h}^{m}+\eta\right]$ where $\left(\hat{u}_{l}\left(u_{h}\right), u_{h}\right)$ remains in $\Gamma(0)$. We now show that $h\left(\hat{u}_{l}\left(u_{h}\right), u_{h}\right)$ remains bounded and that $\left(\hat{u}_{l}\left(u_{h}\right), u_{h}\right)$ remains in $\Gamma(0)$ also as $u_{h}$ increases to $S_{h}^{*}$, implying the existence of a global solution to $\hat{u}_{l}^{\prime}\left(u_{h}\right)=h\left(\hat{u}_{l}\left(u_{h}\right), u_{h}\right)$ on $\left[u_{h}^{m}, S_{h}^{*}\right)$. We further show that $h\left(\hat{u}_{l}\left(u_{h}\right), u_{h}\right)$ remains strictly positive on $\left[u_{h}^{m}, S_{h}^{*}\right)$, that is, we have $\hat{u}_{l}^{\prime}\left(u_{h}\right)>0$, which ensures that the equilibrium we construct is ordered. The problem should be considered for two regions of $u_{h}$ : we show that there exists a value $u_{h}^{c} \in\left(u_{h}^{m}, S_{h}^{*}\right)$ such that $u_{h}^{c}-\hat{u}_{l}\left(u_{h}^{c}\right)=q_{l}^{*} \Delta \theta$ and such that $u_{h}-\hat{u}_{l}\left(u_{h}\right)<q_{l}^{*} \Delta \theta$ for $u_{h} \in\left[u_{h}^{m}, u_{h}^{c}\right)$. We then show that $u_{h}-\hat{u}_{l}\left(u_{h}\right)>q_{l}^{*} \Delta \theta$ for $u_{h}>u_{h}^{c}$.

First, we show that, for $u_{h}>u_{h}^{m}$, provided $u_{h}-\hat{u}_{l}\left(u_{h}\right)$ remains below $q_{l}^{*} \Delta \theta$, then $h\left(\hat{u}_{l}\left(u_{h}\right), u_{h}\right)$ remains in $(0,1)$. First, note that $S_{l}\left(\hat{u}_{l}\left(u_{h}\right), u_{h}\right)-\hat{u}_{l}\left(u_{h}\right)$ remains strictly positive: this follows because $\frac{d}{d u_{h}}\left[S_{l}\left(\hat{u}_{l}\left(u_{h}\right), u_{h}\right)-\hat{u}_{l}\left(u_{h}\right)\right]>0$ whenever $S_{l}\left(\hat{u}_{l}\left(u_{h}\right), u_{h}\right)-\hat{u}_{l}\left(u_{h}\right)$ is sufficiently close to zero.

Second, $h\left(\hat{u}_{l}\left(u_{h}\right), u_{h}\right)$ remains below 1 because

$$
\begin{aligned}
& S_{h}^{*}-u_{h}-\left(S_{l}\left(\hat{u}_{l}\left(u_{h}\right), u_{h}\right)-\hat{u}_{l}\left(u_{h}\right)\right) \\
= & \theta_{h} q_{h}^{*}-\varphi\left(q_{h}^{*}\right)-\left(\theta_{l} q_{l}\left(\hat{u}_{l}\left(u_{h}\right), u_{h}\right)-\varphi\left(q_{l}\left(\hat{u}_{l}\left(u_{h}\right), u_{h}\right)\right)\right)-q_{l}\left(\hat{u}_{l}\left(u_{h}\right), u_{h}\right) \Delta \theta \\
= & \theta_{h} q_{h}^{*}-\varphi\left(q_{h}^{*}\right)-\left(\theta_{h} q_{l}\left(\hat{u}_{l}\left(u_{h}\right), u_{h}\right)-\varphi\left(q_{l}\left(\hat{u}_{l}\left(u_{h}\right), u_{h}\right)\right)\right) \\
> & 0
\end{aligned}
$$


and $\frac{p_{l}}{p_{h}} \frac{\partial S_{l}}{\partial u_{h}}\left(\hat{u}_{l}\left(u_{h}\right), u_{h}\right)>\frac{\partial S_{l}}{\partial u_{l}}\left(\hat{u}_{l}\left(u_{h}\right), u_{h}\right)$ whenever $u_{h}-\hat{u}_{l}\left(u_{h}\right)<q_{l}^{*} \Delta \theta$. Finally, to check that $h\left(\hat{u}_{l}\left(u_{h}\right), u_{h}\right)$ remains strictly positive, we note that $\frac{p_{l}}{p_{h}} \frac{\partial S_{l}}{\partial u_{h}}\left(\hat{u}_{l}\left(u_{h}\right), u_{h}\right)<1$ provided $u_{h}-\hat{u}_{l}\left(u_{h}\right)>$ $u_{h}^{m}$, which is guaranteed in turn by the initial condition and that $h\left(\hat{u}_{l}\left(u_{h}\right), u_{h}\right)$ remains less than 1.

We now verify the existence of $u_{h}^{c} \in\left(u_{h}^{m}, S_{h}^{*}\right)$ for which $u_{h}^{c}-\hat{u}_{l}\left(u_{h}^{c}\right)=q_{l}^{*} \Delta \theta$. Suppose that there is no such value $u_{h}^{c}$. Then the equalities in (40) must continue to hold for all $u_{h} \in\left(u_{h}^{m}, S_{h}^{*}\right)$. Since these expressions are bounded above zero, we must have $S_{l}\left(\hat{u}_{l}\left(u_{h}\right), u_{h}\right)-\hat{u}_{l}\left(u_{h}\right)<0$ as $u_{h}$ approaches $S_{h}^{*}$, contradicting the observation in the previous claim.

Next, consider extending the solution to $u_{h} \in\left(u_{h}^{c}, S_{h}^{*}\right)$. It is easily checked that $\hat{u}_{l}\left(u_{h}\right)=$ $S_{l}^{*}-\alpha\left(S_{h}^{*}-u_{h}\right)$ with $\alpha=\frac{S_{l}^{*}-\hat{u}_{l}\left(u_{h}^{c}\right)}{S_{h}^{*}-u_{h}^{c}} \in(0,1)$ satisfies $\hat{u}_{l}^{\prime}\left(u_{h}\right)=h\left(\hat{u}_{l}\left(u_{h}\right), u_{h}\right)$ and remains in $\Gamma(0)$ (that $\hat{u}_{l}\left(u_{h}\right)$ remains below $S_{l}^{*}$ follows because $\left.S_{l}^{*}-\hat{u}_{l}\left(u_{h}\right)=\alpha\left(S_{h}^{*}-u_{h}\right)>0\right)$.Q.E.D.

Claim 4 The Incentive Constraint $I C_{l}$ is globally satisfied.

Proof The argument in Claim 3hat there is $u_{h}^{c} \in\left(u_{h}^{m}, S_{h}^{*}\right)$ for which $u_{h}-\hat{u}_{l}\left(u_{h}\right)<\Delta \theta q_{l}^{*}$ for all $u_{h}<u_{h}^{c}$. For $u_{h} \in\left[u_{h}^{c}, S_{h}^{*}\right)$ we have

$$
u_{h}-\hat{u}_{l}\left(u_{h}\right)=\left(u_{h}-S_{l}^{*}\right)+\alpha\left(S_{h}^{*}-u_{h}\right) .
$$

Notice that the derivative of the RHS of (41) w.r.t. $u_{h}$ is $1-\alpha>0$. Hence (41) achieves its maximum at $u_{h}=S_{h}^{*}$ and its maximum is given by

$$
S_{h}^{*}-S_{l}^{*}=\Delta \theta q_{l}^{*}+\int_{q_{l}^{*}}^{q_{h}^{*}}\left(\theta_{h}-\varphi^{\prime}(q)\right) d q<\Delta \theta q_{h}^{*} .
$$

Thus we conclude that $u_{h}-\hat{u}_{l}\left(u_{h}\right) \in\left(\Delta \theta q_{l}^{*}, \Delta \theta q_{h}^{*}\right)$ for all $u_{h} \in\left(u_{h}^{c}, S_{h}^{*}\right)$. Therefore, the incentive constraint (16) does not bind along the curve $\left(\hat{u}_{l}\left(u_{h}\right), u_{h}\right)$.Q.E.D.

Claim 5 There exists a unique $\bar{u}_{h} \in\left(u_{h}^{c}, S_{h}^{*}\right)$ such that if we define $F_{h}:\left[u_{h}^{c}, \bar{u}_{h}\right]$ by

$$
\begin{aligned}
& \Lambda\left(F_{h}\left(u_{h}\right) \mid v\right) \sum_{k=l, h} p_{k} \cdot\left(S_{k}\left(\hat{u}_{l}\left(u_{h}\right), u_{h}\right)-\hat{u}_{k}\left(u_{h}\right)\right) \\
= & \sum_{k=l, h} p_{k} \cdot \Lambda(0 \mid v) \cdot\left(S_{k}\left(u_{l}^{m}, u_{h}^{m}\right)-u_{k}^{m}\right):=\pi^{*}
\end{aligned}
$$

then $F_{h}$ is a strictly increasing and absolutely continuous function satisfying $F_{h}\left(u_{h}^{c}\right)=0$ and $F_{h}\left(\bar{u}_{h}\right)=1$.

Proof As noted above (see Step 4 in the proof of Lemma 3), the least generous equilibrium menu must be $\left(u_{l}^{m}, u_{h}^{m}\right)$. Moreover, in equilibrium, all offers must yield the same expected profit $\pi^{*}$. Next, observe that there is a value $\bar{u}_{h}>u_{h}^{m}$ which solves

$$
\Lambda(1 \mid v) \sum_{k=l, h} p_{k} \cdot\left(S_{k}\left(\hat{u}_{l}\left(\bar{u}_{h}\right), u_{h}\right)-\hat{u}_{k}\left(\bar{u}_{h}\right)\right)=\pi^{*}
$$


The existence of such $\bar{u}_{h}$ is guaranteed by the intermediate value theorem, since $\frac{\Lambda(1 \mid v)}{\Lambda(0 \mid v)} \in(1, \infty)$ and since $\lim _{u_{h} \uparrow S_{h}^{*}}\left[S_{l}\left(\hat{u}_{l}\left(u_{h}\right), u_{h}\right)-\hat{u}_{l}\left(u_{h}\right)\right]=\lim _{u_{h} \uparrow S_{h}^{*}}\left[S_{h}^{*}-u_{h}\right]=0$.

Condition (12) is then simply the requirement that

$$
\Lambda\left(F_{h}\left(u_{h}\right) \mid v\right) \sum_{k=l, h} p_{k} \cdot\left(S_{k}\left(\hat{u}_{l}\left(u_{h}\right), u_{h}\right)-\hat{u}_{k}\left(u_{h}\right)\right)=\pi^{*}
$$

for $u_{h} \in\left[u_{h}^{m}, \bar{u}_{h}\right]$ where $F_{h}\left(\bar{u}_{h}\right)=1$. Note then that $\frac{d}{d u_{h}}\left[\sum_{k=l, h} p_{k} \cdot\left(S_{k}\left(\hat{u}_{l}\left(u_{h}\right), u_{h}\right)-\hat{u}_{k}\left(u_{h}\right)\right)\right]<0$ on $\left(u_{h}^{m}, \bar{u}_{h}\right)$. This follows because $\frac{d}{d u_{h}}\left[u_{h}-\hat{u}_{l}\left(u_{h}\right)\right]>0$ and $u_{h}-\hat{u}_{l}\left(u_{h}\right)>u_{h}^{m}$, and because $\hat{u}_{l}^{\prime}\left(u_{h}\right)>0$. Hence, Assumption 1.1 and 1.2 imply that $F_{h}$ is uniquely defined by (12) and is increasing and absolutely continuous on $\left(u_{h}^{m}, \bar{u}_{h}\right)$. Q.E.D.

Claim 6 We have $\frac{\partial \hat{u}_{l}\left(u_{h}, p_{l}\right)}{\partial p_{l}}<0$ for all $u_{h} \in\left(u_{h}^{m}, \bar{u}_{h}\right)$.

Proof. Let $\breve{u}_{h}(\cdot)$ be the inverse of $\hat{u}_{l}(\cdot)$. It is slightly more convenient to show (the equivalent result) that $\frac{\partial \breve{u}_{h}\left(u_{l}^{y}\right)}{\partial p_{l}}>0$ for all $u_{l}^{y} \in\left(0, \hat{u}_{l}\left(\bar{u}_{h}\right)\right)$. Consider the equilibrium impact of an increase of the probability of the low type from $p_{l}^{a}$ to $p_{l}^{b}$. We will show that if for $j=a, b$ we have the utility profile $\left(u_{l}^{j}, u_{h}^{j}\right)$ is offered in the economy in which the probability of the low type is $p^{j}$ then whenever $u_{l}^{A}=u_{l}^{b}$ we must have $u_{h}^{a}<u_{h}^{b}$.

First notice that an increase from $p^{a}$ to $p^{b}$ leads to a change in the monopolist menu changes from $\left(0, u_{h}^{m, a}\right)$ to $\left(0, u_{h}^{m, b}\right)$, with $u_{h}^{m, b}>u_{h}^{m, a}$. Assume that $\left(u_{l}^{y}, \breve{u}_{h}^{j}\left(u_{l}^{y}\right)\right)$ is in the support of the equilibrium $j$, for $j=a, b$. Clearly $\breve{u}_{h}^{b}(0)>\breve{u}_{h}^{a}(0)$. By continuity, there exists $\varepsilon>0$ for which for all $u_{l}^{y} \in[0, \varepsilon]$ we have $\breve{u}_{h}^{b}\left(u_{l}^{y}\right)>\breve{u}_{h}^{a}\left(u_{l}^{y}\right)$. If this inequality holds for all $u_{l}^{y}$ such that $\left(u_{l}^{y}, \hat{u}_{h}^{j}\left(u_{l}^{y}\right)\right)$ is in the support of equilibria $j$, for $j=a, b$ then so does the claim. If not, let $u_{l}^{*}$ be the smallest low-type utility for which $\breve{u}_{h}^{b}\left(u_{l}^{*}\right)=\breve{u}_{h}^{a}\left(u_{l}^{*}\right)$.

First assume that $\breve{u}_{h}^{A}\left(u_{l}^{*}\right)-u_{l}^{*}>\Delta \theta q_{L}^{*}$. In this case, we have $\breve{u}_{h}^{\prime a}\left(u_{l}^{*}\right)=\breve{u}_{h}^{\prime b}\left(u_{l}^{*}\right)$ for all $u_{l}^{y}$ in a neighborhood of $u_{l}^{*}$, a contradiction to the minimality of $u_{l}^{*}$. Next assume that $\hat{u}_{h}^{a}\left(u_{l}^{*}\right)-u_{l}^{*}<\Delta \theta q_{L}^{*}$. In this case, we have

$$
\frac{\breve{u}_{h}^{\prime b}\left(u_{l}^{*}\right)}{\breve{u}_{h}^{\prime a}\left(u_{l}^{*}\right)}=\frac{\left[1-\left(\frac{p_{l}^{A}}{p_{h}^{A}}\right) \cdot \frac{\partial S_{l}}{\partial u_{h}^{y}}\left(u_{l}^{*}, \breve{u}_{h}^{A}\left(u_{l}^{*}\right)\right)\right]}{\left[1-\left(\frac{p_{l}^{B}}{p_{h}^{B}}\right) \cdot \frac{\partial S_{l}}{\partial u_{h}^{y}}\left(u_{l}^{*}, \breve{u}_{h}^{B}\left(u_{l}^{*}\right)\right)\right]}>1
$$

which shows that $\breve{u}_{h}^{b}\left(u_{l}^{y}\right)<\breve{u}_{h}^{a}\left(u_{l}^{y}\right)$ for all $u_{l}^{y}$ in some interval $\left(u_{l}^{*}-\varepsilon, u_{l}^{*}\right)$, which contradicts the definition of $u_{l}^{*}$.

Finally assume that $\breve{u}_{h}^{a}\left(u_{l}^{*}\right)-u_{l}^{*}=\Delta \theta q_{L}^{*}$. In this case, $\breve{u}_{h}^{b}(\cdot)-\breve{u}_{h}^{a}(\cdot)$ achieves a local minimal at $u_{l}^{*}$ and hence since $\breve{u}_{h}^{\prime b}\left(u_{l}^{*}\right)=\breve{u}_{h}^{\prime a}\left(u_{l}^{*}\right)$ we must have $\lim _{u_{l}^{y} \uparrow u_{l}^{*}}\left[\breve{u}_{h}^{\prime \prime \prime}\left(u_{l}^{y}\right)-\breve{u}_{h}^{\prime \prime b}\left(u_{l}^{y}\right)\right] \geq 0$, which holds if and only if $\lim _{u_{h}^{y} \uparrow \breve{u}_{h}\left(u_{l}^{*}\right)}\left[\hat{u}_{h}^{\prime \prime b}\left(u_{l}^{y}\right)-\hat{u}_{h}^{\prime \prime b}\left(u_{l}^{y}\right)\right] \leq 0$. However, using (22) it follows that:

$$
\lim _{u_{h}^{y} \breve{u}_{h}\left(u_{l}^{*}\right)} \frac{\partial\left[\hat{u}_{h}^{\prime \prime b}\left(u_{l}^{y}\right)-\hat{u}_{h}^{\prime \prime b}\left(u_{l}^{y}\right)\right]}{\partial\left(\frac{p_{l}}{p_{h}}\right)}=c^{\prime \prime}\left(q_{l}^{*}\right)\left(\frac{S_{l}^{*}-u_{l}^{*}}{(\Delta \theta)^{2}\left[S_{h}^{*}-\breve{u}_{h}\left(u_{l}^{*}\right)\right]^{3}}\right)>0,
$$


a contradiction. Q.E.D.

The next proof use notation introduced before the proof of the Proposition 4.

Claim 7 Take $p_{l}^{\# \#}, p_{l}^{\#}$ such that $p_{l}^{\# \#}<p_{l}^{\#}$ and index all contracts by $w$. We have $u_{h}^{\# \#}(w)<u_{h}^{\#}(w)$ for all $w \in\left[1, \frac{\Lambda(1 \mid v)}{\Lambda(0 \mid v)}\right)$.

Proof. Suppose towards a contradiction that $u_{h}^{\# \#}(w) \geq u_{h}^{\#}(w)$. Then we must have (using Claim 6) $u_{l}^{\# \#}(w)>u_{l}^{\#}(w)$ and hence

$$
\begin{aligned}
\frac{\left(p_{l}^{\#}\left(S_{l}^{*}-u_{l}^{\#}(w)\right)+p_{h}^{\#}\left(S_{h}^{*}-u_{h}^{\#}(w)\right)\right)}{\sum_{k=l, h} p_{k}^{\#} \cdot\left(S_{k}\left(0, u_{h}^{m, \#}\right)-u_{k}^{m, \#}\right)}>\frac{\left(p_{l}^{\# \#}\left(S_{l}^{*}-u_{l}^{\#}(w)\right)+p_{h}^{\# \#}\left(S_{h}^{*}-u_{h}^{\#}(w)\right)\right)}{\sum_{k=l, h} p_{k}^{\# \#} \cdot\left(S_{k}\left(0, u_{h}^{m, \#}\right)-u_{k}^{m, \#}\right)} \\
>\frac{\left(p_{l}^{\# \#}\left(S_{l}^{*}-u_{l}^{\# \#}(w)\right)+p_{h}^{\# \#}\left(S_{h}^{*}-u_{h}^{\# \#}(w)\right)\right)}{\sum_{k=l, h} p_{k}^{\# \#} \cdot\left(S_{k}\left(0, u_{h}^{m, \# \#}\right)-u_{k}^{m, \# \#}\right)} .
\end{aligned}
$$

The first inequality follows because firms that offer more generous menus earn a higher fraction of their profits from low types. Hence, the increase in $p_{h}$ associated with $p_{h}^{\# \#}$ increases profits proportionally more at the monopoly menu than at the menu associated to the ranking $y(w)$. The second inequality follows because $u_{h}^{m, \# \#}$ is chosen optimally for $\left(p_{l}^{\# \#}, p_{h}^{\# \#}\right)$, and because $u_{h}^{\# \#}(w) \geq$ $u_{h}^{\#}(w)$ and $u_{l}^{\# \#}(w)>u_{l}^{\#}(w)$. But this contradicts that $\left(u_{l}^{\#}(w), u_{h}^{\#}(w)\right)$ and $\left(u_{l}^{\# \#}(w), u_{h}^{\# \#}(w)\right)$ are both equilibrium menus leading to the generosity $w$ (which would require the first and last ratios to instead be equal to $\left.\frac{1}{w}\right)$. We conclude that $u_{h}^{\# \#}(w)<u_{h}^{\#}(w)$. Q.E.D. 